\title{
Uso da Abstração de Classificação na Modelagem de Aplicativos Suportados por Bases de Dados Relacionais - Um Estudo de Caso
}

\author{
Alexandre Della Nina \\ Orientador: Prof. Dr. Caetano Traina Junior \\ Dissertação apresentada ao Instituto de Ciências Matemáticas e \\ de Computação - ICMC-USP, como parte dos requisitos para \\ obtenção do título de Mestre em Ciências - Área: Ciências de \\ Computação e Matemática Computacional.
}

São Carlos

Novembro/1999 
"Equilíbrio edificante e paciência operosa. Freqüentemente, aflição é nossa própria ansiedade, respeitável mas inútil, projetada no futuro, mentalizando ocorrências menos felizes que, em muitos casos, não se verificam como supomos e, por vezes, nem chegam a surgir."

Emmanuel, psicografado por Chico Xavier Trecho do Livro - Rumo Certo

"...Assumamos, portanto, uma atitude de otimismo e de autoconfiança $e$ marchemos, resolutos, para frente, sempre para frente, na conviçcão plena e inabalável de que a vida é bela, boa e venturosa, para todos aqueles que a saibam viver!"

Rodolfo Calligaris Trecho do Livro - As Leis Morais 


\section{Agradecimentos}

Ao meu orientador, Prof. Dr. Caetano Traina Júnior, pela confiança e pela competência demonstrada durante o trabalho. De imensa bondade e compreensão, consegue despertar o que há de melhor nas pessoas, ainda permitindo e incentivando a luta pelos ideais individuais. Acima de tudo um grande ser humano.

À Prof. Dra. Agma J. Traina, à Prof. Dra. Maria Cristina Ferreira de Oliveira e à Prof. Dra. Rosely Sanches pelo apoio e amizade.

À FAPESP, à CAPES e ao CNPq pelo apoio financeiro.

À UNIMED por propiciar o desenvolvimento de um projeto, utilizado como estudo de caso.

Aos meus pais, ao meu irmão, à minha namorada Eva e aos meus amigos pela compreensão, principalmente em relação às muitas ausências motivadas pelo presente trabalho. Pelo apoio sempre obtido nas horas dificeis.

À todos os professores e funcionários do ICMC-USP, especialmente das Secretarias da Computação (Ângela) e da Pós Graduação (Laura e Marília). 


\section{Índice}

Índice de Figuras ..............................................................................................

Índice de Tabelas ..........................................................................................ii

Resumo

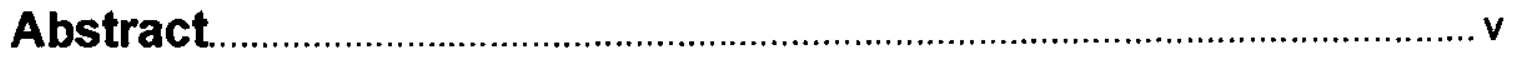

Capítulo 1: Introdução ...................................................................................

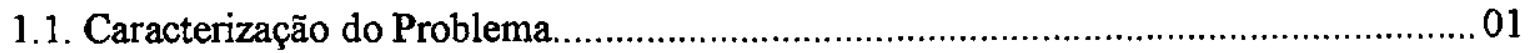

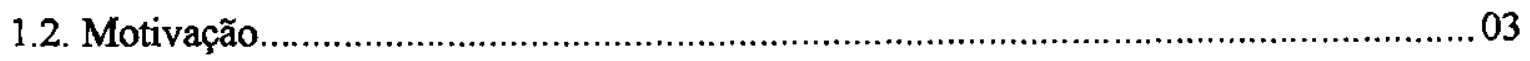

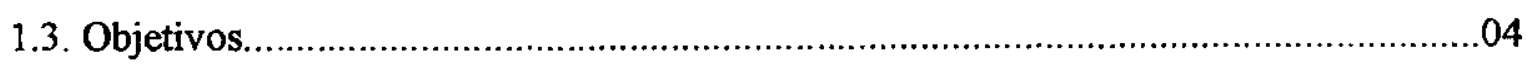

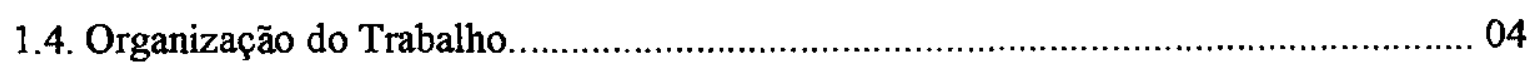

Capítulo 2: Conceitos Envolvidos ……………………………………….........

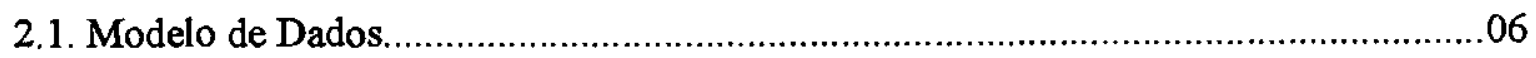

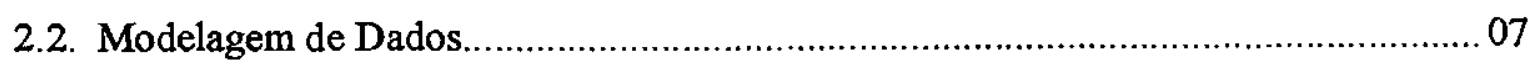

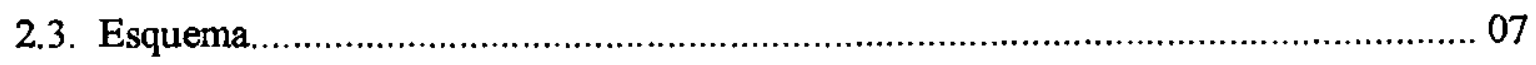

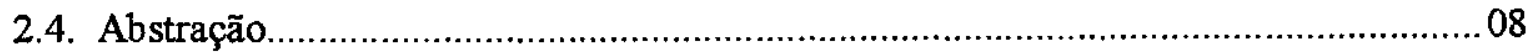

2.5. Mapeamentos de Modelos de Dados Semânticos para Modelos de Dados Lógicos....09

Capítulo 3: Embasamento Teórico ………………………………………......11

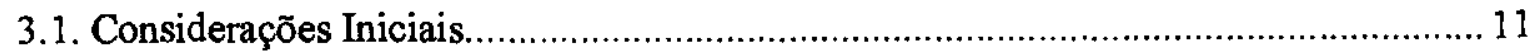

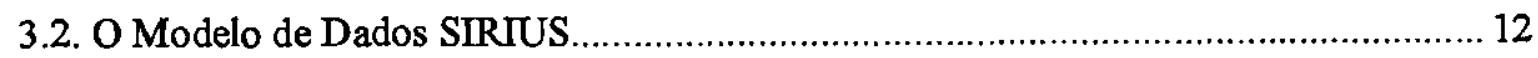

3.2.1. Componentes do Modelo ..................................................................12

3.2.2 Abstração de Agregação.............................................................................. 16

3.2.3. Abstração de Composição........................................................................ 17

3.2.4. Abstração de Generalização.................................................................... 19

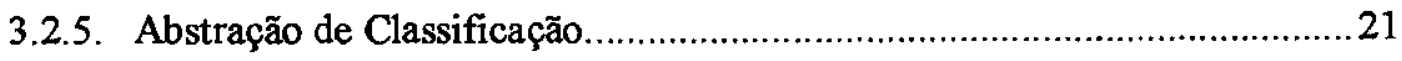

3.3. Modelo Entidade - Relacionamento Estendido (ME-RX) .......................................21

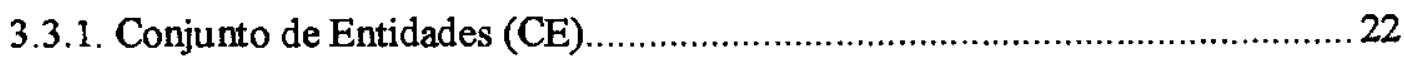

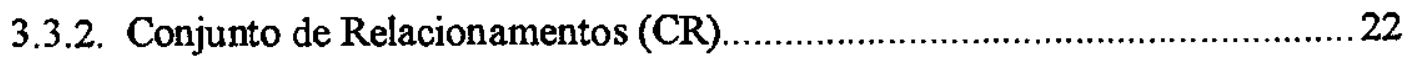

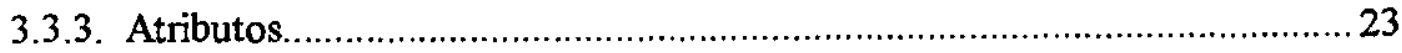




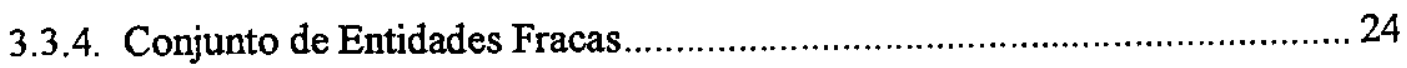

3.3.5. Abstração de Generalização................................................................... 24

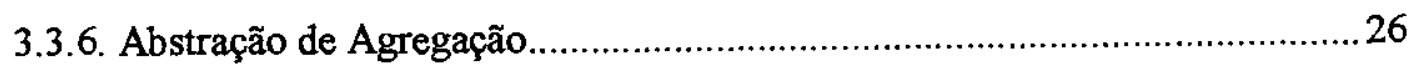

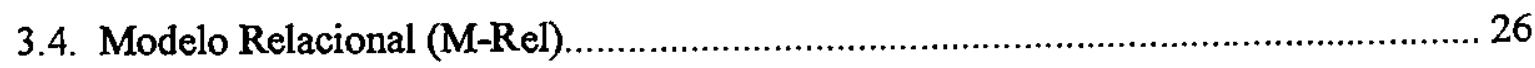

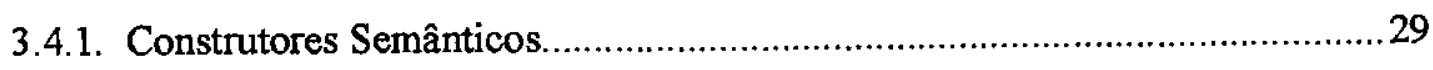

3.5: Mapeamento: Modelo Entidade - Relacionamento Estendido (ME-RX)

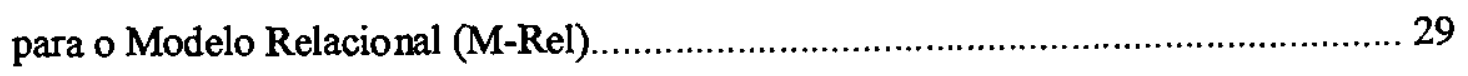

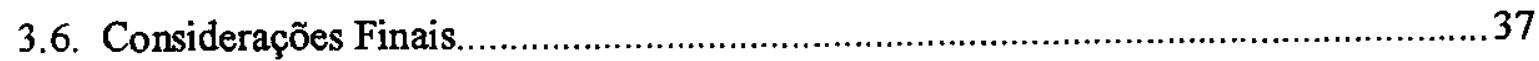

Capítulo 4: A Abstração de Classificaçăo ................................................ 39

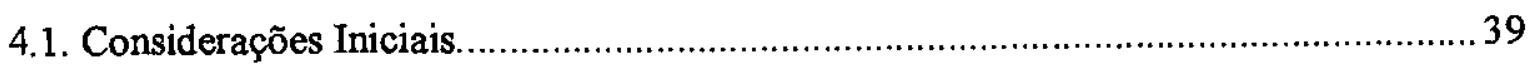

4.2. Caracterização da Abstração de Classificação.......................................................... 39

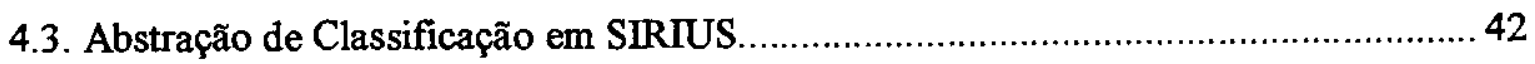

4.4. Estendendo o ME-RX para suportar a Abstração de Classificação............................ 46

4.5. Mapeamento: Modelo Entidade - Relacionamento - Classificação (ME-R-C) para Modelo Relacional (M-Rel) .................................................................. 49

4.5.1. Regras para o Mapeamento da Classificação de CE's.................................... 49

4.5.1.1. Solução Teórica.......................................................................51

4.5.1.2. Solução Prática.........................................................................52

4.5.2. Regras para o Mapeamento de CR Associados a CE Classificados.............. 55

4.5.2.1. Solução Teórica...................................................................... 57

4.5.2.2. Solução Prática.....................................................................57

4.5.3. Regras para o Mapeamento de Agregações...............................................59

4.5.3.1. No mínimo um CE componente é classificável..........................60 60

4.5.3.1.1. Solução Teórica.......................................................60

4.5.3.1.2. Solução Prática..........................................................61

4.5.3.2. Um dos CE's componentes define uma estrutura de dados

que atua como indexador do CE Agregação...................... 62

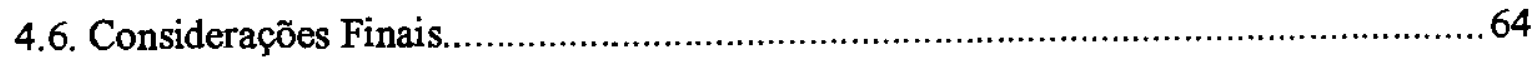

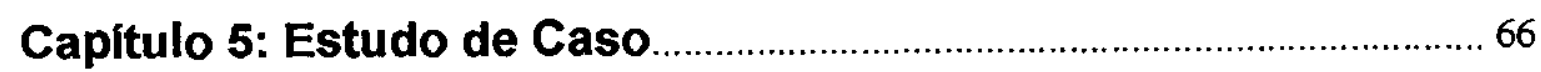

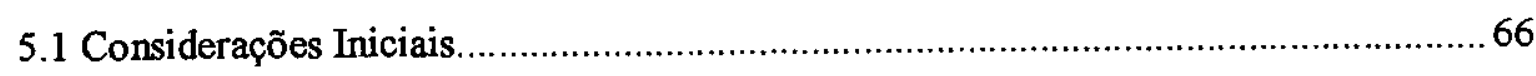


5.2. Descrição do Estudo de Cooperativas Médicas ..........................................................68

5.3.1. Inovação Tecnológica......................................................................... 70

5.4. Exemplos Práticos de Classificação.......................................................................... 73

5.4.1. Classificação de CEs / CR Associados a CE Classificados..........................73

5.4.1.1 Mapeamento de CE's classificados......................................... 75

5.4.1.2. Mapeamento do CR de um CE com um CE Instância...................77

5.4.2. Classificação de Agregação onde um dos CEs componentes

atua como Índice.................................................................. 79

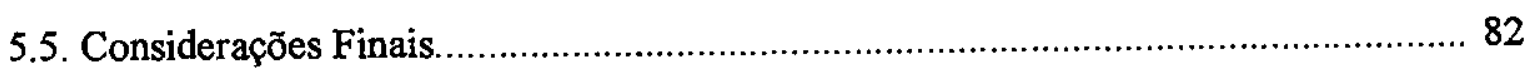

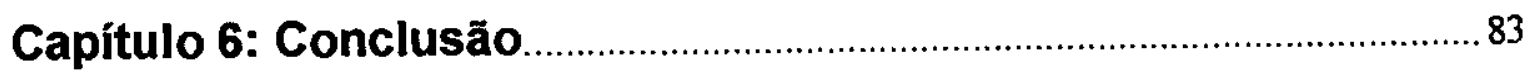

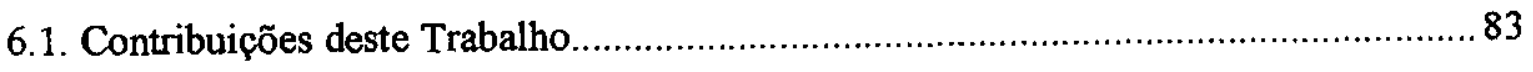

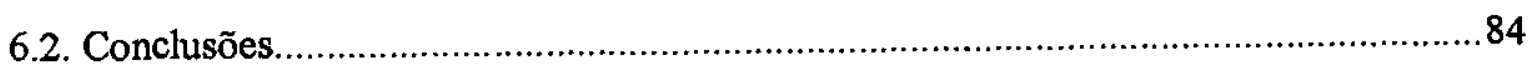

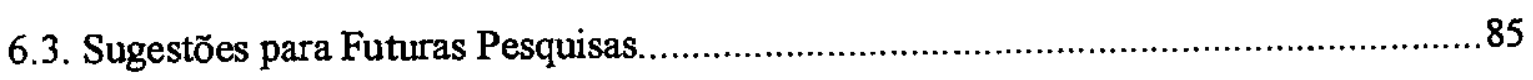

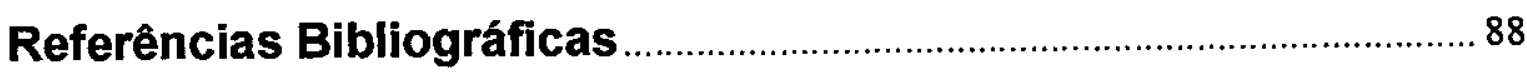




\section{Índice de Figuras}

\section{Capítulo 1}

Figura I.1 - Os 'Três Reinos da Informação.

\section{Capítulo 3}

Figura 3.1 - Abstrações no Modelo de Dados SIRIUS................................................... 12

Figura 3.2 - Representação do Objeto no Modelo de Dados SIRIUS ............................. 13

Figura 3.3 - Tipos de Atributos em SIRIUS......................................................... 14

Figura 3.4 - Relacionamento Binário entre Objetos........................................... 17

Figura 3.5 - Representação da Composição (Colônia de Objetos) …................................ 18

Figura 3.6 - Representação da Notação da Abstração de Generalização............................20

Figura 3.7 - Exemplo da Ocorrência da Abstração de Generalização................................ 21

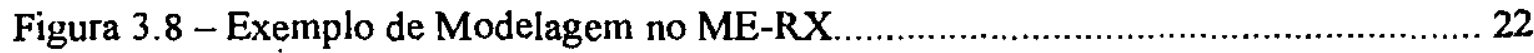

Figura 3.9 - Modelagem com Representação de Atributos no ME-RX ..........................23

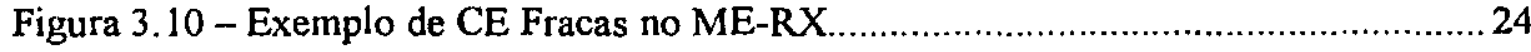

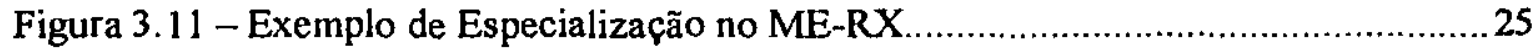

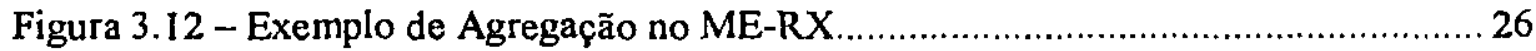

Figura 3.13 - Exemplo de Esquema no Modelo Relacional ........................................27

Figura 3.14 - Exemplo de CE Fracas no ME-RX ............................................................ 30

Figura 3.15 - Exemplo Genérico de Especialização em ME-RX ...................................... 3 I

Figura 3.16 - Exemplo de Generalização em ME-RX.....................................................33

\section{Capítulo 4}

Figura 4.1 - Representação Gráfica de Objetos e de Tipos de Objetos......................... 43

Figura 4.2 - Abstração de Classificação e seus Atributos de Classificação ...................... 45

Figura 4.3 - O Construtor de Classificação em ME-R-C ...........................................47

Figura 4.4 - Estrutura de Classificação de um CE em ME-R-C.....................................50

Figura 4.5 - Exemplo de Classificação em ME-R-C .............................................. 53

Figura 4.6 - Estrutura de Classificação Genérica de CR associado a CE instância

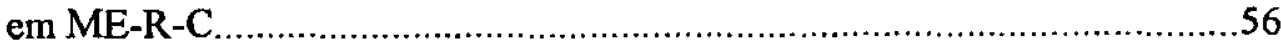

Figura 4.7 - Esquema Genérico de Classificação de Agregação no ME-R-C....................60 
Figura 4.8 - Esquema Genérico de Classificação de Agregação com Índice em ME-R-C

\section{Capitulo 5}

Figura 5.1 - Sistema Master. 69

Figura 5.2 - Exemplo de Ocorrência da Classificação no Estudo dc Caso 74

Figura 5.3 - Exemplo de Ocorrência da Classificação de um Agregação com Índice.. .80 


\section{Indice de Tabelas}

\section{Capitulo 3}

Tabela 3.1 - Características de Atributos em SIRIUS.................................................. 15

Tabela 3.2 - Alternativas de Mapeamento para a Especialização..........................................34

Tabela 3.3 - Abstrą̧̃̃es Suportadas pelos Modelos de Dados......................................... 38

\section{Capítulo 4}

Tabela 4.1 - Casos da Abstração de Classificação e as Relações geradas no Mapeamento.. .65 


\section{Resumo}

Devido à falta de meios para a representação da Abstração de Classificação, situações do mundo real onde ela ocorre a são representadas através de outros mecanismos ou mesmo desprezadas, induzindo falhas semânticas no projeto, dificilmente reparáveis em fases subsequentes. Tal fato é devido principalmente à pouca exploração e suporte dessa abstração. Por exemplo o Modelo Entidade - Relacionamento Estendido (ME-RX), o mais usado na prática profissional, não possui mecanisınos para representá-la. Este trabalho caracteriza precisamente essa abstração,

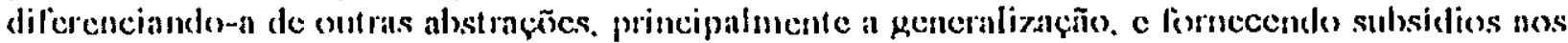
projetistas para a escolha e uso correto da mesma para representar as várias situações de um projeto. Para tal, utilizam-se as construções teóricas de modelos de dados conhecidos aliado ao conhecimento adquirido em um estudo de caso real - o desenvolvimento de um sistema de automação de autorizações para cooperativas médicas. É feita uma nova extensão ao ME-RX para introduzir um construtor semântico destinado à representação da classificação, sendo o novo modelo denominado Modelo Entidade - Relacionamento Classificą̧ão (ME-R-C). A partir desse novo modelo são analisadas as interações da classificação com os demais construtores existentes, e pela primeira vez na literatura da área são definidas as regras de mapeamento da classificação para o Modelo Relacional. 


\begin{abstract}
Current data models and tools to aid in software development do not have ways to express occurrences of the Classification Abstraction. Situations in the real world where it occurs are represented through other mechanisms or even not represented at all, introducing semantic weaknesses in the design, hardly restored in subsequent phases. Such fact are due mainly to the little support of this abstraction. One symptom of this fact is that all widely accepted data modeling tool, like the Extended Entity_Relationship (EE-R) Model, does not have mechanisms to represents it. This work characterizes the classification abstraction and distinguishes it from the other, mainly from the generalization one. It also give to designers clues to correctly use classification in a project. The theoretical foundation of the classification and the knowledge acquired in of real case study - the development of a system for medical cooperatives automation were used to guide this work. We propose a new extension to the EE-R Model to include a semantic constructor supporting classification. We designate this new model the Classification Entity - Relationship model (CE-R Model). Using this new model, we analyze the interactions of classification with the other existing constructors, and define the rules to map classification constructs to the Relational Model. This is the first time in the literature of the area that this mapping is described.
\end{abstract}




\subsection{Caracterização do Problema}

Em 1976, Chen [CHEN_76] propôs uma figura mental importante, muito utilizada para o desenvolvimento dos modelos semânticos da década de 80. Ela apresentou o conceito dos 'lrês Reinos da Informação: o Reino Real (ou mundo real), o Reino da Imaginação e o Reino da Representação. As coisas do mundo real podem ser entendidas pelas pessoas, c pelos projetistas em particular, que criam uma imagem mental própria, que não está no Reino Real, mas no Reino da Imaginação. Nem todos os dctalhes do mundo real são compreendidos na formação dessa imagem mental, que pode até nem corresponder, necessariamente, à exata realidade. Por outro lado, as imagens mentais do Reino da Imaginação podem scr usadas para criar representações utilizáveis ha comunicação chtre as pessons. Tais representaçooss intçram o Reino da Representação. linalmente, uma representação pode scr implementada, o que cria uma nova entidade - um sistema, ou outro engenho qualquer - do Reino Real. $\Lambda$ Figura 1.1 ilustra esses conceitos.

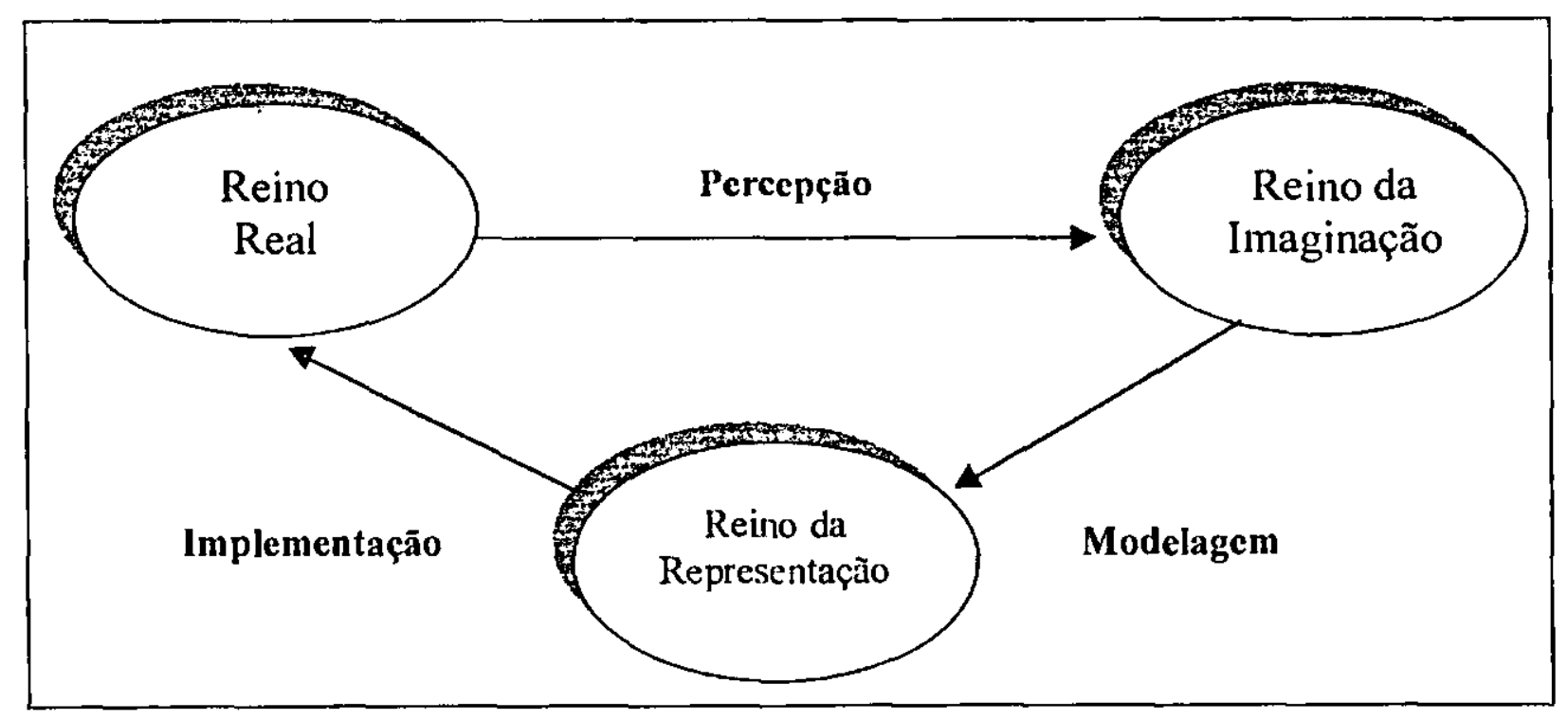

Figura 1.1 - Os Três Rcinos da Informação 
É importante notar que essa figura mental localiza diversos pontos do processo de construção de um sistema onde podem ser introduzidas distorções: a imagem mental é criada a partir do que se entende do mundo real, sendo assim, necessário, que se cntenda corretamente o que se pretende construir. A seguir deve-se representar adequadamente o que se entendeu: apenas e nem tudo 0 que se entendeu é representado. Finalmente faz-se a implementação sobre o que foi representado, embora nem sempre a implementação seja fiel à representação originalmente construída.

Um modelo de dados é uma das ferramentas conceituais que permitem a um projetista representar, em uma estrutura adequada, o significado das informaçôes que ele entendeu de uma determinada situação do mundo rcal. Informação é uma cntidade do Reino da Imaginação, ou seja, somente existe informação se houver interpretação, entendimento: scmântica. Dados sâo entidades do Reino da Representação; são estruturas para a representação dos valores medidos no mundo real, amostrados em qualquer dominio (números, cadeias de caracteres, datas, imagens, etc.). Já no Reino Real estão as propriedades reais, que podem ser medidas para serem entendidas e representadas.

Parte-se do pressuposto que o projetista utiliza um modelo de dados para executar o processo de modelagem de um sistema, analisando a informação de que dispõe em vários niveis de detalhe. Para considerar mais ou menos detalhes, usa-se o recurso conceitual chamado abstraçâo. Abstrair significa desconsiderar detalhes, para se ter uma visâo mais ampla e geral do fato sob análise. Por outro lado, o processo inverso pode ser efetuado, detalhando determinado aspecto para se ter uma visâo pormenorizada do fato em questâo. $O$ tipo de detalhe desprezado/considerado numa abstração e o processo utilizado para tal fim variam, resultando em diferentes abstraçôes e detalhamentos. Quando o mesmo tipo de detalhe é utilizado em uma abstração e em um detalhamento, têm-se uma abstração/detalhamento dual. Toda abstração tem seu detalhamento dual e vice-versa. $\Lambda$ ssim existem as abstrações/detalhamentos de generalização/especialização, agregação/separação, classificação/instanciação, etc. [TRAINA_98]. Neste trabalho, por simplicidade de escrita, usa-se o termo abstraçcio para designar o tipo de detalhe c o processo de escolha da informação manipulada nos proccssos de abstraçâo e detalhamento.

Sob esse ponto de vista, pode-se considerar que um modelo de dados é constituído de uma coleçâo de abstraçôes semanticamente integradas [BIAJIZ_96]. Cada modelo suporta a 
representação de um conjunto de abștraçõos, e cada abstraça pode ser utilizada de dilerentes maneiras entre modelos distintos. Mais ainda, uma mesma abstração pode ser usada em mais de uma forma $\mathrm{cm}$ um mesmo modelo de dados.

Os primeiros modelos de dados a receber amplla aceitação - Rede, Hierárquico, Relacional (MRel), e mesmo o Modelo Entidade - Relacionamento (ME-R) - suporlam um conjunto reduzido de abstrações, o que dificulta o desenvolvimento de aplicações mais complexas. Já os modelos de dados orientados a objetos foram propostos para sanar essas dificuldades, comportando um número maior de abstrações em seus construtores semânticos.

Os melhores e mais utilizados gerenciadores comerciais disponíveis seguem o modelo de dados relacional, que apresenta uma capacidade de representação semântica bastante reduzida. Para contornar as restrições semânticas desse modelo de dados, representa-se o sistema complexo alvo segundo outro modelo (por exemplo o Modelo Entidade Relacionamento Estendido), e posteriormente, para utilizar os gerenciadores relacionais na implementação do sistema, efetuase um mapeamento dessa representação o Modelo Relacional, utilizando-se para isso restriçŏes que garantam o mínimo de perda semântica.

\subsection{Motivação}

Uma das abstraçôes existentes, a abstração de classificação, é fundamental para a conceituaçåo de modelos de dados, mas niuito pouco reconhecida como fazendo parte de um construtor semântico disponível no modelo para ser utilizado na representação dos sistemas alvo, sendo mais explorada em outras áreas de pesquisa, como Lógica e Inteligência Artificial [1'AIVALSAARJ_96]. Dado que a abstração de classificação existe de fato em diversas situaçôes reais, que precisam ser modeladas, é comum a utilizaçâo das outras abstraçòes disponíveis para a reprcsentação dessas informaçőes, originando-se sobrecargas semânticas, que são indesejáveis por corresponder a situações que não ficam adequadamente representadas. lsso conduz à existência de pontos obscuros na modelagem, que não são percebidos nas fases iniciais do projeto e que freqüentemente levam a problemas de soluçào cara em fases mais avançadas. 
Através do estudo de um conjunto de situações práticas representadas através da utilização do Modelo Entidade - Relacionamento Estendido (ME-RX), que suporta a abstração de generalização mas não a de classificação, constatou-se que ć freqücnte a representação de situaçôes típicas de classilicação através da generalização, justamente devido à falta de um mecanismo próprio para a representação da classificação. Essa situação não é convenicntc, pois além de causar uma sobrecarga semântica no construtor de generalização, torna o mapeamento dessas situações potencialmente difícil e mais propenso a erros e à geração de inconsistências de atualização na base de dados resultante.

\subsection{Objetivos}

Neste trabalho pretende-se caracterizar precisamente a diferença existente entre as abstraçóes de generalização e de classificação, fornecendo subsidios ao projetista para que este possa decidir qual delas representa melhor cada situação do projeto. Para tal, utiliza-se o conteúdo tcórico de modelos de dados conhecidos aliado ao conhecimento adquirido em um estudo de caso, para caracterizar a abstração de classificação em situaçõcs práticas. Tambćm, analisam-sc as ocorrências da abstração de classilicação e as suas formas de interação com as demais abstraçõcs do ME-RX, modelo de dados escolhido para o desenvolvimento do estudo de caso.

O principal resultado deste trabalho é a caractcrização da classificação e a definição de suas formas de mapeamento para o modelo relacional. Esta é a primeira vez que esse mapeamento é descrito na literatura da área.

\subsection{Organização do Trabalho}

Preliminarmente, no capítulo 2, são abordados os conceitos mais importantes utilizados no trabaiho, tais como modelos de dados e abstraçòes.

No capítulo 03 são apresentados os modelos de dados envolvidos: SIKIUS, ME-RX e M-Rel, enfocando-se, resumidamente, seus principais conceitos e as abstrações suportadas. Também são 
explanadas as opçóes de mapeamento do ME-RX para final do capítulo faz-se a comparação entre as abstrações suportadas pelos modelos envolvidos e por outros modelos disponíveis.

O capítulo 4 caracteriza a abstração de classificação, diferenciando-a, principalmente, da abstração de generalização. A partir do conhecimento adquirido com a análise da representação da abstração de classificação em SIRIUS, o ME-RX é novamcnte estendido para suportar um construtor semantico que a represente, sendo então denominado de Modelo Entidade Relacionamento - Classificação (ME-R-C). Também são descritas, segundo as formas teórica c prática, as regras de mapeamento desse novo construtor semùntico para o $\mathrm{M}$-Rel, para que o esquema inicialmente concebido possa ser implementado através da utilização de um gerenciador comercial disponivel.

O ambiente do estudo de caso e as algumas ocorrências da abstração de classificação cm partes da modelagem sầo explanados no capítulo 5. Finalmente, o capítulo 6 apresenta as conclusòes e contribuições do trabalho, bem como sugestões para futuras pesquisas. 


\section{Capítulo 2: Conceitos Envolvidos}

\subsection{Modelo de Dados}

Um modelo de dados é uma coleção de regras e conceitos utilizados para se descrever uma situação do mundo real através dos conjuntos de dados dos conjuntos de operações que os manipulam, e que sejam relevantes a um projeto ou outra atividade alvo que os envolvam [CER_ 92]. Uma maneira alternativa de se descrever um modelo de dados é que trata-se de um conjunto de abstrações semanticamente integradas, voltadas à representação de informação [BIAJIZ_96].

Os modelos de dados classificam-se em:

- Modelos de Dados Conccituais: são ferramentas para a representação da rcalidade em um alto nível de abstraçao, de mancira que a descrição scja fácil de entender c interpretar [HULL87][CER__92]. São conccituais, cntre outros, os modclos Lintidade Relacionamento e Entidade - Relacionamento Estendido;

- Modelos de Dados Lógicos: são modelos que suportam descrições dos dados que podem ser processadas pelo computador, sendo mapeados para a estrutura de um banco de dados de maneira relativamente direta [CERI_92]. Os modclos Rede, Hierárquico e Relacional são alguns dos exemplos de modelos de dados lógicos mais utilizados.

- Modelos de Dados Orientados a Objetos: são modelos que pretendem representar a realidade com um grau elevado de detalhe, mantendo, entretanto, formas de implementação imediata. Além dos recursos próprios dos modclos de dados lógicos, os modelos orientados a objetos possuem, basicamente, a capacidade de representaçào da abstração de generalização e de represcntação das operações sobre os dados, fato este que vai além da mera representação das estruturas de dados, tal como é feito nos modelos lógicos. 
Um modelo de dados oferece recursos para a representação da realidade segundo um conjunto de símbolos denominados construţores semânticos, os quạis incluem diretrizes para sua rcpresentação e um conjunto de regras que simbolizam o significado das informações representadas. É importante notar que apesar do nome, os construtores "semânticos" são cstruturas sintáticas, que apenas reprcsentam o significado entendido pelo projetista $\mathrm{em}$ uma csirutura.

\subsection{Modelagem de Dados}

Nome dado ao processo onde estruturam-se as informaç̃es de um sistema alvo segundo um modelo de dados, produzindo-se um esquema [TRAINA_92]. É importante destacar aqui a diferença entre modelo e modelagem. Um modelo é, basicamente, uma coleção de regras que guia a criação de uma modelagem, sendo independente de uma situação em particular, como por exemplo o Modelo Relacional e o Modelo Entidade - Relacionamento Estendido. Já uma modelagem é a aplicação de um modelo em uma sit tuạâo em particular, como por exemplo a modelagem de um sistema de folha de pagamento utilizando-se o Modelo Relacional.

\subsection{Esquema}

Um esquema é a representação de uma porção especifica da realidade, construida através da utilização de um modelo de dados em particular. Mais precisamente, um esquema é uma coleção estática de representaçôes gráficas ou escritas que descrevem a estrutura dos dados de interesse [CERI_.92], e nos casos de utilização de modelos de dados orientados a objetos, das operações sobre esses dados. 


\subsection{Abstração}

Abstração é o nome dado ao processo mental usado para a seleção de algumas características e propriedades de um conjunto de objetos e exclusão de outras, que não são relevantes. $O$ termo abstração é utilizado em duas situaç̃es: quando analisam-se mentalmente as informaçð̃es sobre determinada realidade, para compreensão com um grau maior ou menor de detalhe, e quando representa-se a realidade entendida segundo um modelo de dados. Como resultado da primeira situação, os detalhes de um sistema são integrados segundo uma estrutura lógica que é representada no esquema. Já como resultado da segunda situação, a realidade entcndida pelo projetista é representada através de uma modelagem segundo as regras de representação de um modelo de dados. Somados os processos, obtém-se como resultado que as abstrações utilizadas pelo projetista para entender uma situação da realidade são representadas na modelagem através dos construtores semânticos do modelo de dados.

Uma abstração é aplicada quando é importante tratarem-se as propricdades de um conjunto de objetos julgadas essenciais, sendo as dilerenças entre eles esquecida [CERI_92]. Por outro lado, o processo inverso pode ser efetuado, detalhando determinado aspecto para se ter uina visão pormenorizada do fato em questão. $O$ tipo de delalhe desprezado/considerado numa abstração e o processo utilizado para tal fim variam, resultando em diferentes abstraçôes e detalhamentos. Quando o mesmo tipo de detalhe é utilizado em uma abstração e em um delalhamento, tèm-se uma abstração/detalhamento dual. Toda abstração tem seu detalhamento dual e vice-versa. As ahstrações/detalhamentos de genernlização/especialização, agregação/separaçào e

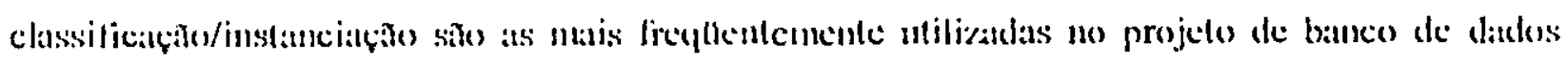
conceituais. Exemplos de outras abstraç̧es/detalhamentos que ocorrem em modelos de dados são composição/separação, categorização/especialização de categoria, versão genérica/versionamento, etc. $\Lambda$ s abstrações/detalhamentos mais freqüentes são descritas a seguir:

- Abstração de Classificação / Instanciação - o processo mental utilizando por cssa abstração envolve a classificação de objetos similares do mundo real em elasses de objctos. Os grupos de objetos compartilham os mesmos tipos de atributos e constantes, sendo a classificação útil para o processo de definição de suas propriedades comuns. Já o nome instanciação relèe-se ao processo inverso (detalhamento), onde gera-se c examina-se especificamente cada objcto 
distinto de uma classe [ELMASSRI_94]. Um objeto que representa a classe é o objeto tipo, e cada um dos objetos construídos segundo esse tipo é um objeto instância. Na literatura, construtores semânticos que representam essa abstração são tambćm chamados dc materialização [PIROTTE_94] [PIROTTE_97] [DAHCHOUR_98].

- Abstração de Generalização / Especialização - a abstração de generalização, também chamada de síntese conceitual, consiste em se generalizar vários tipos de objetos (subtipos), formando uma classe de nivel superior (mais abstrato) que inclui as caractcrísticas compartilhadas por todos os objetos, de qualquer de seus sub-tipos. Já especializaçào, também chamada de refinamento conceitual, corresponde ao processo inverso, onde um tipo de objetos é dividido em subtipos mais especializados [ELMASRI994].

- Abstração de Agregação / Sepa ração - $\Lambda$ agregação corresponde à idćia de que clcmentos já existentes concatenam-se para criar outros, com características próprias [TRAINA_92]. Já a scparação ć o processo inverso, onde scparam-sc objctos cxistentes em scus clcmentos coimponentes.

As três abstraçð̃es são independentes: nenhuma delas pode ser expressa em termos de outra. Cada uma fornece mecanismos diferentes para o processo de estruturação da informação [CERI_92]. No entanto, um construtor scmântico pode incluir conccitos de mais de uma abstraçâo.

\subsection{Mapeamentos de Modelos de Dados Semânticos para Modelos de Dados Lógicos}

O mapeamento é a transformação de um esquema concebido segundo um modelo, para outro esquema, segundo outro modelo, diferente do primeiro. $\dot{1}$, portanto, simplificadamente, um conjunto de regras que visam a maximizaçâo do grau de scinelhança entre os csquemas, a lim de se evitarem perdas ou ganhos semânticos não pertinentes à representação inicialmente desejada. 
Nesse trabalho, estuda-se o mapeamento de um modelo conceitual (entidade relacionamento estendido, novamente estendido para suportar um construtor semântico que permite representar a abstração de classificação) para um modelo lógico (relacional). Dessa forma pode-se aproveitar ao máximo o alto nível de abstração de um modelo conceitual, garantindo-se uma representação clara, de entendimento facilitado, durante as fases iniciais do projeto. Após a consolidação da representação, já nas etapas finais do projeto, faz-se o mapeamento para um modelo lógico, mais próximo da maneira suportada pelos computadores, tentando preservar-se ao máximo as propriedades do modelo entidade relacionamento, semanticamente mais rico. Esse mapeamento também é estimulado pelo fato de muitos gerenciadores comerciais seguirem o modelo relacional. 


\section{Capítulo 3: Embasamentó Teórico}

\subsection{Considerações Iniciais}

Nesse capltulo faz-se uma breve descrição dos modelos de dados analisados no trabalho c utilizados no estudo de caso. Na seção 3.2 analisa-se o Modelo SIRIUS, desenvolvido pelo Grupo de Bases de Dados do ICMC - USP. Esse modelo de dados orientado a objetos foi criado para suprir as lacunas semânticas deixadas por outros modelos, sendo utilizado nesse trabalho para a caracterização da diferença conceitual existente entre as abstrações de generalização e classificação, pretendida pelo estudo de caso.

O segundo modelo, Entidade - Relacionamento Estendido, é descrito na seção 3.3, e corresponde ao modelo conceitual escolhido para o desenvolvimento do estudo de caso, por ser um modelo bastante difundido entre os profissionais da área, sendo considerado simples e de fácil utilização.

Já na scção 3.4, descreve-sc o último modclo analisado - Modclo Rclacional - utilizado no projeto como modelo alvo para o mapeamento do esquema previamente concebido no Modelo Entidade - Relacionamento Estendido. Isso foi realizado para a simplificação da implementação do esquema em um gerenciador de banco de dados disponivel comercialmente. $\Lambda$ s regras usuais de mapeamento também foram descritas na seção 3.5 .

Nesse capítulo procurou-se sempre descrever as abstrações suportadas por cada modelo, devido d̀ relevância para o estudo de caso em questâo. Deste modo, concluindo, na seção 3.6 realiza-se uma breve comparação semântica entre os modelos de dados, através da apresentação de um quadro resumo das abstraçôes suportadas e disponibilizadas através de construtores semànticos nos modelos de dados analisados $\mathrm{c}$ cm outros encontrados na litcratura. 


\subsection{O Modelo de Dados SIRIUS}

$O$ modelo de dados SIRIUS fò desenvolvido a partir de uma evolução de conceitos do Modelo de Representação de Objetos - MRO, para atender às necessidades de aplicações de banco de dados não convencionais, onde os dados não apresentam uma expressiva homogeneidadc

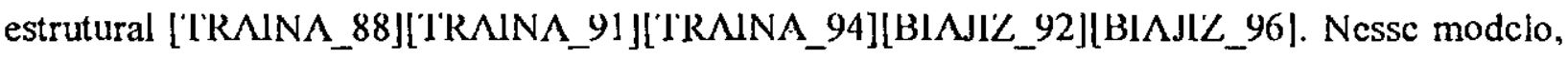
os conceitos de objetos, atributos, características de atributos, tipos de objetos e tipos de atributos constituem os seus elementos primários, sendo estruturados scmântica e sintaticamente scgundo as abstrações de classificação, associação e generalização; a abstração de associação têm sua ocorrĉncia cspccializada $\mathrm{cm}$ outras duas abstraçõcs: composição c agregação, conforme representado na Figura 3.1:

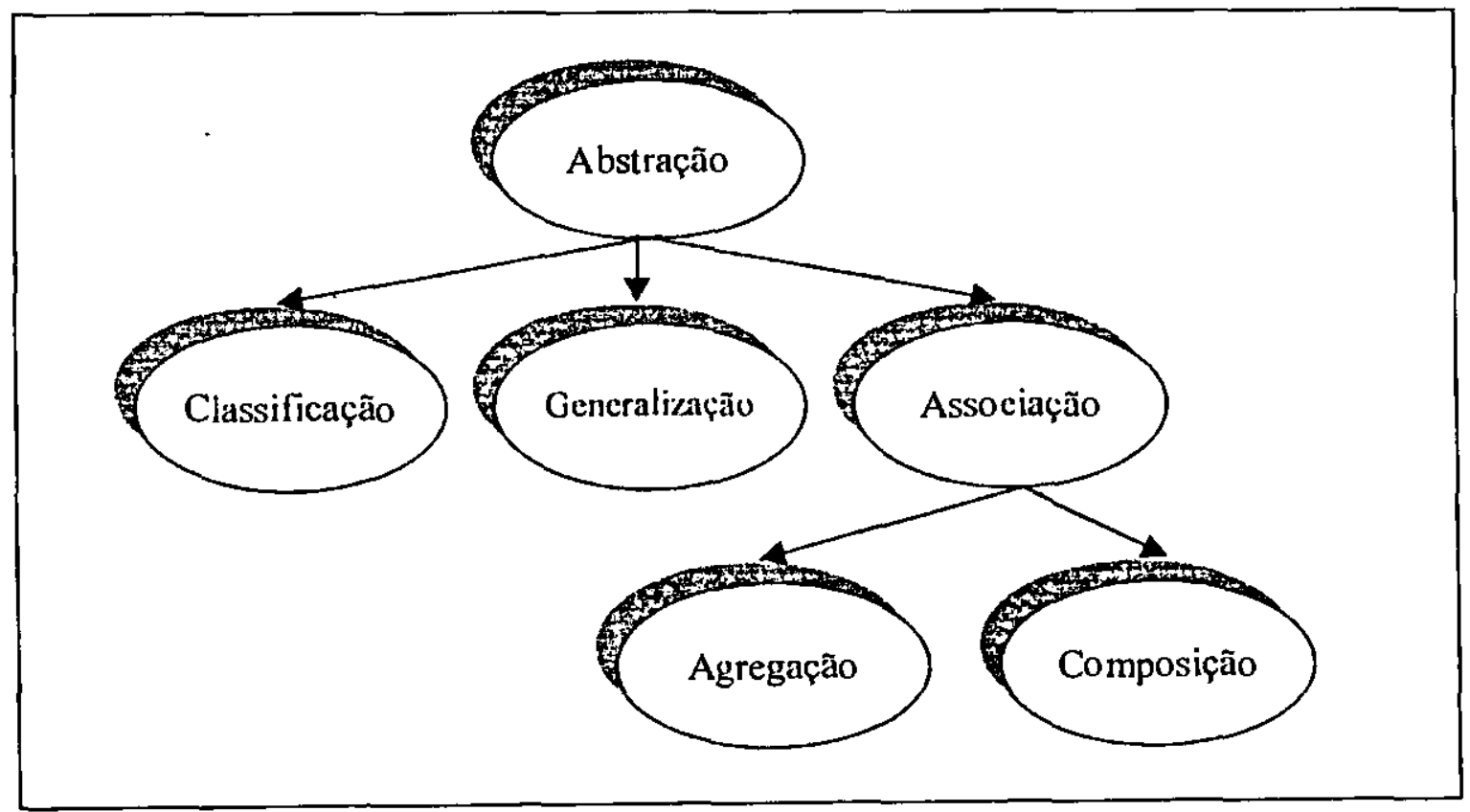

Figura 3.1 - Abstrações no Modelo de Dados SIRIUS

\subsubsection{Componentes do Modelo}

\section{Objetos}

Em SIRIUS, objetos são as entidades do mundo rcal que podem ser identificadas univocamente pelo usuário. Nesse modelo de dados, o termo "objeto" é utilizado de acordo com cada uma dạs três situações: 
- quando o usuário reconhece um elemento do mundo real, utiliza-se o tcrmo "objeto definido pelo usuário", ou simplificadamente o termo "objeto" sem qualificador. Por exemplo, veículos ou pessoas são objetos definidos pelo usuário, ou simplesmente objetos;

- quando o sistema manipula os objetos visando sua conceituação algébrica, o termo utilizado é "objeto primário". Os objetos primários nâo são transparentes ao usuário, mas podem ser identificados apenas através de abstraçõcs com outros objetos. Por exemplo, um relacionamento é um objeto primário entre dois objetos definidos pelo usuário, mas pode ser identificado apenas através de referências aos objetos relacionados;

- o objeto que engloba os objetos primários e os objetos definidos pelo usuário é definido como "objelo conceito".

Um objeto, que representa uma entidadc do mundo real, é representado pclo seu nome, pelo nome do seu tipo e por atributos a ele associados. Um tipo é também um objeto, portanto existem objetos que são tipo e outros que não o são. É importante observar que todo objeto tem exatamente un tipo.

A representação genérica de um objeto é feita usando-se um retângulo dividido em duas partes: superior e inferior. A parte superior é também é dividida en duas partes, direita e esquerda. Na partc esquerda coloca-se o nome do tipo objcto e na parte direita colocam-se os dados da abstração de composição (descrita a seguir). Na parte inferior coloca-se o nome do objeto. Um exemplo é dado na Figura 3.2.

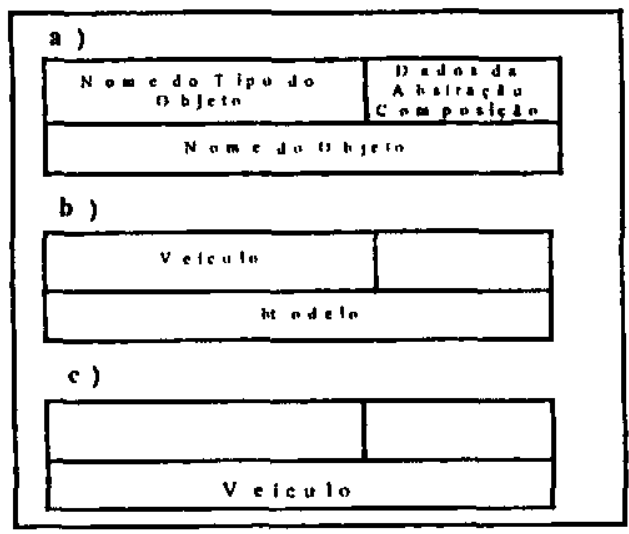

Figura 3.2 - Represcntação do Objeto no Modcio de Dados SIRIUS 


\section{Tipos de Atributos}

São objetos primários - dados do mundo real que estabelecem informaçôes sobre os objetos definidos pelo usuário. Esses dados são modelados como valores de atributos associados a objetos, estabelecendo sua estrutura e "comportamento", caracterizando sua sintaxe e sua semântica na modelagem. No modelo, os tipos de atributos desempenham o papcl de caractcrizar os tipos de objetos, podendo ser instanciados através de seus valores em atributos. Um exemplo da sua representação pode ser visto na Figura 3.3.

Os tipos de atributos são associados aos objctos atravćs dc uma ligação monovalorada ou multivalorada. Um tipo de atributo monovalorado é aquele que possui apenas um valor para cada atributo instanciado, sendo representado por uma seta simples. Já o tipo de atributo multivalorado possui mais de um valor para cada instància, podendo ser organizado segundo estruturas de dados, tais como vetores, conjuntos ou listas. É representado com uma seta dupla, indicando-se a estrutura utilizada: \{\} para conjunto, $<>$ para lista e [] para vetor.

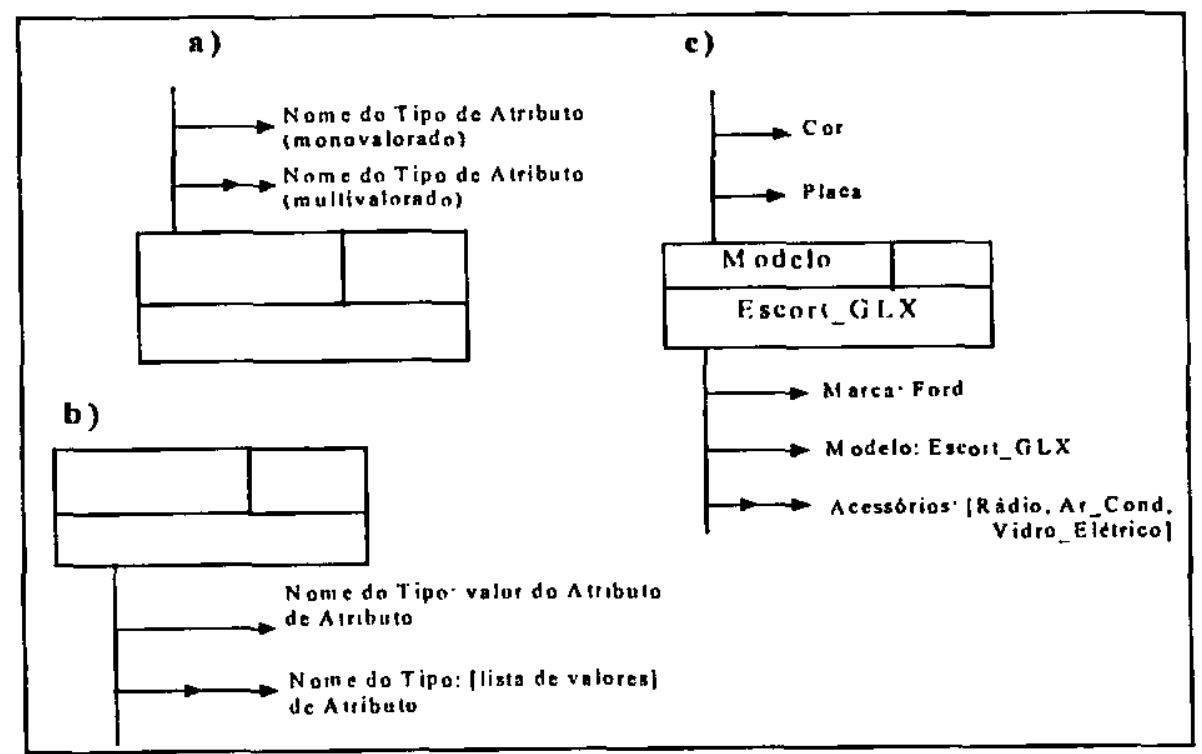

Figura 3.3 - lipos de $\Lambda$ tributos em SIRIUS

lodo objeto possui atributos com os valores que representam a instância correspondente a esse objeto. Fsses atributos são chanados arributos de instcinciaçiōo. Um objeto que é tipo possui ainda a definição dos atributos que deverão ser associados aos objetos instanciados a partir desse tipo. Esses atributos são chamados de atributos de classificação. Na parte superior da 
representação de um objeto são colocados os tipos de atributos de classificação, enquanto que os atributos de instanciação são colocadös na parte inferior do mcśmo.

Na Figura 3.3a tem-se a representação de atributos de classificação, enquanto que na Figura 3.3b representam-se tipos de atributos instanciados. Na Figura $3.3 \mathrm{c}$ é apresentado um excmplo em que o objeto é do tipo "modelo de veículo", e identificado como "Escort_GLX", com tipos de atributos de classificação cor e placa, situados acima do objeto, caractcrizando que instâncias desse modelo têm placa e cor individuais.

$\mathrm{Na}$ parte inferior do objeto tem-se os atributos de instanciação do tipo, que são: marca instanciado com o valor ford; modelo instanciado com o valor Escort-GLX; e o tipo de atributo multivalorado accssórios instanciado como vetor, que possui os valores rádio, ar cond $c$ vidro_clétrico.

\section{Caracteristicas de Atributos}

No Modelo SIRIUS todo o atributo possui um tipo e um conjunto de valores não vazio. Todo tipo de atributo deve estar associado a uma caracteristica de atributo. A caracteristica de um atributo define o conjunto de operações que um gerenciador de dados pode efetuar sobre essc atributo, estabelccendo portanto o comportamento junto ao objeto ao qual o atributo está associado.

Tabela 3.1 - Caracteristicas de Atribulos em SIRIUS

\begin{tabular}{|c|c|c|c|}
\hline $\begin{array}{c}\text { Classe de } \\
\text { Caracteristica }\end{array}$ & Característica & Símbolo & Tipo de Dado \\
\hline Estática & Texto & $T x^{2}=1$ & String ASCII, RTF \\
\hline 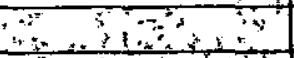 & Número & $\because \mathrm{Nu}$, & Inteiro real ${ }^{\text {rat }}$ \\
\hline$\frac{1}{1}$ & Booleano & $3^{3} \mathrm{BO}^{\cos } \mathrm{i}^{4}$ & Booleanow $y$, \\
\hline Dinámica & Regra & $\mathrm{Rg}$ & Trigger \\
\hline & Procedimento & Pc & Stored Procedure, Método \\
\hline Interface? & Visualizaçao & 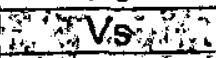 & 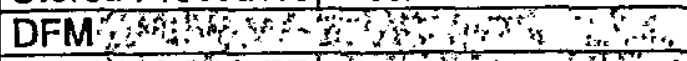 \\
\hline 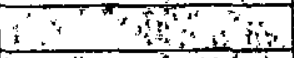 & 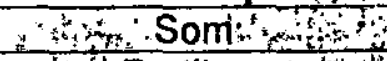 & +10.50 & WAV VOC AIFF H \\
\hline$\therefore 45$ & in Partitura: & $\mathrm{A}^{2} \mathrm{~Pa}+\mathrm{q}$ & MIDI,MOD, SNG \\
\hline 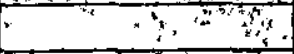 & is lmagem , & 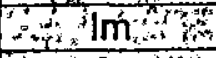 & BMP,TIFF, J-PEG \\
\hline 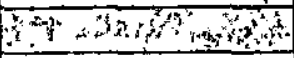 & tom Gráfico & 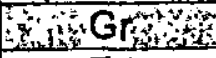 & 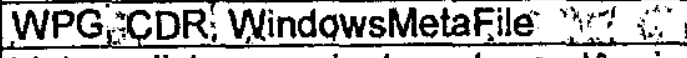 \\
\hline Estruturais & Estrutura de Dado & Ed & $\begin{array}{l}\text { Vetor, lista, conjunto, dependência } \\
\text { funcional }\end{array}$ \\
\hline & Ten & $\mathrm{Tm}$ & Absoluto, relativo \\
\hline & Tupla & $T p$ & \\
\hline & Atributo de Atributo & $\mathrm{Aa}$ & \\
\hline & Relacionamento & $\mathrm{Re}$ & \\
\hline
\end{tabular}


Em SIRIUS as características dos atributos são divididas em 04 classes: estática, dinâmica, interface e estrutural. A Tabela 3.1 define a lista das características de atributos suportados, juntamente com os possiveis tipos de dados correspondentes.

\subsubsection{Abstração de Agregação}

A agregação entre os atributos acontece para constituir um conjunto de dados, a fim dc representar as informações do objeto do mundo real na modelagem ou para constituir outros atributos. Atributos estabelecem tambem relacionamentos entre os objetos, ou scja, dois ou mais objetos são agregados através de um objeto conceito. Deste modo, a abstração de agregação caracteriza-se, no Modelo SIRIUS, através da agregação de atributos e da ağregação de objetos entre si, formando relacionamentos.

Verifica-se que a agregação de atributos pode ocorrer de várias maneiras, através da associação de atributos simples em tuplas, vetores, listas ou conjuntos sem repetição. Pode-se dizer entào, que tuplas, vetores, listas e conjuntos são estruturas de dados organizadas a partir da agregação de atributos.

Um atributo também pode ser associado a um outro atributo, o qual denomina-se atributo de atributo. Utiliza-se essa agregação quando um determinado atributo possui características próprias (outros atributos) diferentes para cada valor que the é atribuido, não havendo interesse, porém, para o projeto ao qual ele se insere, en modelá-lo como um objeto à parte. Note-se que um atributo de atributo pode ser visto como uma tupla, porém um dos atributos dessa tupla ć o identificador da mesma.

Já a agregação entre objetos pode acontecer de duas maneiras. A primeira, mais imediata, consiste em referenciar-se, a partir de um dos objetos envolvidos, os demais objetos. Essa mancira de indicar a agregação cntre objetos não acrescenta nenhum conccito novo ao modelo, correspondendo apenas ao fato de que o valor de um atributo pode ser um objeto.

A segunda maneira, que institui o conceito de relacionamento, considera a associação entre objetos como um objeto primário. Nesse caso, os objetos envolvidos tèm como atributo uma refcrência para o "objeto relacionamento". O tipo do rclacionamento ć caractcrizado pclo tipo 
de atributo e a característica desse tipo de atributo é "relacionamento". O relacionamento pode, também, ter atributos associados, denominados atributos de relacionamento.

$\mathrm{Na}$ Figura 3.4 representa-se um relacionamento binário entre os objetos posfo e voículo. A notação representa um "arco" com a ligação dos atributos faz troca de óleo e recebe troca de óleo, onde cada arco parte de um objeto, caracterizando uma agregação entre eles. $\mathrm{O}$ círculo no centro representa o objeto relacionamento (objeto primário) e a chave que o envolve representa a existência de um conjunto de instâncias do atributo do conjunto de relacionamentos. Un exemplo de instância do relacionamento é o atributo data com valor 23/06/98.

Também são representados relacionamentos ternários, quaternários, etc. Nesse caso, em mais de dois objclos existem atributos com características de relacionamento, associando-se através do objcto primário representado pelo círculo central.

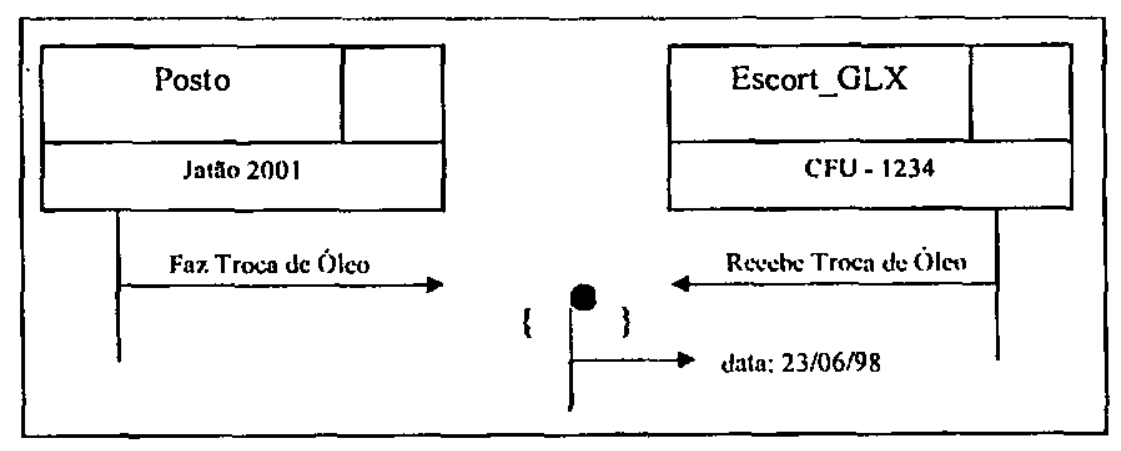

Figura 3.4 - Rclacionaniento Binario cntre Objetos

\subsubsection{Abstração de Composição}

Utiliza-se o termo composiçâo para se caraterizar situaçôes onde os objetos são realmcnte "compostos por" outros. Mais que a agregaçấo de valores representada pela agregaçào, a composição compõc partes, que são objctos autônomos, $\mathrm{cm}$ outros objctos tambćm autônomos, independentes da existência de suas partes elementares. A composição pode definir também papćis cspecificos a sercm assumidos por cada uma de suas partes. Um carro, por cxcmplo, ć composto por rodas, motor, suspensão, etc. e precisa de objetos especílicos que assumam os papéis de motor, suspensâo, etc. 
$\Lambda$ abstração de composição, tal como a abstração de agregação, é uma especialização da abstração dc associação. Porém, represcnta um significado diferente, pois cada instância da abstração de composição determina a existência de um objeto composto - objcto abstrato - e de um conjunto de objctos que são "parte" desse objeto - objetos detalhe. Os objctos detalhe são objetos de fato, definidos e reconhecidos pelo usuário.

Os objetos compostos e suas partes formam um conjunto com propriedades distintas. O modelo de dados SIRIUS aproveilou essa idéia e defmiu o conceito de colônia de objelos. Uma colônia de objetos pode ser definida como um conjunto de objetos que compõe um objeto composto segundo um determinado aspecto. A idéia de aspecto representa o fato de um objeto poder ser visto como composto de diferentes manciras, dișuntas entrc si.

A Figura 3.5a mostra os relacionamentos implicitos que ocorrent entre os objetos envolvidos ma ocorrência de uma abstração de composição: um objelo composto constringe uma colônia, na qual habitam objços que são parte daquele objeto composto. As colônias detcrminam objctos primários, quc como quaisquer outros, possuem um tipo. Logo, toda colônia tem um tipo.

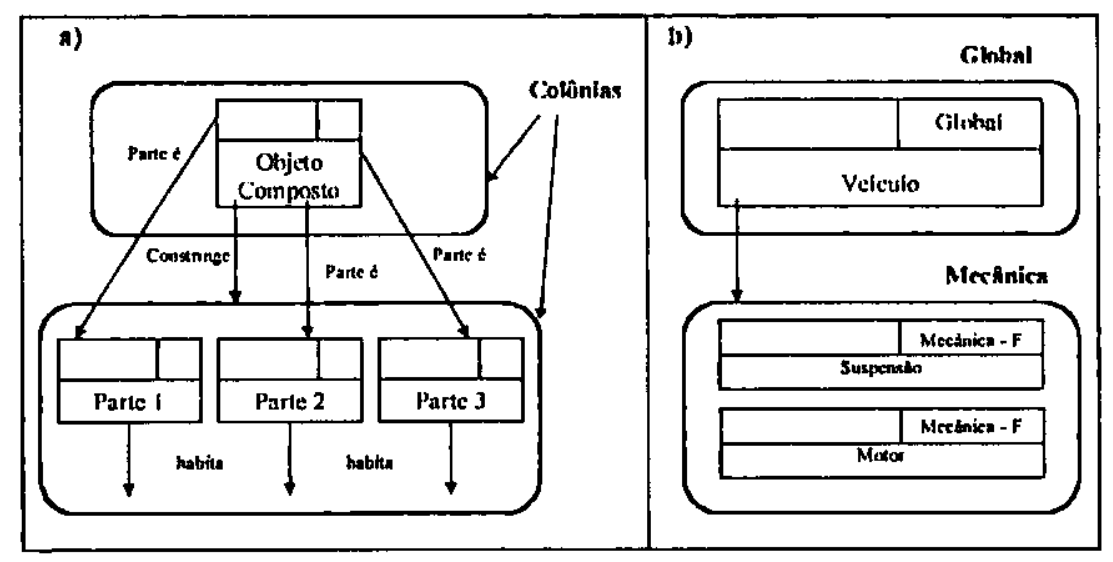

Figura 3.5 - Representação da Composição (Colônia de Objetos)

Una colònia pode representar composição lógica ou fisica de objetos. Impõe-se a restriçâo de que todo objeto deve habitar fisicamente uma colônia, e esse vínculo estabelece uma relação de dependência existencial entre o objeto c a colônia: se a colônia deixar de existir, todos os objctos que a habitam deixam de existir também. Por outro lado, um objeto pode habitar logicanıente qualquer quantidade de colônias, sem causar nenhum tipo de dependência existencial.

\footnotetext{
- $\wedge$ palavta constringe $\bar{e}$ usada no scntido de envolver, delimilar um conjunto de clemenlos vislos sob um delcrninado aspecto
} 
A indicação do tipo da colônia que um objeto habita.é efetuada no diagrama através da colocação do nome da colônia na parte direita da linha do retângulo que representa o tipo de objeto, seguida das letras $F$ ou $L$ para indicar habitação fisica ou lógica. Para todo tipo ć obrigatória a indicação de exatamente uma colônia onde o objeto habita fisicamente.

Existe uma colônia denominada "global", da qual pode haver apenas uma instância. A partir dela define-se a hierarquia de composição, que estabelece o contexto em que os objetos estâo sendo compostos.

A Figura 3.5 b representa o fato de que o objeto veiculo constringe a colônia mecânica.

\subsubsection{Abstração de Generalização}

Caracteriza-se pelo fato de um tipo de objeto abstrair o comportamento e o significado de tipos de objetos mais especificos. Por outro lado, um tipo de objeto pode acrescentar mais detalhes a um outro tipo já existente, ou seja, especializá-lo.

Conceitualmente, não há restrições para que quaisquer objetos possam ser especializados ou generalizados. Porém, quando o objeto não é um tipo, não há justificativa para sua especializaçẫo ou generalização, uma vez que recai-se na sitıação trivial de inserção ou eliminação de atributos no objeto. Conclui-se que a abstraçào de generalização é significativa quando aplicada sobre objetos que são tipo.

Para uma ggeneralização, o modelo impõe a definição de: um tipo a ser especializado (supertipo); um conjunto de lipos especializados (subtipos); um criterio de especializaçào/generalizaçào; restrições para a especialização/generalização; e um conjunto de regras de inicialização para instanciar cada tipo especializado/generalizado.

O critério de especializaçâo/generalização dá-se pela avaliação de um predicado sobre os valores de um ou mais atributos. As restriçôes associadas a esta abstração são:

- Sobreposição: indica se um objeto do tipo genérico pode scr apenas um (disjunção) ou mais dc um tipo especifico (sobrcposição); 
- Participação: indica se todo objeto do tipo genérico deve necessariamente scr também dc um tipo especffico (participação total) ou não (participação parcial);

- Categorização: indica se todo objeto de um tipo específico deve necessariamente ser também do tipo genérico (categoriá total ou subtipo) ou não (categoria parcial).

$\mathrm{Na}$ literatura aprescnta-se a última restrição como uma outra abstração, normalmente denominada abstração de categorização. No modelo de dados SIRIUS, a abstraçâo de categorização é considerada uma especialização da abstração de generalização, não sendo detalhada neste trabalho.

A notação utilizada para esta abstração pode ser vista na Figura 3.6. Constitui-se de uma rede aciclica, onde cada nó é um tipo de objeto. $O$. supertipo é representado por um retângulo no topo da figura, sendo ligado aos subtipos por um trapćzio, no qual reprcscnta-sc o atributo critćrio, que define a especialização, e as restriçôes de disjunção ou sobreposição, e participaçâo total ou parcial.

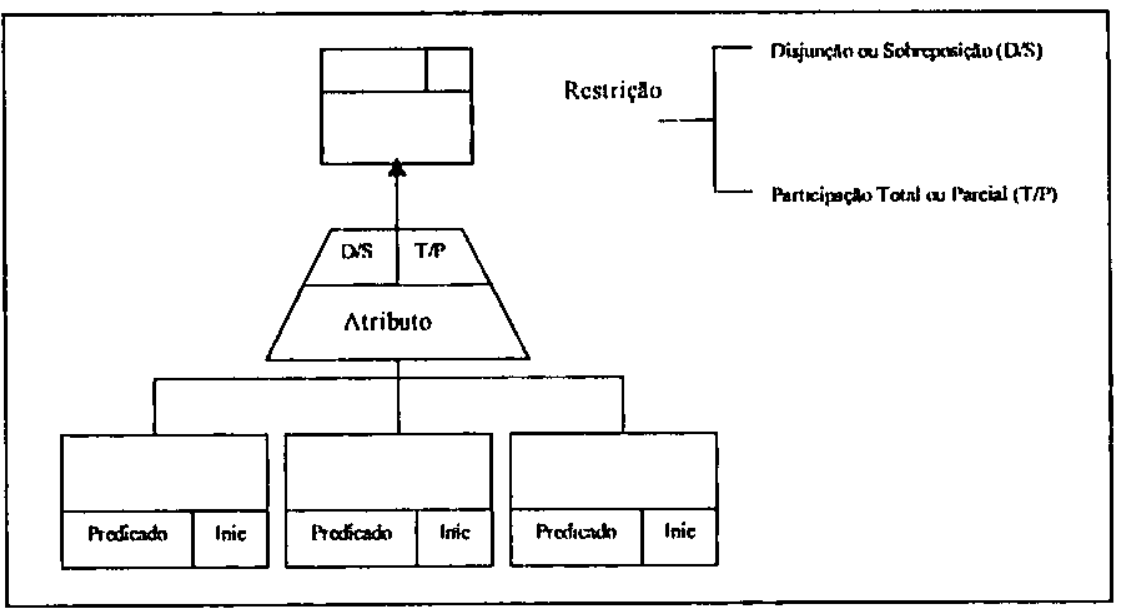

Figura 3.6 - Representação da Notação da $\Lambda$ bstraçĩo de Generalização

O predicado e os valores de inicialização inic são representados no retângulo, juntamente com os sublipos. Quando o crilério de especialização/generalização depende do valor de um atributo cujo domínio é discrcto e finito, o predicado é rcpresentado pelo valor do atributo critćrio; caso contrário, o predicado é representado por uma expressão ou um conjunto de valores. 
Ilustra-se um dos critérios na Figura 3.7, onde a especialização depende do resultado da avaliação do predicado $P$ ol., que significa a polência do veículo. A partir desse número, os carros são divididos em populares, comuns e esportivos.

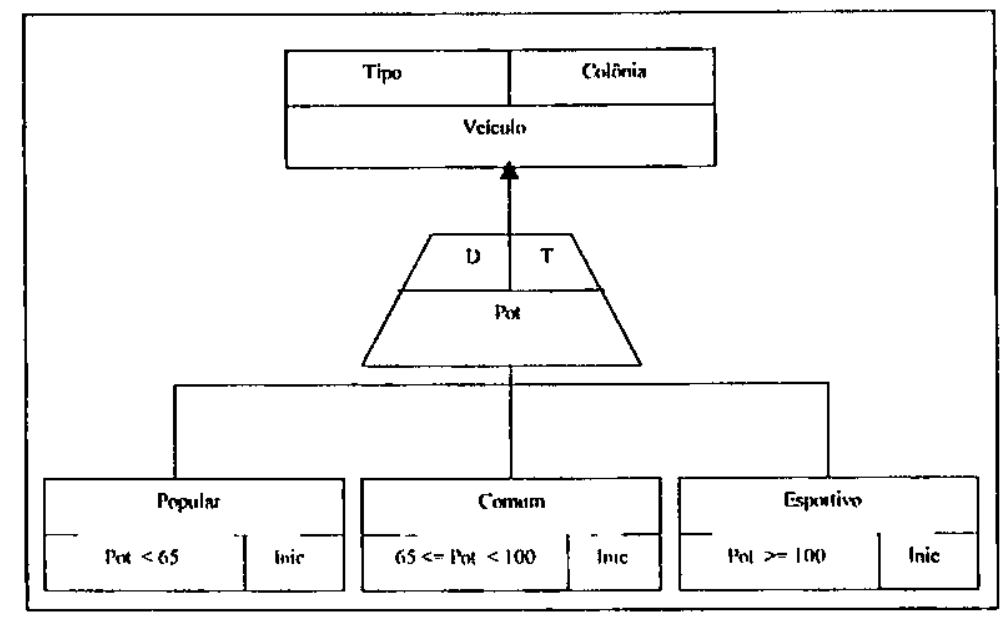

Figura 3.7 - Excmplo da Ocorrência da $\Lambda$ bstração de Generalização

\subsubsection{Abstração de Classificação}

Por tratar-se da abstração que norteia o presente trabalho, essa abstração e sua representação em SIRIUS serão explanadas no próximo capítulo.

\subsection{Modelo Entidade - Relacionamento Estendido (ME-RX)}

O Modelo Entidade - Relacionamento [CHEN_76] é, seguramente, o modelo conceitual mais aceito e utilizado para projetos de bancos de dados no meio profissional. Mediante sua grande . utilização, logo aparcceram deficiências de scu emprcgo $\mathrm{cm}$ casos rcais. Assim, o modelo foi estendido [ELMASRI_94] para oferecer um conjunto maior de construtores semânticos. Em particular, adicionaram-se as abstrações de generalização e uma nova representação para a abstração de agregação, cujo construtor semântico foi cxplicitamente chamado de agrcgação (note-se que o ME-R original já suportava a abstração de agregação através da agregação de atributos criando entidades, e da agregação de entidades criando relacionamentos). 
A seguir faz-se um resumo dos principais construtores semânticos do Modelo Entidade Relacionamento Fstendido (MF,-RX) [I.OUCOPOUI,OS_94].

\subsubsection{Conjunto de Entidades (CE)}

$\dot{E}$ uma classe de objelos do mundo real que compartillam os mesmos atribulos. Esses objelos podem existir lisicamente (carro, molor, etc.) ou podem exislir somente conceituaintente (cmprego, curso, elc.). Represchta-sc um CE de acordo com a ligura 3.8, ou scja, um retângulo.

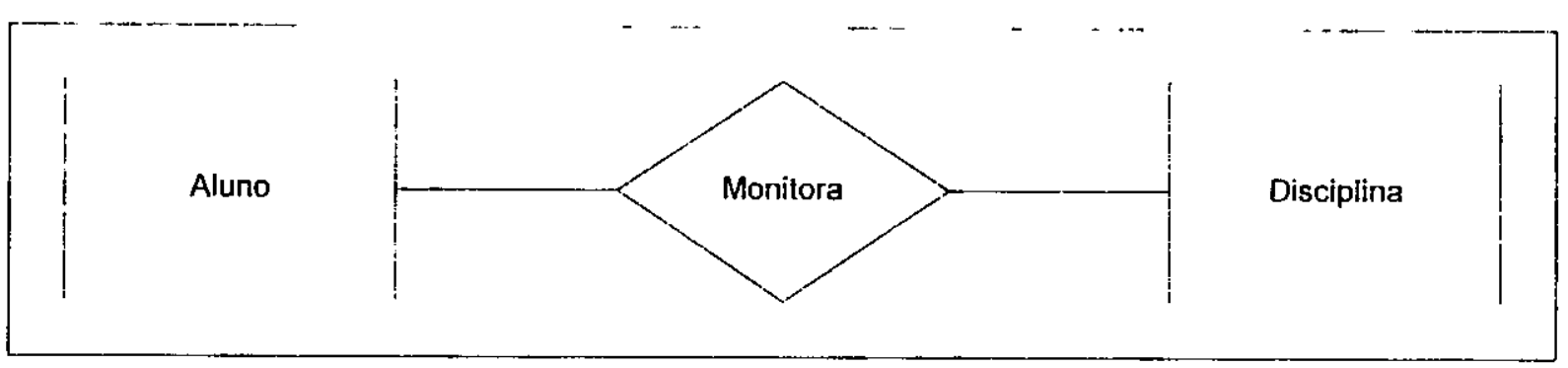

Figura 3.8 - Exemplo de Modelagem no ME-RX

\subsubsection{Conjunto de Relacionamentos (CR)}

É representado através de um losango, ligando os CE's associados. Um CR pode associar um conjunto de enlidades a ele mesmo [CERI 92]. Nesse caso o CR é chamado de autorelacionamento. Diz-se que um relacionamento é total quando todas as entidades de ao menos un dos conjuntos de entidades associados participam de, ao menos, um relacionamento desse conjunto [TRAINA_92]. Cada CE associado por um CR assume um papel no CR.

Um relacionamento entre dois conjuntos de entidades pode gerar três tjoss de associação entre eles, de acordo con a sua cardinalidade:

- $\quad$ : 1 (um para um) - o relacionamento liga uma entidade de um dos papéis a uma entidade do outro papel;

- 1:N (um para muitos) - o relacionamento liga uma entidade de um papel a várias entidades do outro papel; 
- N:M (muitos para muitos) - o relacionamento liga várias entidades a várias entidades.

Um conjunto de relacionamentos pode envolver dois ou mais conjuntos de entidades. O grau do CR é o número de conjuntos de entidades envolvidos em cada relacionaınento. Um exemplo de conjunto de relacionamentos de grau binário pode ser visto na Figura 3.8.

\subsubsection{Atributos}

Os atributos são, basicamente, propriedades particulares que descrevem as entidades e' os relacionamentos. Utilizando-se a notação proposta por Ceri [CERI_92], os atributos são · representados através de linhas com circunferências na extremidade, ligadas ao respectivo CE ou CR. Existem conjuntos de relacionamentos sem atributos. Entretanto, tal fato não ocorre com os conjuntos de entidades, pois os mesmos perderiam o significado na modelagem.

Os conjuntos de entidades também devem possuir pelo menos um atributo chave, ou seja, um atributo que identifique univocamente cada entidade do conjunto. A representação desse atributo é feita através da utilização de uma linha com um círculo na ponta, conforme pode ser observado na Figura 3.9.

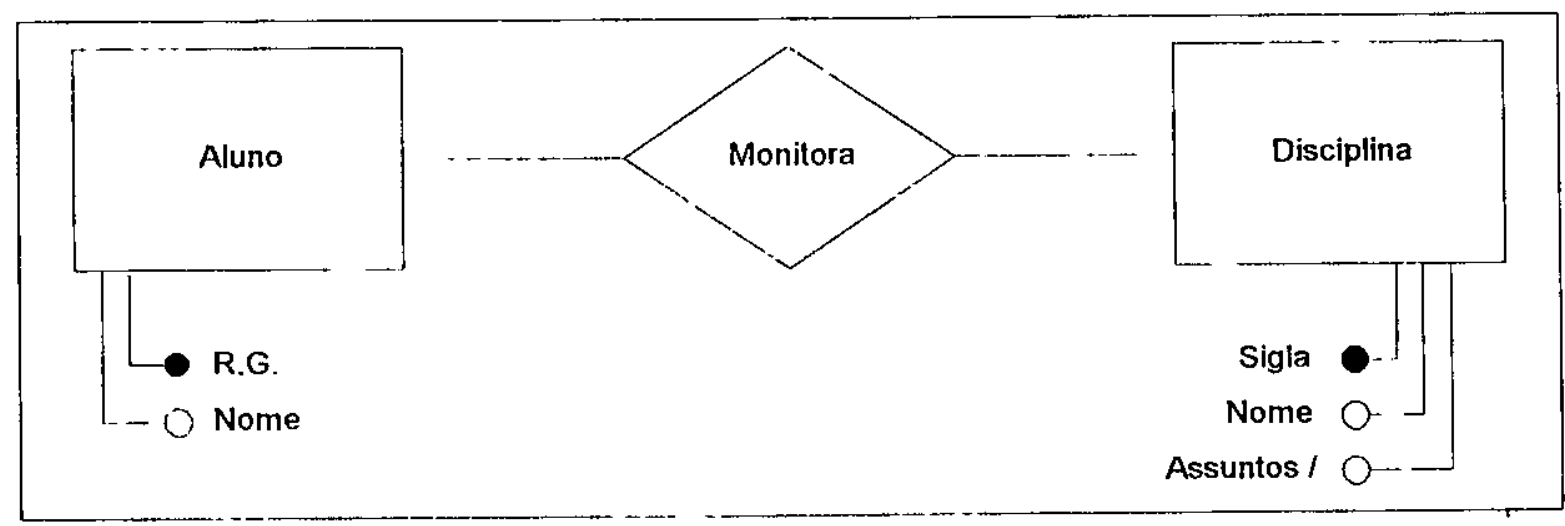

Figura 3.9 - Modelagem com Representação de Atributos no ME-RX

Um atributo pode assumir mais de um valor para uma única ocorrência do $C E$ ou $C R$, sendo chamado, então, de atributo mulivivalorado. Não há uma simbologia universal para se indicar esse atributo. Neste trabalho, adota-se a colocação de uma " / " após o nome do atributo, conforme pode-se observar na Figura 3.9, atributo do CE Disciplina channado assmmos. 


\subsubsection{Conjunto de Entidades Fracas}

Representado por um retângulo de linhas duplas [CERI 92], um conjunto de entidades fracas é aquele que não possui atributo chave próprio. $\dot{A}$ identificação das entidades desse conjunto é feita através do atributo chave de outra entidade (associada através de um relacionamento) combinado com um ou mais atributos próprios. Dizer que um $\mathrm{CE}$ é fraco para um relacionamento, significa dizer que não interessa manter na base os dados relativos à entidade fraca se o relacionamento (total) com o qual ela se relaciona for eliminado. Um CE fracas pode participar de mais de un CR, podendo não ser fraco para todos eles [TRAINA_92]. O(s) CR(s) que torna fraco o CE é denominado CR /olal. Um exemplo dessa situação é dado na figura 3. I0.

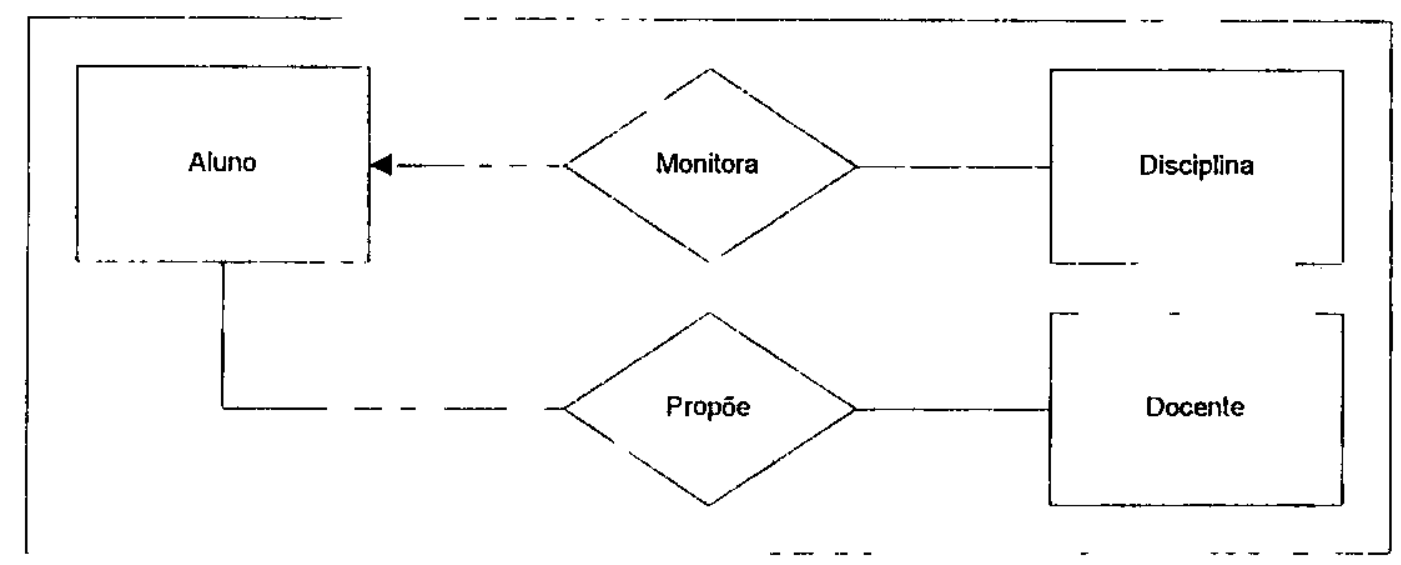

Figura 3.10 - Exemplo de CE Fracas no ME-RX

Nesse caso, o CE Ementa é fraco pelo CR Possui (relacionamento total, representado por uma seta), não sendo fraco, entretanto, pelo CR Propõe.

\subsubsection{Abstração de Generalização}

A abstração de generalização/especialização, suportada no modelo estendido, corresponde à idéia de que os elementos de modelagem possuem tipos próprios, que podem ser especializados através do conceito de subtipos. Por outro lado, vários tipos podem ser getıeralizados em um supertipo. O conjunto de entidades que se especializa é chamado de conjumo de entidades genéricas (CEG), enquanto que os conjuntos de entidades especializadas são chamadas, individual mente, de conjumlo de entidades especificas (CEE).

Una especialização ocorre porque os subconjuntos de entidades especificas possuem atributos adicionais aos já associados ao $\mathrm{CE}$ genérico, e/ou porque se relacionam de maneira diferente 
com outros conjuntos de entidades. Uma das possiveis representações da abstração de generalização, no ME-RX, realiza-se através de um hexágono, conforme pode-se observar na Figura 3.11.

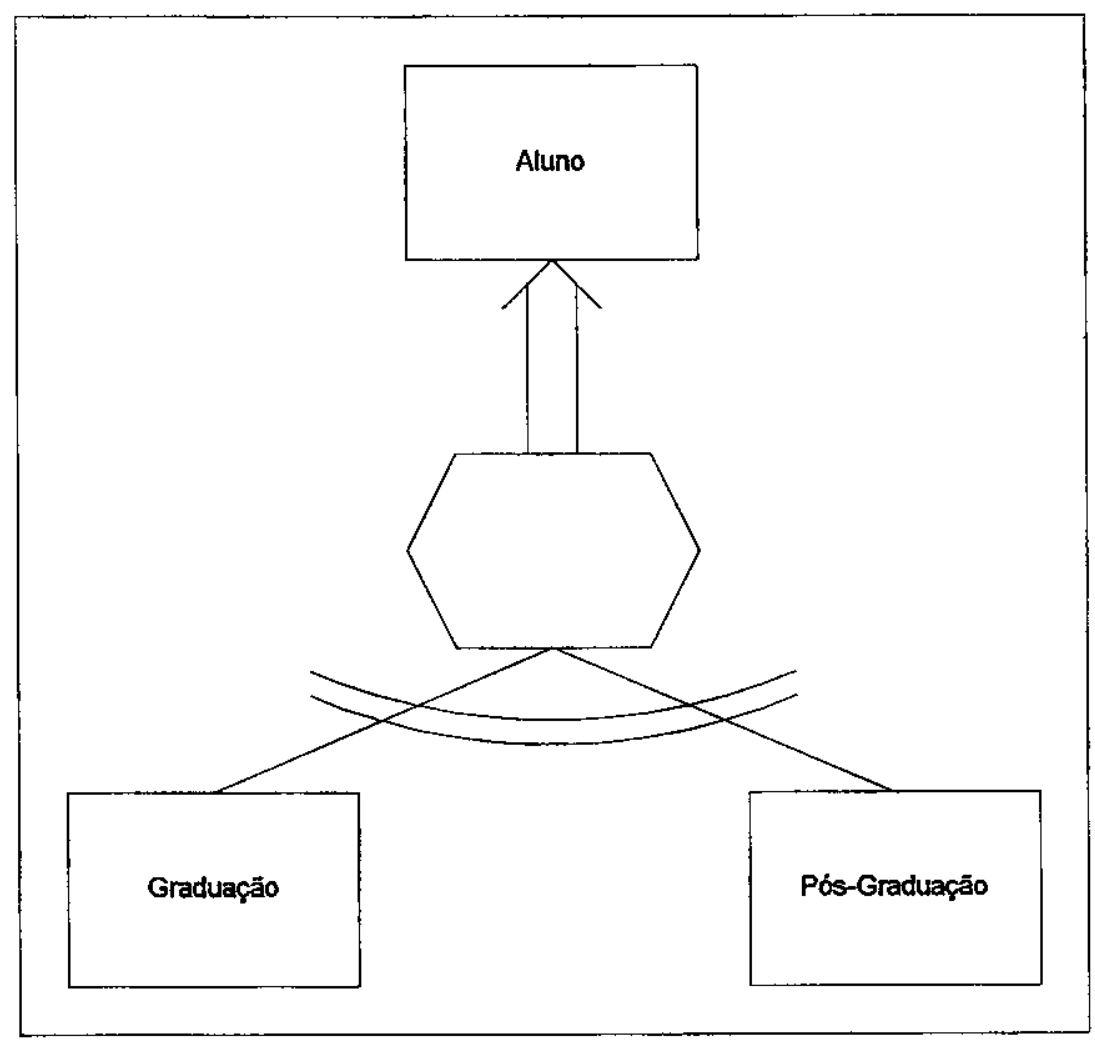

Figura 3.11 - Exemplo de Especialização no ME-RX

Dados um CEG e vários CEE, a generalização é mutuamente exclusiva quando, para quaisquer $\mathrm{j}$ e $\mathrm{k}$ distintos, $\mathrm{CEE}_{\mathrm{j}} \cap \mathrm{CEE}_{\mathrm{k}}=\varnothing$. Caso a interseção não seja um conjunto vazio, têm-se uma especialização sobreposta. Os arcos da Figura 3.11 indicam que as entidades especializadas são mutuamente exclusivąs. Sua ausência indica que as entidades especializadas são sobreponíveis.

A generalização é total quando todas as entidades genéricas também estão em pelo menos um dos CE específicos, ou seja, $U^{n}{ }_{i=1} C_{E E}=C E G$. Por outro lado, quando existir ao menos uma entidade genérica que não esteja em nenhum dos conjuntos de entidades específicos, a generalização será parcial, ou seja, $\mathrm{U}_{\mathrm{i}=1}^{\mathrm{n}} \mathrm{CEE}_{\mathrm{i}} \neq \mathrm{CEG}$. Na representação, a haste dupla (Figura 3.11) indica generalização total, enquanto que a haste simples indica generalização parcial. 


\subsubsection{Abstração de Agregação}

Também suportada apenas no modelo estendido, essa abstração permite a associação de elementos a partir de seus objetos componentes, resultando em outros objetos. É sempre gerada a partir de um único conjunto de relacionamentos, ocorrendo, freqüentemente, em duas situações:

- Caso 1: quando é necessário identificar-se cada relacionamento de um conjunto, ou seja, o relacionamento tem chave;

- Caso 2: há mais de um relacionamento envolvendo as mesmas entidades, necessitando-se diferenciá-los.

Uma das formas de representar o conjunto de entidades gerado a partir da agregação é através de um retângulo envolvendo o conjunto de relacionamentos e os conjuntos de entidades envolvidos na agregação, conforme a Figura 3.12. O conjunto de relacionamentos da agregação é chamado de conjunto de relacionamentos gerador (CR gerador); chama-se conjunto de entidades agregação (CE agregação - CEA) ao conjunto de entidades resultante da agregação.

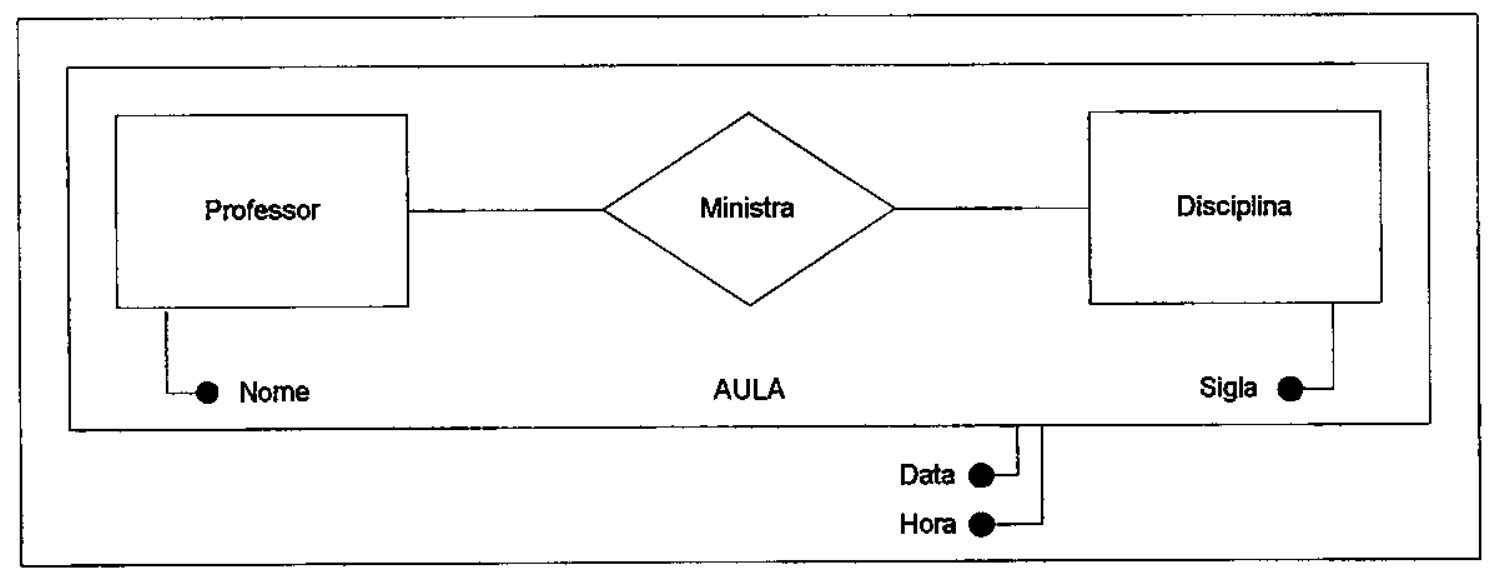

Figura 3.12 - Exemplo de Agregação no ME-RX

\subsection{Modelo Relacional (M-Rel)}

Introduzido por Codd em 1970, o Modelo Relacional é um modelo de dados lógico bastante simples, com estruturas de dados muito uniformes. Ele representa os dados através de uma coleção de relações [ELMASRI_94]. 
Uma relação é uma tabela de valores, onde cada linha representa uma coleção de dados relacionados. Esses valores podem ser interpretados como a descrição de uma instância de uma entidade ou de um relacionamento. $O$ nome da tabela e o nome das colunas são usados para ajudar na interpretação do significado dos valores em cada linha da tabela, conforme pode-se observar no exemplo da Figura 3.13.

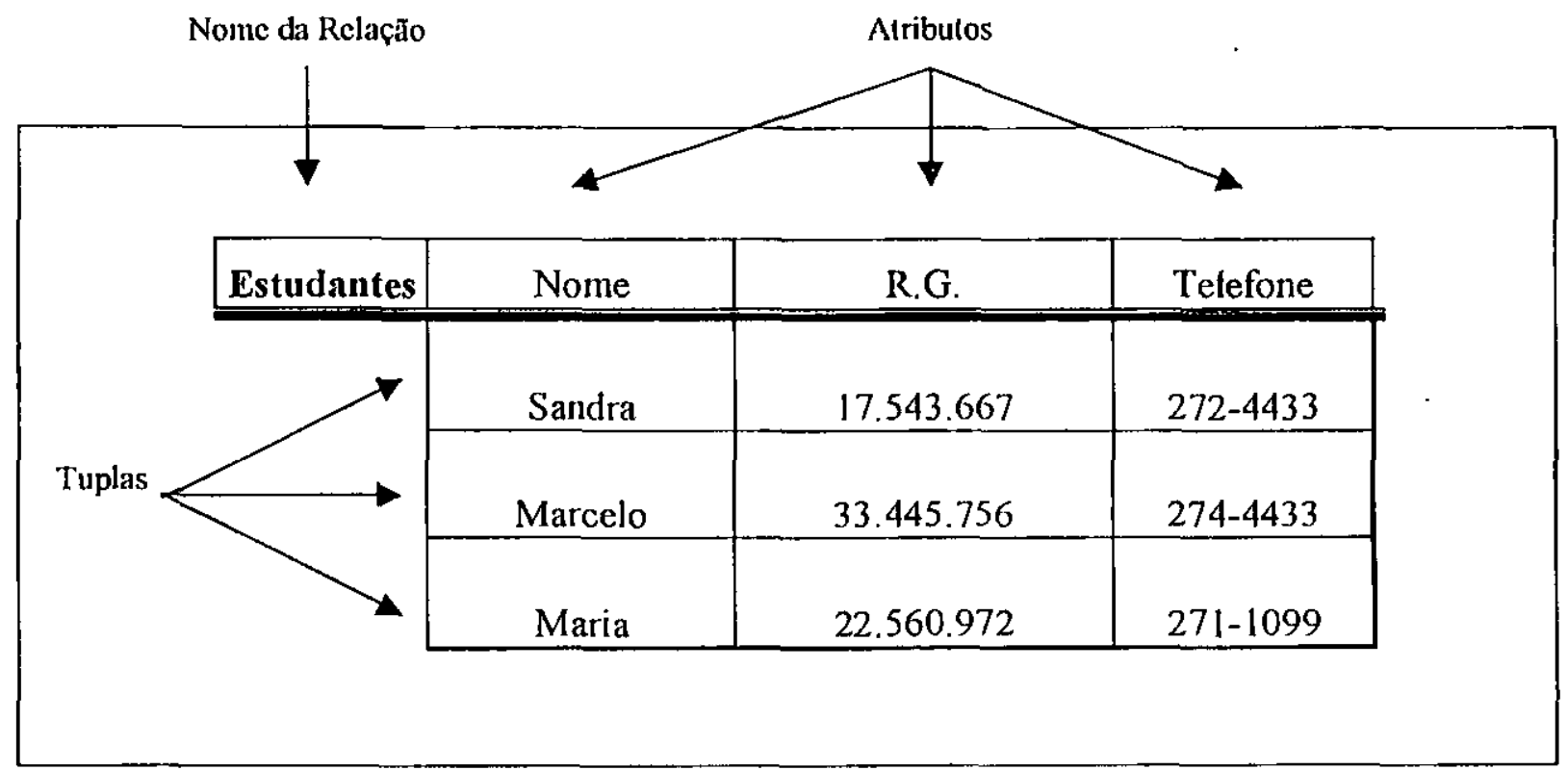

Figura 3.13 - Exemplo de Esquena no Modelo Relacional

$\mathrm{Na}$ terminologia do Modelo Relacional, originada no formalismo algébrico que embasa o modelo, cada linha é clıamada de $(1 / p) / \mathrm{c}$, cada coluna é chamada de alriburo e a tabela chama-se relaçcĩo. O tipo de dado que descreve os lipos de valores que podem aparecer em cada coluna é chamado domínio. Esses valores devem ser indivísiveis, ou seja, em nenhum lugar do banco de dados podem ocorrer partes deles. Por exemplo, a data de nascimento de um aluno será indivisivel se não for necessário, em alguma parte do banco de dados, saber o seu dia de aniversário (dia e mês, desprezando-se o ano). Satisfeita essa condição, pode-se dizer que a data de nascimento de um aluno é indivisível, sendo chamada também de crômica. Sob esse ponto de vista, pode-se considerar dominio como sendo um conjunto de valores atômicos [TRAINA_92].

Pode-se, simplificadamente, representar o esquema de uma relação da seguinte maneira:

$$
R=\left\{\Lambda_{1}, A_{2}, \Lambda_{3}, \Lambda_{4}, A_{5}, \ldots . A_{n}\right\}
$$


onde $\mathrm{R}$ é o nome da relação e $\mathrm{n}$ é o grau da relação. Cada atributo $\Lambda_{\mathrm{i}}$ é o nome de um papel que um domínio Dom $\left(A_{i}\right)$ assume na relação $R$. Uma relação de alunos, contendo nome, $R G$ e telefone, serve como exemplo dessa forma de representação (esquema de grau 3):

$$
\text { Aluno }=\{\text { Nome, } \underline{\mathrm{RG}}, \text { Telefone }\}
$$

Chama-se de superchave o conjunto de atributos de uma relação $\mathrm{R}$ que identifique univocamente cada tupla. Já o conceito de chave corresponde à superchave da qual não se pode retirar atributo algum e ainda preservar-se a propriedade de identificação unívoca. Geralmente, grifam-se os atributos chaves [CERI_92], como o atributo RG do exemplo anterior. Se mais de um atributo participa de uma mesma chave, grifam-se todos com o mesmo número de traços.

É comum que exista mais de uma chave para uma mesma relação, sendo cada uma delas chamada de chave candidata. Havendo mais de uma chave candidata, escolhe-se uma para ser a chave primária. Essa é a chave que pressupõe-se ser a mais freqüentemente utilizada para acessos nessa relação. Grifa-se a chave primária com apenas um traço, aumentando-se o número de traços para as demais chaves candidatas.

Dados dois conjuntos de atributos quaisquer $\mathrm{C}$ e D, diz-se que ambos são compatíveis quando existe uma ordem entre os atributos de ambos os domínios tal que o primeiro atributo de $\mathrm{C}$ tenha o mesmo domínio do primeiro atributo de $\mathrm{D}$, e assim sucessivamente. Chave estrangeira é nome dado ao conjunto de atributos $C \subseteq R_{y}$, que não é chave na relação $R_{x}$, mas é compatível com a chave primária (conjunto de atributos $\mathrm{D}$ ) da relação $\mathbf{R}_{\mathbf{x}}$. Por exeinplo, tomando-se os conjuntos de atributos:

$$
\begin{gathered}
C C=\{A, B\} \text { e } D=\{F, H\} \\
\text { e as relaçðes } R_{x}=\{A, B, J, \ldots\} \text { e } R_{y}=\left\{F, G, H_{, \ldots}\right\} \\
\text { tal que Dom }(A, B)=\operatorname{Dom}(F, H)
\end{gathered}
$$

Se $\{A, B\}$ é chave primária de $R_{x}$, então $\{F, H\}$ é chave estrangeira em $R_{y}$ 


\subsubsection{Construtores Semánticos}

O Modelo Relacional é, conforme já mencionado anteriormente, um modelo de dados lógico, criado para poder suportar representações de dados que possam ser processadas por um computador [CERI_92]. Desse modo, o enfoque utilizado privou o modelo de possuir um grande número de construtores semânticos, optando-se pela simplicidade de representação. O Modelo Relacional suporta somente dois construtores semânticos:

- Relações, que integram a abstração de classificação/instanciação à abstração de agregação/separação;

- Tuplas, que correspondem à abstração de agregação/separação.

\subsection{Mapeamento: Modelo Entidade - Relacionamento Estendido (ME- RX) para o Modelo Relacional (M-Rel)}

O mapeamento do Modelo Entidade - Relacionamento Estendido (modelo semântico) para Modelo Relacional (modelo lógico) permite que se "traduza" um esquema concebido segun um modelo semanticamente mais rico, para um modelo suportado por grande número gerenciadores disponíveis comercialmente.

O diagrama ME-RX não proporciona um mapeamento tão direto quanto o de um diagrama $\mathrm{R}$, porém é mais completo e adequado semanticamente ao estudo de caso a ser analisado. $\mathrm{C}$ $\mathrm{R}$ original pode ser mapeado para o Modelo Relacional através de um algoritmo em 7 pass gera um esquema relacional normalizado até a terceira forma normal. A inclusão de s construtores semânticos torna necessária a incorporação de novos passos aos sete origina a contemplar o mapeamento das abstrações de generalização e agregação, sendo que o al 10 resultante não garante a normalização da base resultante. Os passos modificados o mapeamento do ME-RX [TRAINA_92][ELMASRI_94][BIAJIZ_96][GOMES_99] são: 


\section{Primeiro Passo:}

Mapear todos os conjuntos de entidades regulares (que não são fracas e nem especializadas ou agregadas) do diagrama ME-RX. Cada CE dá origem a uma relação que inclui todos seus atributos. Caso exista atributo composto, deve-se incluir todos os atributos elementares que compõem o atributo composto. $O$ atributo chave do $C E$ será a chave da relação. Se esse atributo for composto, a chave primária será o conjunto dos atributos que o compõem.

\section{Segundo Passo:}

Mapear todos os conjuntos de entidades fracas do diagrama ME-RX. Para cada CE fracas, devese criar uma relação que inclua todos os seus atributos, mais os atributos chaves das relações que mapeiam os $\mathrm{CE}$ 's envolvidos pelo $\mathrm{CR}$ total que torna esse $\mathrm{CE}$ fraco. A chave da relação criada será a chave do $\mathrm{CE}$ fracas concatenada às chaves das demais relações que mapeiam os $\mathrm{CE}$ envolvidos no $\mathrm{CR}$ total que o tornam fraco. Deve-se notar que as chaves estrangeiras que irão compor a chave primária da nova relação provêem das relaçóes resultantes do mapeamento dos $\mathrm{CE}$ envolvidos, as quais não são necessariamente as chaves dos $\mathrm{CE}$ originais. Com isso, há uma ordem a ser seguida no mapeamento: um CE fracas só poderá ser mapeado após o mapeamento dos demais $\mathrm{CE}$ envolvidos no relacionamento total que torna o conjunto de entidades fraco. $\mathrm{O}$ exemplo da Figura 3.14 demonstra um esquema com de CE fracas.

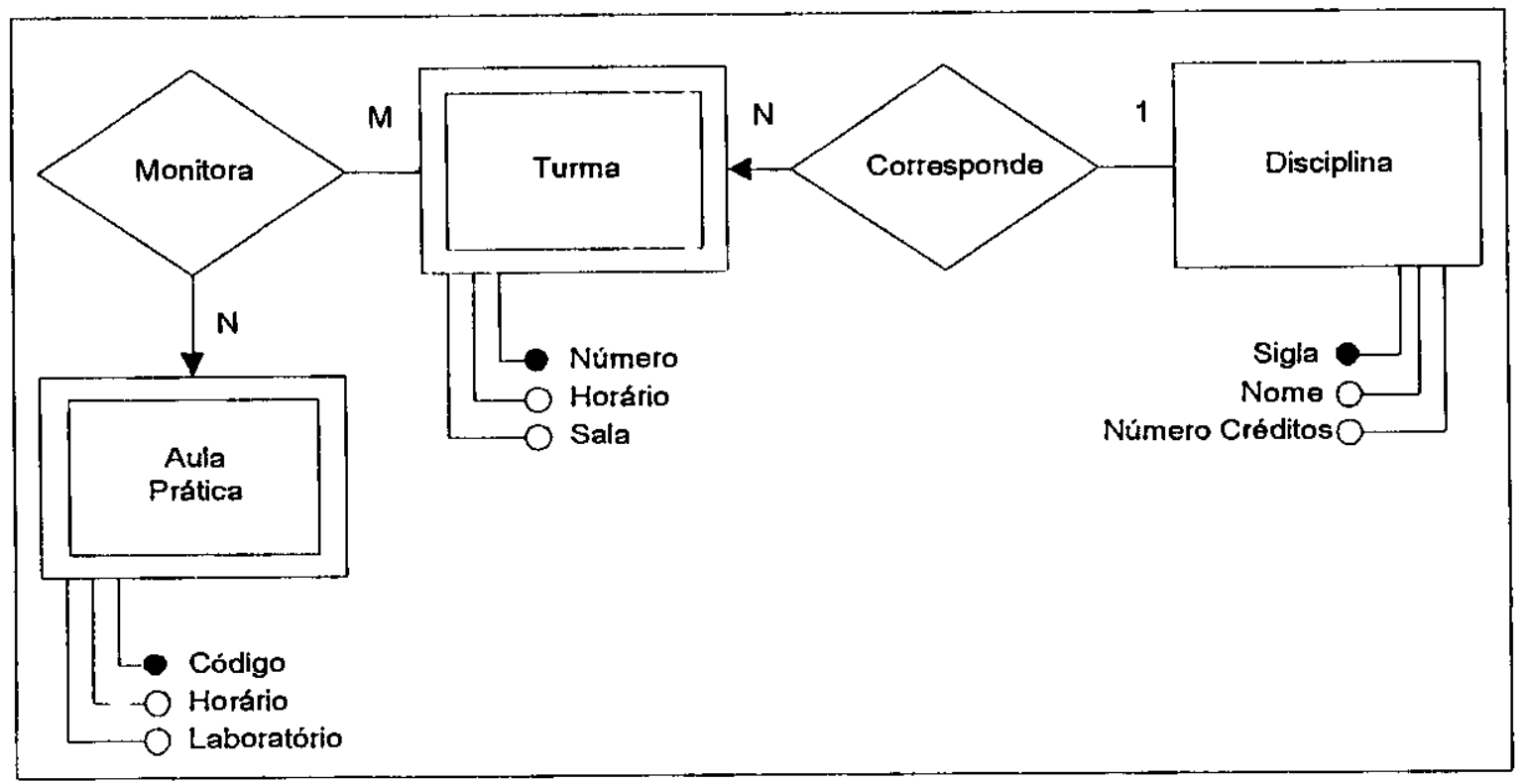

Figura 3.14 - Exemplo de CE Fracas no ME-RX 
As relações resultantes (mapeadas nessa ordem) são:

$$
\text { Turma }=\{\text { Número, Horário, Sala, Sigla }\}
$$

$$
\text { Aula Prática }=\{\underline{\text { Código, }} \text { Horário, Laboratório, } \underline{\text { Sigla }}, \underline{\text { Número }}\}
$$

\section{Terceiro Passo:}

Para cada ocorrência de abstração de generalização, mapear os CE específicos e os CE genéricos conforme uma das 4 alternativas abaixo elencadas. Para a discussão das condições de utilizaçẫo de cada alternativa e melhor demonstração de sua utilização, considera-se um conjunto de entidades genérico EG, com atributos $\left\{\mathrm{ag}_{d_{1}}, \mathrm{ag}_{1}, \mathrm{ag}_{2}, \ldots, \mathrm{ag}_{\mathrm{n}}\right\}$, sendo $\mathrm{ag}_{\mathrm{d}_{1}}$ a chave primária, e $\mathrm{m}$ conjuntos de entidades especializadas $\left\{\mathrm{ES}_{1}, \mathrm{ES}_{2}, \ldots, \mathrm{ES}_{\mathrm{m}}\right\}$, mostrados na Figura 3.14 de acordo com uma das possiveis representações da abstração de generalização/especialização no ME-RX.

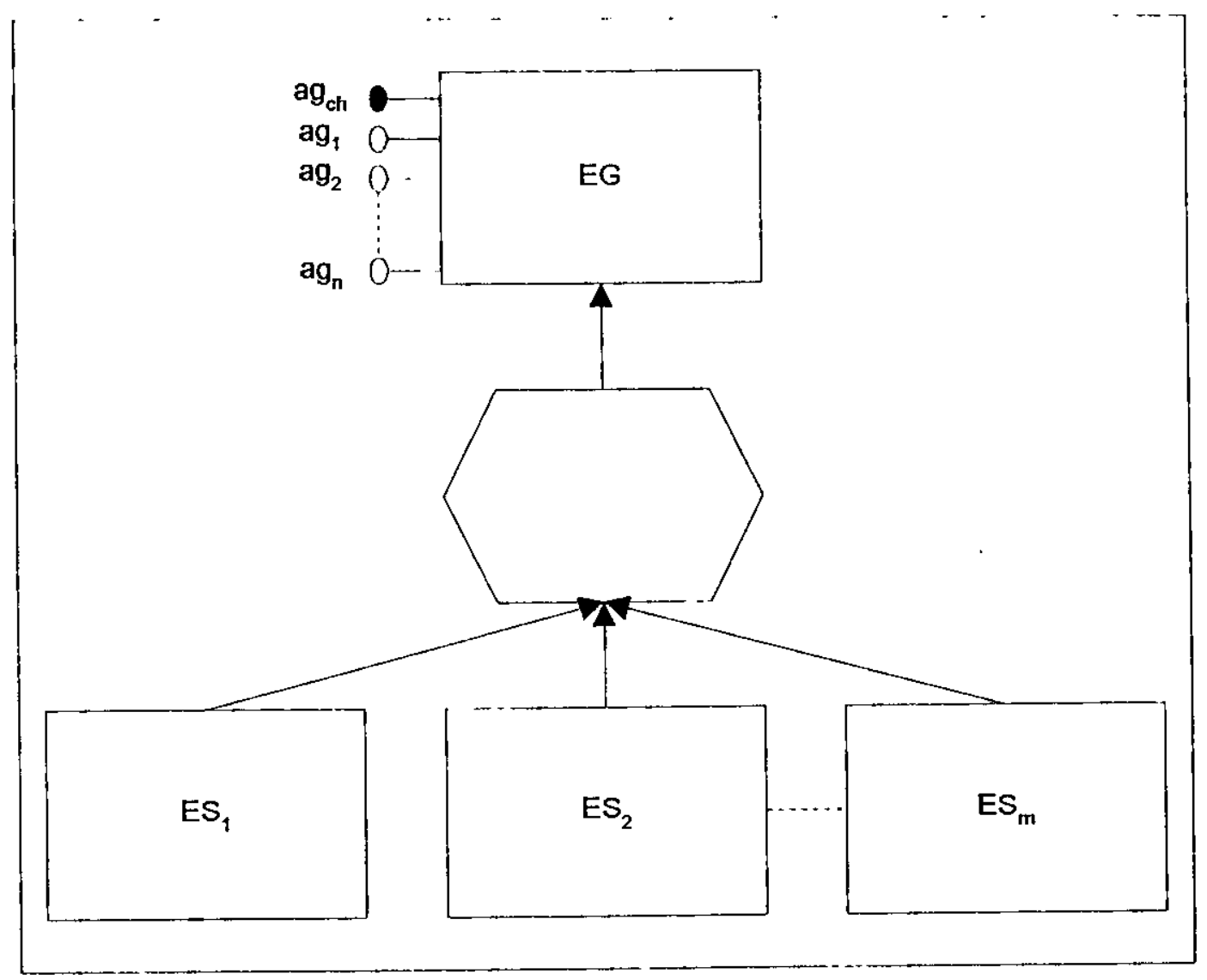

Figura 3.15 - Exemplo Genérico de Especialização em ME-RX 
I' Alternativa: Cria-se a relação $\mathrm{R}=\left\{\mathrm{ag}_{c h}, \mathrm{ag}_{1}, \mathrm{ag}_{2}, \ldots ., \mathrm{ag}_{\mathrm{n}}\right\}$ para $\mathrm{EG}$, onde $\mathrm{ag}_{\mathrm{d}}$ é chave primária da relação. Cria-se também uma relação $R i=\left\{a_{c h}\right\} \cup$ \{atributos de $\left.E S_{i}\right\}$, para cada $E S_{i}$, onde $1 \leq \mathrm{i} \leq \mathrm{m}$. Esta opção é usada para qualquer restrição sobre a abstração de generalização/especialização: mutuamente exclusiva ou sobreposta, total ou parcial. Uma operação equijoin sobre a chave primária entre algum $R_{i}$ e $R$ produz todos os atributos especificos e herdados das entidades em $R_{i}$.

$2^{a}$ Altemativa: Cria-se uma relação $\mathrm{R}_{\mathrm{i}}=\left\{\right.$ atributos de $\left.\mathrm{ES}_{\mathrm{i}}\right\} \cup\left\{\mathrm{ag}_{\mathrm{d} \text {, }}, \mathrm{gg}_{\mathrm{i}}, \mathrm{ag}_{2}, \ldots, \mathrm{ag}_{\mathrm{n}}\right\}$ para cada $\mathrm{ES}_{\mathrm{i}}, 1 \leq \mathrm{i} \leq \mathrm{m}$, sendo ag a chave primária de cada Ri. Esta opção é viável apenas com as restrições de exclusão mútua e participação total. Se a especialização não é total, uma entidade que não pertence a nenhum LSi é perdida. Se a especialização não for exclusão mútua, uma entidade irá pertencer a mais que um $\mathrm{ES}_{\mathrm{i}}$ e terá os atributos herdados de $\mathrm{EG}$ armazenados redundantemente em mais de uma $R_{i}$. Nesse caso, sempre que for necessário pesquisar um atributo qualquer de $\mathrm{EG}$, será preciso pesquisá-lo em todos os $\mathrm{ES}_{\mathrm{i}}, \mathrm{l} \leq \mathrm{i} \leq \mathrm{m}$, aplicando-se, para isto, a operação outer union nas relações $\mathbf{R}_{\mathbf{i}}$.

$3^{a}$ Alternativa: Cria-se uma relação $\mathrm{R}=\left\{\mathrm{ag}_{\mathrm{ch}}, \mathrm{ag}_{1}, \mathrm{ag}_{2}, \ldots, \mathrm{ag}_{\mathrm{n}}\right\} \cup\left\{\right.$ atributos de $\left.\mathrm{ES}_{1}\right\} \cup$ \{atributos de $\left.\mathrm{ES}_{2}\right\} \cup\left\{\right.$ atributos de $\left.\mathrm{ES}_{\mathrm{m}}\right\} \cup\{\mathrm{t}\}$. Esta opção é apropriada para a especialização onde os conjuntos de entidades especializados são disjuntos e té um atributo que indica o ES a qual cada tupla pertence. Portanto, o domínio de t deve ser $\{1,2, \ldots, \mathrm{m}\}$. Se a especialização é parcial, $t$ pode ter valor nulo das tuplas que não pertencem a nenhum ES. No caso da especialização ser definida por um atributo, tal atributo exerce o mesmo papel de $t$, que torna-se desnecessário.

No exemplo da Figura 3.16, o atributo qualificação determina se um funcionário é motorista, porteiro ou secretária, de acordo com uma das possíveis notações de representação da abstração de generalização/especialização. As restrições definidas para esta especialização são: participação parcial e disjunção. 


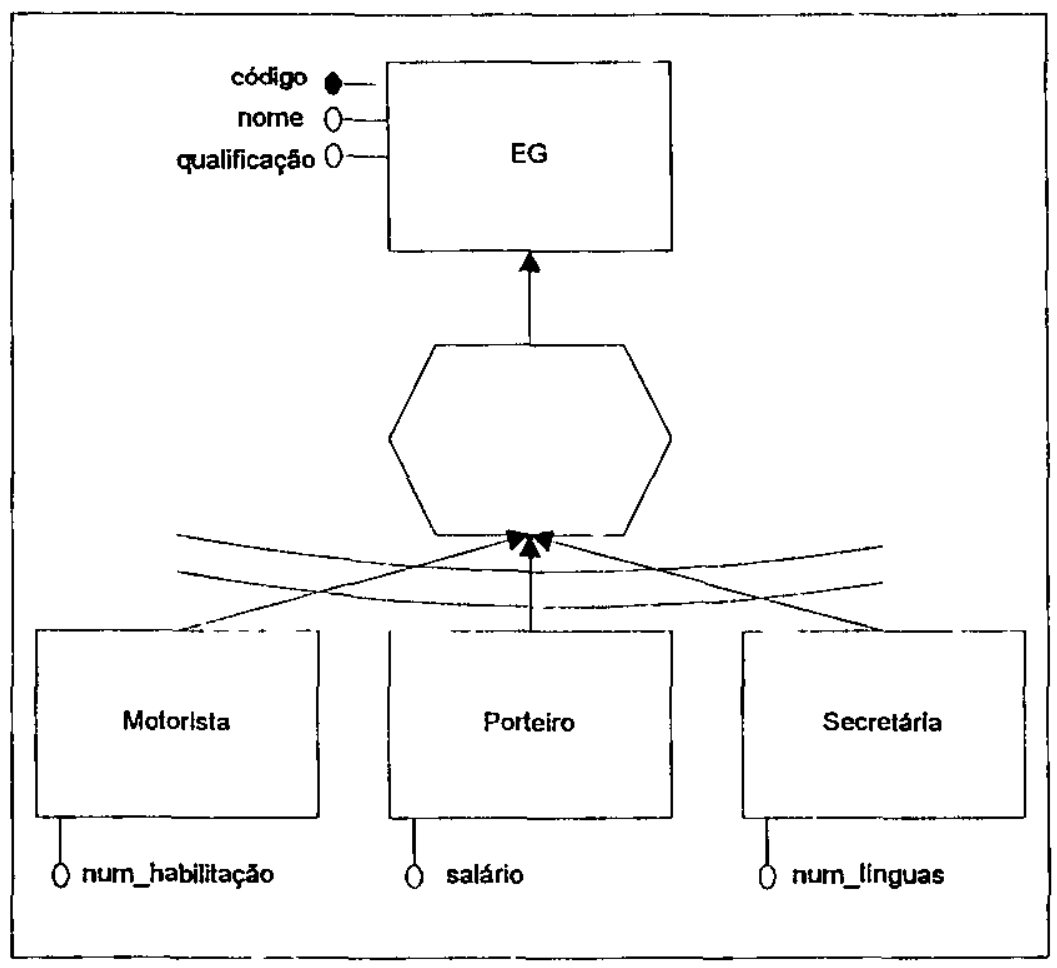

Figura 3.16 - Exemplo de Generalização em ME-RX

Mapeando-se esse esquema de acordo com a $3^{\circ}$ alternativa, gera-se a seguinte relação:

Funcionário $=\{\underline{\text { código }}$, nome, qualificação, num_habilitação, salário, num_línguas $\}$

$4^{a}$ Alternativa: Cria-se uma relação $\mathrm{R}=\left\{\mathrm{ag}_{\mathrm{c}}, \mathrm{ag}_{1}, \mathrm{ag}_{2}, \ldots, \mathrm{ag}_{\mathrm{n}}\right\} \mathrm{U}$ \{atributos de $\left.\mathrm{ES}_{1}\right\} \mathrm{U}$ \{atributos de $\left.\mathrm{ES}_{2}\right\} \cup$ \{atributos de $\left.\mathrm{ES}_{\mathrm{m}}\right\} \cup\left\{\mathrm{t}_{t}, \mathrm{t}_{2}, \ldots, \mathrm{t}_{\mathrm{m}}\right\}$. Esta opção é apropriada para a especialização cujos conjuntos de entidades especializadas são sobrepostas e cada $\mathrm{t}_{\mathrm{i}}, 1 \leq \mathrm{i} \leq \mathrm{m}$ é $\mathrm{um}$ atributo booleano, indicando se a tupla pertence a um $\mathrm{ES}_{\mathbf{i}}$. Cada campo $\mathrm{t}_{\mathbf{i}}$ tem como domínio $\left\{\operatorname{sim}_{2}\right.$ não\}, onde o valor "sim" indica que a tupla é um membro de $\mathrm{ES}_{\mathrm{i}}$.

$\mathrm{Na} 3^{\mathrm{a}}$ e $4^{\mathrm{a}}$ alternativas de mapeamento cria-se uma única relação para representar o conjunto de entidades genérico e todos os conjuntos de entidades especializadas $\mathrm{ES}_{\mathrm{i}}$, com $1 \leq \mathrm{i} \leq \mathrm{m}$. Uma entidade que não pertence a nenhum conjunto de entidades especializadas terá valores nulos para todos os atributos específicos dos $\mathrm{ES}_{\mathfrak{i}}$. Se existirem poucos atributos específicos, essas duas alternativas de mapeamento são preferíveis às $1^{a}$ e $2^{a}$ alternativas, pois não há a necessidade de 
realização das operações equijoin e outer union, resultando em uma maior eficiência com relação às consultas.

Quando há especialização em vários níveis, não é necessária a adoção da mesma alternativa de mapeamento para todos os niveis, sendo possivel a utilização de alternativas diferentes para cada nivel [ELMASRI_94].

A Tabela 3.2 resume as quatro alternativas de mapeamento apresentadas e suas restrições de utilização.

Tabela 3.2 - Alternativas de Mapeamento para a Especialização

\begin{tabular}{|c|c|c|}
\hline 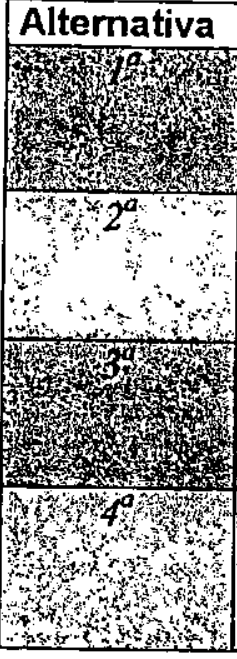 & 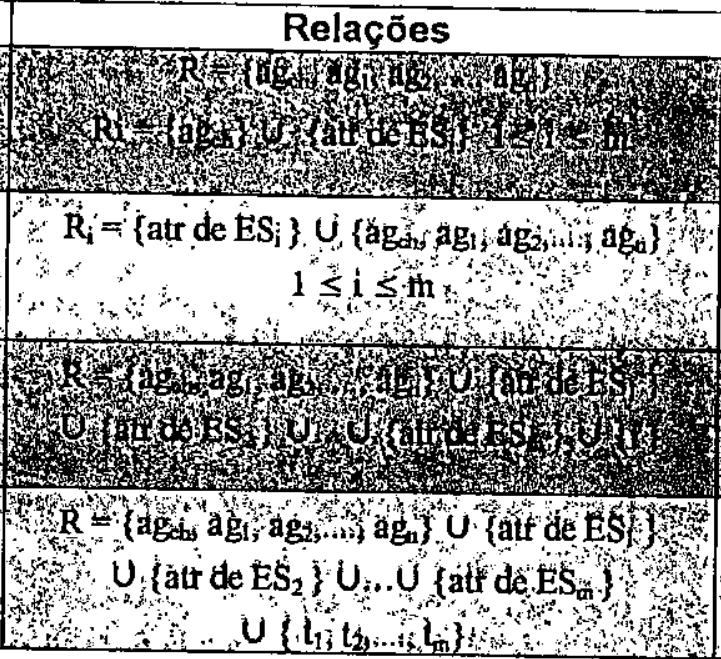 & 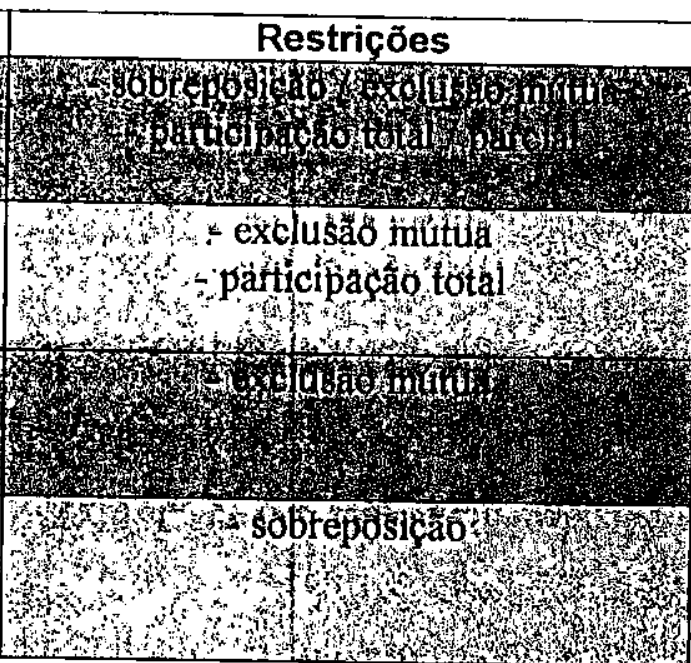 \\
\hline
\end{tabular}

\section{Quarto Passo:}

Mapear os conjuntos de entidades agregação. De acordo com o tipo da agregação, tem-se as seguintes formas de mapeamento:

$I^{a}$ Alternativa (quando existe apenas uma entidade agregação para cada relacionamento gerador da agregação): Mapear os CE envolvidos pelo CR Gerador, conforme o primeiro e o segundo passo. Os atributos do CR gerador deverão ser repassados para o CE agregação. Deve-se criar uma relação para o CE agregação, incluindo-se os atributos chaves dos CE's envolvidos como chave candidata. 
$2^{a}$ Alternativa (quando pode haver mais de uma entidade agregação para cada relacionamento gerador da agregação): Deve-se verificar se é possível repassar os atributos do CR gerador para o CE agregação. Para se mapear o CE agregação, cria-se uma relação composta por sua chave (seus identificadores unidos às chaves dos $\mathrm{CE}$ envolvidos) e seus atributos, repassados ou não. Caso o relacionamento tenha atributos que não possam ser repassados ao $\mathrm{CE}$ agregação, mapeiase esse conjunto de relacionamentos normalmente, seguindo os próximos passos.

\section{Quinto Passo:}

M̈apear os conjuntos de relacionamentos binários de cardinalidade $1: 1$ do diagrama ME-RX. Nesse caso, não serão criadas novas relações. Os atributos do CR binário 1:1, se existirem, deverão ser incorporados a qualquer uma das relações que mapeiam os CE's envolvidos. Nesta mesma relação escolhida, devem ser acrescidos os atributos chave da relação que mapeia o outro CE.

\section{Sexto Passo:}

Mapear todos os conjuntos de relacionamentos bimários de cardinalidade I: $N$ do diagrama MERX. Da mesma forma que os conjuntos de relacionamentos binários de cardinalidade $1: 1$, os CR's 1:N não geram novas relações. Seus atributos serão incorporados à relação que mapeia o $\mathrm{CE}$ de cardinalidade $\mathrm{N}$ no relacionamento. Nessa mesma relação deverão ser acrescidos também os atributos chave da relação que mapeia o CE com cardinalidade 1 .

\section{Sétimo Passo:}

Mapear todos os conjumıs de relacionamentos binários de cardinalidade $N: M$ do diagrama ME-. RX. Cada CR de cardinalidade M:N criará uma nova relação, cujos atributos são os do próprio CR (se existirem), mais os atributos chaves das relações que mapeiam os CE's envolvidos; esses últimos, concatenados, formam a chave dessa relação.

\section{Oitavo Passo:}

Mapear todos os conjuntos de relacionamentos de ordem $\geq 3$ do diagrama ME-RX. Para este tipo de relacionamento, sempre se considera cardinalidade vários:vários:vários. Para cada CR será criada uma nova relação, cujos atributos são os do CR (se existirem) e cuja chave é formada pelos atributos chaves das relações que mapeiam os CE's envolvidos. Os CR's de ordem maior 
que três são tratados da mesma maneira que os ternários. Seu mapeamento cria uma relação para cada CR, possuindo os atributos do $\mathrm{CR} e$, como chave, os atributos concatenados de cada relação que mapeia os CE's envolvidos.

\section{Nono Passo:}

Existem duas alternativas para o mapeamento de atributos multivalorados:

$I^{a}$ Allernativa (não considera conhecimento adicional sobre o atributo que está sendo mapeado): Para cada atributo multivalorado cria-se uma nova relação que tem como chave os atributos chave da relação que mapeia o CE ou CR ao qual pertencia o atributo, juntamente com o atributo multivalorado tomado como movalorado. Isto pode ser verificado no mapeamento da relação paciente, descrita abaixo, que armazena informação a respeito de um paciente de algum consultório médico. Nesta relação, o atributo alergias é multivalorado e por isso a relação paciente foi dividida em duas relações - paciente e alergias:

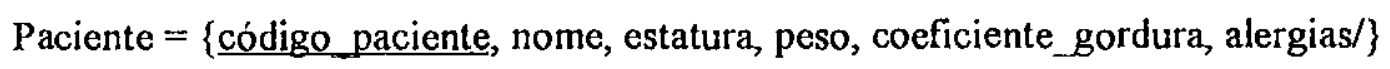

Extraindo-se o atributo multivalorado alergias, criam-se duas relações:

Paciente $=\{\underline{\text { código paciente }}$, nome, estatura, peso, coeficiente_gordura $\}$

Alergias $=\{$ código paciente, alergia

$2^{a}$ Allernativa (considera conhecimento adicional sobre o atributo que está sendo mapeado): Em alguns casos é possivel determinar a quantidade de ocorrências de valores nos atributos. Quando isso acontece e essa quantidade é pequena, pode-se instanciar essa quantidade de atributos como monovalorados na mesma relação que mapeia o $\mathrm{CE}$ ou $\mathrm{CR}$ ao qual o atributo multivalorado está associado. Desta forma, a relação com o atributo multivalorado grau_das_lentes:

$$
\text { Paciente }=\{\underline{\text { código paciente }}, \text { nome, estatura, grau das lentes } /\}
$$

Seria mapeada como:

$$
\text { Paciente }=\text { código_paciente, nome, estatura, grau_esq, grau_dir }
$$


Entretanto, com a utilização da $2^{\text {a }}$ alternativa de mapeamento de atributos multivalorados, impede-se a total automação do procedimento de mapeamento do ME-RX para o M-Rel [ELMASRI_94].

A descrição dos passos para o mapeamento de um diagrama ME-RX para o M-Rel é mais complicada que a atividade em si, cujo entendimento torna-se simples com a aquisição de experiência prática.

\subsection{Considerações Finais}

O Modelo SIRIUS é o modelo com maior grau de representação semântica entre os comparados, conforme pode-se observar, pois foi desenvolvido com o intuito de representar situações onde os dados não apresentam homogeneidade estrutural.

O Modelo Entidade - Relacionamento Estendido é mais pobre semanticamente, notando-se a falta da abstração de classificação, o que pode gerar uma sobrecarga semântica na abstração de generalização, que geralmente é utilizada para representar a existência da classificação em casos reais. Quando isso ocorre, há uma representação equivocada da realidade, introduzindo-se erros no projeto desde sua fase inicial, o que é altamente indesejável. As alternativas de mapeamento para a abstração de generalização propostas na literatura até agora não cobrem nenhum dos casos de classificação, tal como será mostrado nos capítulos seguintes.

Já o Modelo Relacional atende bem ao propósito para o qual foi desenvolvido, mesmo suportando somente os construtores semânticos mais elementares. Assim, é uma boa base para a construção dos sistemas de software, desde que seja suplementado nas fases de projeto do sistema por um modelo conceitual adequado às necessidades do sistema a ser desenvolvido. Aplicações comerciais típicas são bem atendidas pelo ME-RX, como a prática tem mostrado desde sua introdução no final dos anos 70 . No entanto, aplicações mais complexas, tais como as que envolvem suporta para aplicativos científicos e de engenharia, ou aplicações que envolvem manipulação de dados multimídia, necessitam de recursos do modelo conceitual que vão além daqueles fornecidos pelo ME-RX. 
A Tabela 3.3 resume os modelos apresentados e alguns amplamente utilizados atualmente, mostrando quais suportam as principais abstrações discutidas neste trabalho

Tabela 3.3 - Abstrações Suportadas pelos Modelos de Dados

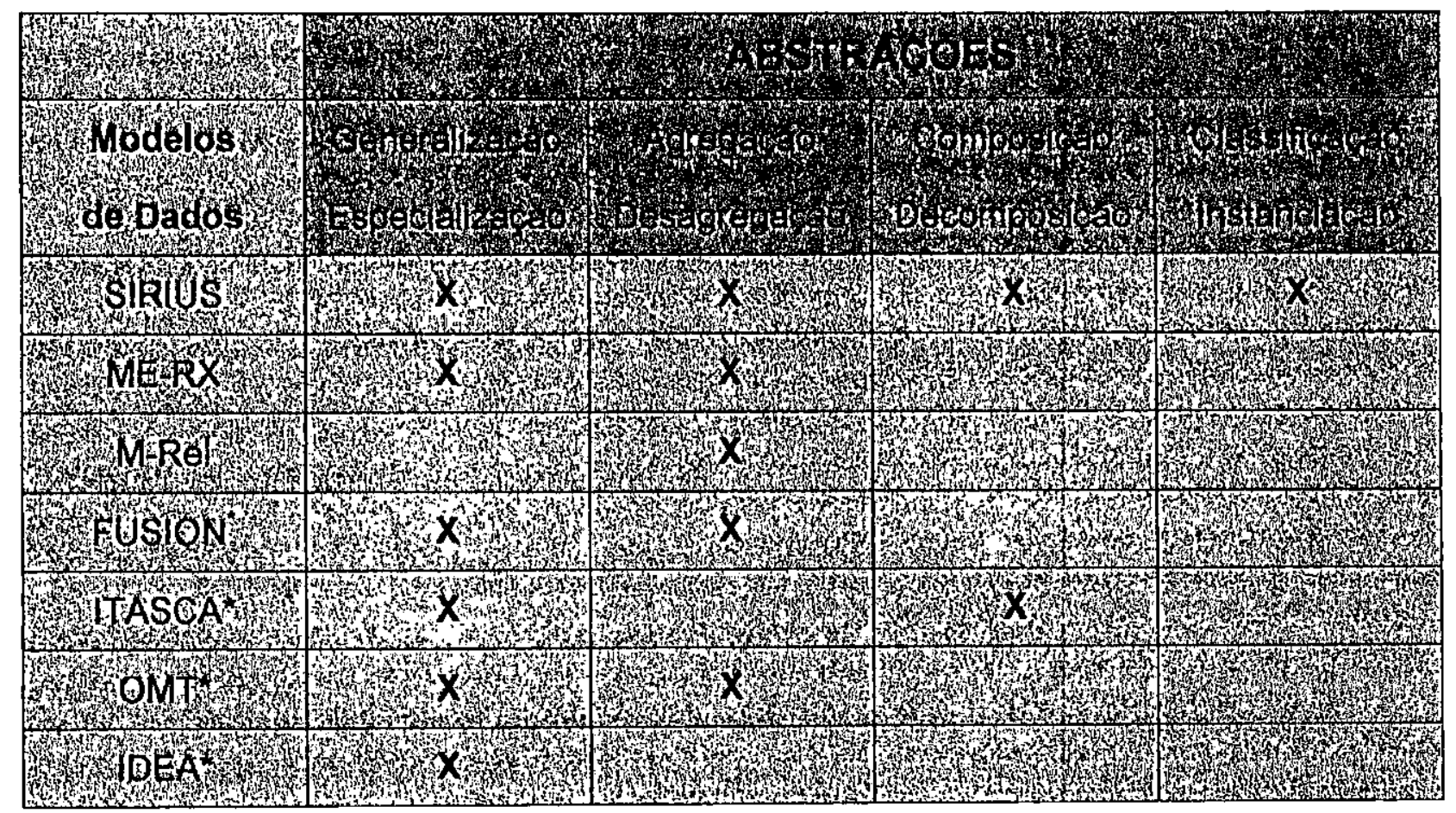

* Modelos inseridos para simples comparação [GOMES_99] 


\section{Capítulo 4: Abstração de Classificação}

\section{Considerações Iniciais}

- abstração de classificação existe de fato em diversas situações reais, sendo comum a utilização le outras abstrações disponíveis para a representação dessas informações, introduzindo-se sobrecargas semânticas não desejáveis e que levam a pontos obscuros na modelagem.

Para que estas dúvidas de interpretação sejam dirimidas, caracteriza-se precisamente, neste capitulo, a abstração de classificação, diferenciando-a das demais abstrações, especialmente a abstração de generalização.

Na seção 4.2 apresentam-se os principais conceitos relacionados à abstração de classificação. Na seção 4.3 aborda-se a abstração de classificação do ponto de vista do modelo de dados SIRIUS, que serviu como base conceitual para o presente trabalho. Já na seção 4.4 cria-se uma nova extensão do Modelo Entidade - Relacionamento Estendido (ME-RX), introduzindo-se um construtor semântico específico para a abstração de classificação. Ressalta-se que esse modelo de dados foi o escolhido para a utilização no estudo de caso devido à sua simplicidade e à capacitação técnica dos funcionários da empresa envolvida no estudo de caso. Na seção 4.5 são criadas as regras de mapeamento da abstração de classificação representada no ME-RX e seu novo construtor semântico para o Modelo Relacional (M-Rel), processo descrito pela primeira vez na literatura. Finalmente, são apresentadas as considerações finais na seção 4.6.

\subsection{Caracterizaçăo da Abstração de Classificação}

A classificação, também chamada de materialização na literatura [PIROTTE_94] [PIROTTE_97], é um novo e poderoso padrão não ambíguo de abstração, consistindo, intuitivamente, de um relacionamento semântico entre um conjunto de categorias de objetos (por 
exemplo modelos de carros) e os objetos concretos (por exemplo os carros individualmente considerados).

A abstração de classificação é normalmente utilizada em modelos de dados para definir o conceito de tipo ou classe. Modelos que têm a característica de serem meta-modelos possuem essa abstração ocorrendo em três níveis:

- $\quad \mathbf{1}^{0}$ nível: instancia-se os conceitos no meta esquema;

- $2^{\circ}$ nível: cada conceito do modelo é instanciado nos elementos de uma modelagem em particular (criando-se a base intencional);

- $3^{0}$ nível: cada elemento da modelagem é instanciado nas respectivas ocorrências de dados da base de dados (criando-se a base extensional)

O Modelo Relacional, por exemplo, é um meta modelo. Ele tem inicialmente seus conceitos instanciados, criando-se, teoricamente, uma tabela com os mesmos conceitos ("relações" e "atributos" seriam cada um uma tupla). Cada tupla dessa tabela hipotética define uma tabela do segundo nível de instanciação: tabela de tabelas, tabela de atributos, etc. Quando uma modelagem é efetuada, essas tabelas recebem como tuplas cada uma das tabelas, atributos, etc., criados na modelagem. No terceiro nível de instanciação, finalmente as tabelas modeladas são instanciadas nas tabelas da aplicação e recebem os dados do sistema do mundo real.

Embora seja indispensável num modelo de dados, porque apenas através da classificação é possível a existência de esquemas de dados, cujos elementos são instanciados nas bases extensionais, a abstração de classificação não é geralmente disponibilizada aos projetistas/analistas para ser usada nas modelagens, ou seja, como um construtor semântico, conforme pode-se observar na Tabela 3.3 do capítulo anterior, comparativa entre as abstrações suportadas pelos modelos de dados. Verifica-se ainda, pela análise da mesma tabela, que o único modelo que suporta a classificação como construtor semântico é o SIRIUS, que foi portanto utilizado no presente trabalho como base teórica, fornecendo os principais conceitos envolvidos.

Quando um modelo de dados tem um construtor que suporta a classificação no modelo, acrescentam-se outros níveis, em quantidade que depende do emprego do construtor. 
Teoricamente qualquer número de níveis é possivel. Na prática, um único nível adicional é a situação mais freqüente, dificilmente encontrando-se dois ou até três níveis.

Durante o desenvolvimento do estudo de caso explanado no próximo capítulo, constatou-se que quando são colocadas à disposição do projetista as abstrações de classificação e de generalização, diversas situações do mundo real o colocam em dúvida na escolha da representação mais adequada. Uma provável razão para este problema é a grande difusão da abstração de generalização com o advento das técnicas de orientação a objeto, situação diversa da abstração de classificação, que tem sido pouco explorada. Conforme anteriormente mencionado, os modelos de dados orientados a objeto, em geral, suportam bem a representação da abstração de generalização/especialização, mas não permitem a representação da abstração de classificação/instanciação nas modelagens, embora a abstração de classificação ocorra obrigatoriamente para permitir a definição das instâncias dos tipos de objetos definidos no esquema. Desta forma, situações do mundo real que seriam adequadamente representadas com o uso da abstração de classificação são representadas através de outros mecanismos ou até mesmo desprezadas, havendo, invariavelmente, perdas semânticas, dificilmente reparadas em outras fases de projeto.

É comum o projetista considerar muito sutil a diferença entre classificação e generalização nas primeiras vezes em que se depara com ambas as situações. No entanto, com exposição ao conceito, e do ponto de vista teórico, a diferença entre elas é muito grande. Como uma regra básica, que pode servir de guia para essas pessoas, adota-se a seguinte:

- Na generalização um objeto de um tipo específico é o mesmo objeto do tipo genérico, enquanto que na classificação um objeto do tipo instância é outro objeto; ele apenas é do tipo do objeto classe .

Por exemplo, um curso noturno ou diurno é um curso, ou seja, o mesmo curso quando se despreza o detalhe período. Portanto, curso noturno e curso diurno são especializações de curso. Já turma é instância de curso, existindo turmas que são instâncias de curso diurno e turmas que são instâncias de curso noturno, cada uma respeitando as particularidades de cada um de seus tipos em particular. 
Deve-se destacar que a herança de atributos e métodos é uma propriedade da abstração de generalização, enquanto que a associação de valores "default" a atributos de objetos é propriedade da abstração de classificação. Assim, qualquer atributo de um curso é aquele mesmo valor para, por exemplo, o curso noturno que ele é. Qualquer substituição daquele valor no curso noturno corresponde à mes ma mudança no curso genérico. Já a mudança no valor de um atributo de algum curso que tenha sido instanciado em alguma turma (por "default") com aquele valor, não altera o valor do tipo.

Pode haver também, embora menos freqüente, certa dúvida do projetista ao comparar as abstrações de classificação e composição (esta última na maneira em que é retratada pelo SIRIUS, conforme descrito no capitulo 03). Ressalte-se que a abstração de composição é utilizada para a representação da associação entre objetos que são realmente compostos por outros, como por exemplo quando se descreve a composição de um prédio (objeto composto) por salas e corredores (objetos abstratos), enquanto que a abstração de classificação relaciona semanticamente categorias de objetos e objetos concretos. Utilizando o mesmo cenário, pode-se criar uma sala (objeto tipo) e várias instâncias dessa sala, tais como sala 01, sala 02, sala 03, etc., na planta do prédio, o que leva à classificação da composição.

A seguir, conforme mencionado no capítulo 3, faz-se a descrição dos principais aspectos da representação da abstração de classificação em SIRIUS.

\subsection{Abstração de Classificação em SIRIUS}

O Modelo SIRIUS trata a abstração de classificação de maneira impar quando comparado aos demais modelos de dados em geral, pois disponibiliza-a como um construtor semântico, ou seja, um construtor utilizável pelos projetistas/analistas.

Uma ocorrência da abstração de classificação dá-se através da classificação de um conjunto de objetos pelo seu tipo. Em SIRIUS, caracteriza-se um tipo como sendo também, por sua vez, um objeto. Assim, esse processo se repete, permitindo estabelecer uma hierarquia de classificação. Dessa forma, um objeto é classificado pelo seu tipo, o qual pode ser classificado novamente até que se atinja o tipo de objeto máximo da hierarquia de classificação.[BlAJlZ_96]. 
A classificação incorpora a distinção entre formalo e conceito. Um tipo quase sempre é um conceito, sem existência material. Já uma instância pode ser tanto coriceitual quanto ter existência fisica - possui um formato. Daí a classificação ser tratada também como materialização ${ }^{*}$ na literatura [PIROTTE_94][PIROTTE_97][DAHCHOUR_98]. A hierarquia de classificação pode ser vista através de níveis de classificação, que vão do objeto mais "básico" até o objeto máximo da hierarquia (denotado por "objeto abstração de classificação").

Em SIRIUS, considera-se que não existe um número máximo de níveis de instanciação, sendo esse número determinado pela realidade que está sendo modelada. Nele, a capacidade «de representação de um tipo de objeto e de suas instâncias constituem um elemento de representação do modelo, ou seja, um construtor semântico. Quando o tipo de um objeto não é outro tipo definido pelo usuário, constitui-se então num tipo inicial (instanciado do objeto metatipo). Nesse caso, a sua representação é feita num diagrama onde o retângulo do tipo fica em branco, conforme pode-se observar na Figura 4.1. Uma peculiaridade desta forma de representação é que ela permite representar num mesmo diagrama os tipos de objetos e suas instâncias.

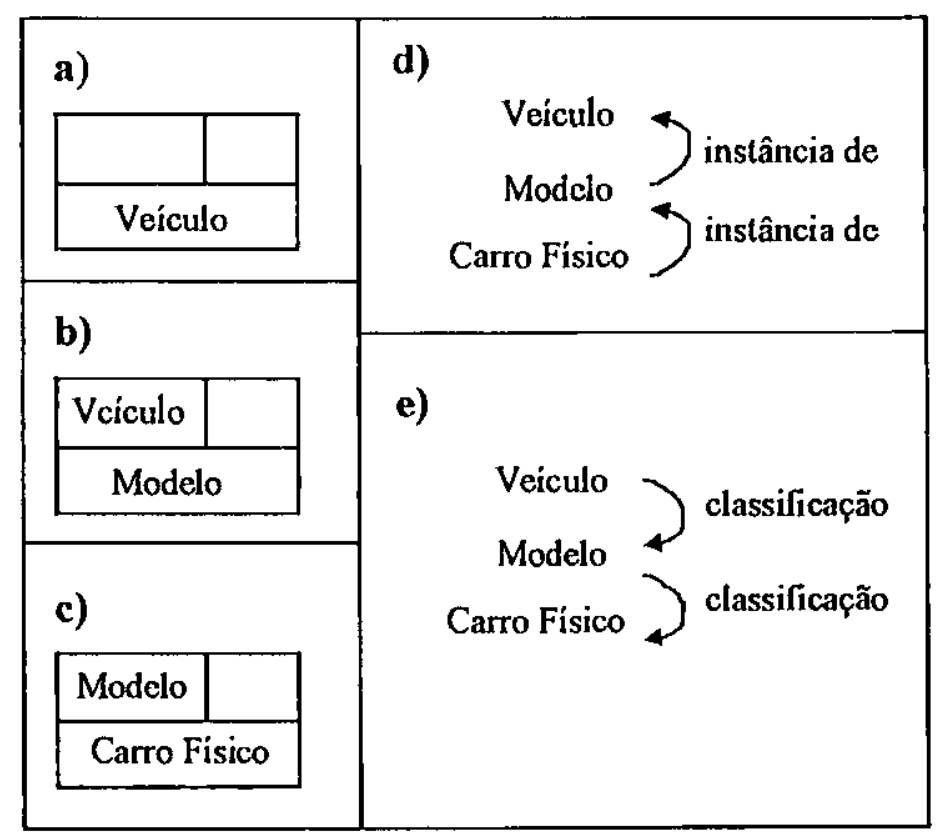

Figura 4.1 - Representação Gráfica de Objetos e de Tipos de Objetos

\footnotetext{
- Conccito não rclacionado à matcrialização de relações no Modclo Relaciona!
} 
A maneira como um objeto é instanciado é estabelecida através de um subconjunto dos atributos de um objeto que é tipo, e que são denominados atributos de classificação. São representados através de uma linha vertical na parte superior do objeto. Para cada tipo de atributo coloca-se uma linha perpendicular à primeira. Os atributos do próprio objeto, chamados de atributos de instância, são representados da mesma forma, porém na parte inferior do objeto.

Um atributo de instância pode estar definido ou indefinido, e estando definido pode ter um valor ou ser nulo. Um atributo instanciado não pode mais ser tepassado para suas instâncias. Um atributo de classificação pode ter valor ou não, além de ter um conjunto de propriedades que estabelecem critérios para a instanciação do objeto ao qual está associado. Um atributo de classificação que tenha valor representa o fato de que esse é o valor "default" repassado para . todas as instâncias do objeto ao qual está associado. Note-se que esse processo é dinâmico, no sentido que se o valor mudar, as novas instâncias terão como valor "default" o novo valor alterado, fato que entretanto não altera as instâncias criadas anteriormente à mudança. Um atributo instanciado nunca fica indefinido se no objeto de onde foi instanciado este tiver um valor, porém localmente pode ter valor nulo.

Alguns objetos podem necessitar de atributos extras, ou seja, necessitam de caracterização adicional em relação aos tipos de objetos do qual foram instanciados. Eles podem ser atributos de classificação ou de instância, sendo naturalmente adicionados a esses objetos, sem distinção em relação aos atributos pré-definidos.

É importante caracterizar a distinção entre valor "default" e valor herdado (este último decorrente da abstração de generalização). Um valor "default" é carimbado no objeto instanciado quando de sua criação, valor esse que pode ser posteriormente substituido caso a caso, pois cada instância pode ter um valor diferente para esse atributo. Já um valor herdado corresponde a um atributo que não está associado ao objeto cujo tipo está em questão, mas a um de seus supertipos. Assim, qualquer alteração no valor de um atributo herdado é repassada, alterando-se igualmente o valor do atributo do objeto que é supertipo. Por exemplo, todo Escort possui tanque de 50 litros, que é o valor "default" para qualquer instância desse modelo de carro. Um corredor de "rally" pode necessitar de um tanque com volume maior, efetuando a troca. Assim, altera-se apenas o valor do tanque do carro do corredor (carro fisico), que é uma das instâncias de Escort (modelo). As outras instâncias e o "default" permanecem inalterados. Já se o 
Escort "Rally" for considerado uma especialização de Escort, qualquer alteração no tanque de combustível é repassada ao carro genérico, pois ambos são o mesmo objeto - visto com mais ou menos detalhes é certo - mas ainda assim o mesmo objeto.

Uma propriedade dos atributos de classificação é a indicação do número mínimo de níveis da hierarquia, explicitando-se assim quais atributos são instanciados enn cada nível. Indica-se essa propriedade no diagrama através de um número que precede o nome do atributo: o número 1 indica que esse atributo será instanciado no primeiro nível (primeira instanciação) desse tipo de objeto; o número 2 indica que será instanciado no segundo nível, e assim sucessivamente.

Outra propriedade é a indicação se o atributo será um identificador (de usuário) do objeto onde ele for instanciado. Isso fica determinado quando o número que indica o nível em que o objeto será instanciado é colocado entre parênteses. Observa-se na Figura 4.2 que o atributo modelo de veículo é chave que classifica o objeto escort, e o atributo placa é a chave que classifica xp_9999, ou seja, xp__9999 é instância de placa (carro fisico) e escort é instância de veículo.

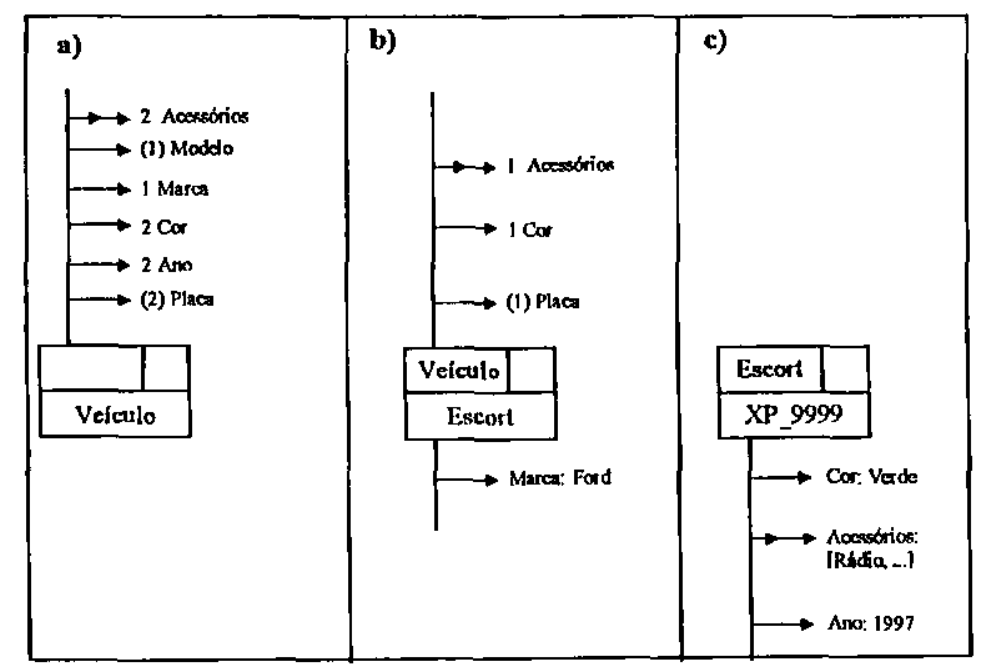

Figura 4.2 - Abstração de Classificação e seus Atributos de Classificação

Assim, o número 1 no atributo modelo significa que ele será um identificador do objeto instanciado a partir dele, garantindo que não deverá, no caso deste exemplo, haver duas instâncias de vetculo com o mesmo modelo. No caso da Figura 4.2a, o objeto representado é do tipo mais primitivo de objeto, nada sendo escrito no campo reservado para o tipo do objeto. 


\subsection{Estendendo o ME-RX para suportar a Abstração de Classificação}

Para que um modelo de dados possa suportar determinada abstração, é necessário que tal modelo possua um construtor semântico que a incorpore. Os conceitos de classificação/instanciação utilizados no desenvolvimento do projeto utilizado como estudo de caso foram originalmente desenvolvidos no modelo de dados orientado a objetos SIRIUS, conforme anteriormente explanado. No entanto, parte da equipe de desenvolvimento (técnicos e analistas da empresa) não possuía grande capacitação técnica, sendo porém muito treinada na utilização do Modelo Entidade - Relacionamento Estendido (ME-RX), situação essa semelhante à de grande parte dos projetistas atuantes no mercado.

Devido a esse fato, considerou-se adequada a criação de uma nova extensão ao ME-RX, para que ele viesse a suportar um construtor semântico que representasse a abstrạção de classificação, de maneira análoga à abordagem em SIRIUS. O modelo re-estendido foi denominando Modelo Entidade - Relacionamento - Classificação (ME-R-C). Definiu-se que este novo modelo inclui as abstrações e construtores semânticos do ME-R original, mais os dois construtores semânticos tradicionais do ME-RX comumente conhecidos como construtores de generalização e de agregação, e o novo construtor que representa a abstração de classificação. Esse novo modelo (ME-R-C) incorpora, portanto, os seguintes construtores semânticos:

- Conjuntos de Entidades - CE (introduzido no ME-R original);

- Conjuntos de Relacionamentos - CR (introduzido no ME-R original);

- Atributos de Entidades - AE (introduzido no ME-R original);

- Atributos de Relacionamentos - AR (introduzido no ME-R original);

- Construtor de Generalização - AG (introduzido no ME-RX);

- Construtor de Agregação - AA (introduzido no ME-RX);

- Construtor de Classificação - AC (introduzido no ME-R-C). 


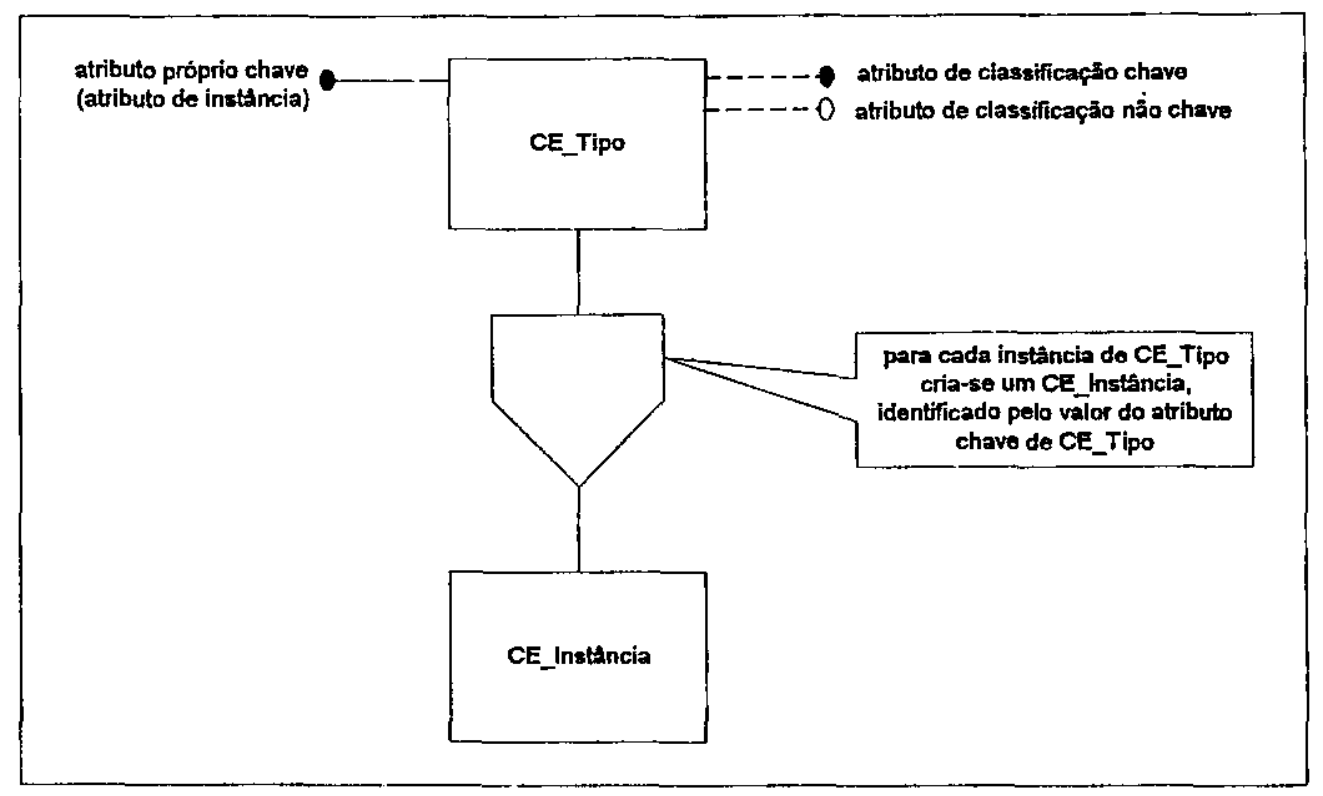

Figura 4.3 - O Construtor de Classificação etn ME-R-C

A Figura 4.3 ilustra a representação gráfica adotada para o construtor de classificação em ME-RC. A extensão feita permite apenas que conjuntos de entidades (CE's), chamados CE_Tipos, sejam instanciados em outros CE's, chamados CE_Instâncias. O construtor de classificação é representado pelo pentágono irregular do centro da figura. Qualquer $\mathrm{CE}$, seja ele regular, tipo ou instância, pode ter atributos próprios, cuja notação segue aquela proposta por Ceri [CERI_92], ligando cada atributo ao $\mathrm{CE}$ (ou CR) através de uma linha contínua com um círculo na ponta (•) se 0 atributo faz parte da chave do $\mathrm{CE}$, ou uma circunferência (O), se o atributo não faz parte di chave. Os atributos próprios são chamados também, nesse trabalho, de atributos de instância para que seja simplificada a analogia com os conceitos em SIRIUS.

A extensão feita permite que um CE_Tipo defina os atributos que ocorrerão em suas instâncias, ou seja, os atributtos de classificação. Isso é indicado ligando-se cada atributo ao CE_Tipo através de uma linha tracejada, sendo que sua ponta pode indicar:

- Círculo - nome de um atributo integrante da chave do CE instância criado;

Circunferência - nome de uın atributo que não faz parte da chave do CE instância criado. 
Preservando-se a analogia com o SIRIUS, salienta-se que o nome de cada CE instância gerado é obtido através do valor do atributo de instância (próprio) que é chave do CE Tipo.

Assim, com a introdução dessa nova notação, pode-se representar em ME-R-C a maioria dos conceitos semânticos da abstração de classificação representáveis em SIRIUS. Optou-se pela não indicação, na nova notação, do número mínimo de níveis da hierarquia de classificação, propriedade esta representada em SIRIUS pelo número entre parênteses colocado antes do nome do atributo de classificação. Esta decisão foi tomada considerando que, embora seja possível o acréscimo ilimitado de níveis de classificação em SIRIUS (ou outro modelo de dados que disponibiliza a abstração de classificação como um construtor semântico), verificou-se ser criado apenas um nível de classificação adicional na maioria dos casos observados, dificilmente ocorrendo dois ou três níveis. Por outro lado, considerar apenas a indicação de um dos níveis não restringe o modelo de fato; apenas "espalha" a representação, pois é possível representar o próximo nível da hierarquia nos conjuntos de entidades instanciados.

Quando um novo construtor semântico é acrescentado a um modelo de dados, ele deve somar-se ortogonalmente a todos os demais conceitos já existentes. Portanto, ele deve poder ser aplicado igualmente a todos os demais construtores já existentes, sem afetar seu significado, estruturas e restrições. Assim, a inclusão de um construtor no ME-RX para suportar a classificação não deve afetar aos outros construtores, podendo ser igualmente aplicada a todos eles.

O objetivo final do modelo continua sendo o suporte à modelagem conceitual, prevendo ferramentas de mapeamento para que o resultado final de uma modelagem possa ser mapeado para o Modelo Relacional, e em seguida ser implementado, utilizando-se de gerenciadores de dados existentes. Para suportar a classificação também para isso, todas as ocorrências do construtor de classificação tiveram que ser estudadas para que se determinassem também as suas regras de mapeamento para o M-Rel. No caso da abstração de classificação, em cada situação em que ela se associa com os demais conceitos do ME-RX existe uma ou mais maneiras de efetuarse o mapeamento, preservando-se as propriedades semânticas do construtor no M-Rel.

Neste trabalho considerou-se que apenas entidades podem ser classificadas, uma vez que é prática usual, quando se utiliza o ME-RX e também o SIRIUS, "promover" atributos e/ou conjuntos de relacionamentos à conjuntos de entidades, quando existem razões semânticas para essa alteração. Considera-se que a classificação é sempre uma razão suficiente para a alteração 
do esquema, tratando-se apenas da classificação de conjuntos de entidades. Esse tratamento envolve a análise de CE regulares ou fracas, subtipos ou supertipos de abstrações de generalização, $\mathrm{CE}$ resultantes ou não da abstração de agregação. Do ponto de vista da abstração de classificação, não existe diferença o fato do $\mathrm{CE}$ serem regulares ou fracas, não sendo necessário, portanto, tratamento diferenciado para os casos. Quanto à abstração de generalização, considera-se que uma entidade que pertença a um determinado subtipo é a mesma entidade que pertence ao supertipo dessa ocorrência de generalização. Deste modo, são passiveis de classificação apenas os CE maximais de hierarquias de generalização. Assim, de maneira análoga a entidades regulares/fracas, o fato de um CE ser ou não especializável em um esquema não afeta a maneira de seu mapeamento quando ele fizer parte de uma ocorrência da abstração de classificação.

Portanto, são tratados no presente trabalho os seguintes casos:

- Mapeamento de conjuntos de entidades (CE's);

- Mapeamento de conjuntos de relacionamentos (CR's) associados a CE's instâncias;

- Mapeamento de agregações (AA).

\subsection{Mapeamento: Modelo Entidade - Relacionamento - Classificação (ME-R-C) para Mọdelo Relacional (M-Rel)}

\subsubsection{Regras para o Mapeamento da Classificação de CE's}

Para melhor demonstrar o mapeamento de CE's envolvidos pela abstração de classificação, considera-se, de acordo com o ilustrado pela Figura 4.4, um conjunto de entidades tipo, ConjTipo, com atributos de instância $\left(a_{c h}, a\right)$, sendo $a_{d 1}$ a chave primária e $a=\left\{a_{1}, a_{2}, \ldots, a_{n}\right\}-0$ conjunto de atributos não chave; e atributos de classificação $\left(\mathrm{ac}_{\mathrm{ch}}, \mathrm{ac}\right)$, sendo $\mathrm{ac}_{\mathrm{ch}} \mathrm{o}$ atributo de classificação que será o atributo chave do conjunto de entidades instanciadas e $a c=\left\{a_{1}, a_{2}, \ldots . .\right.$, $\mathrm{ac}_{\mathrm{m}}$ \} - o conjunto de atributos não chave do conjunto de entidades instanciadas. 


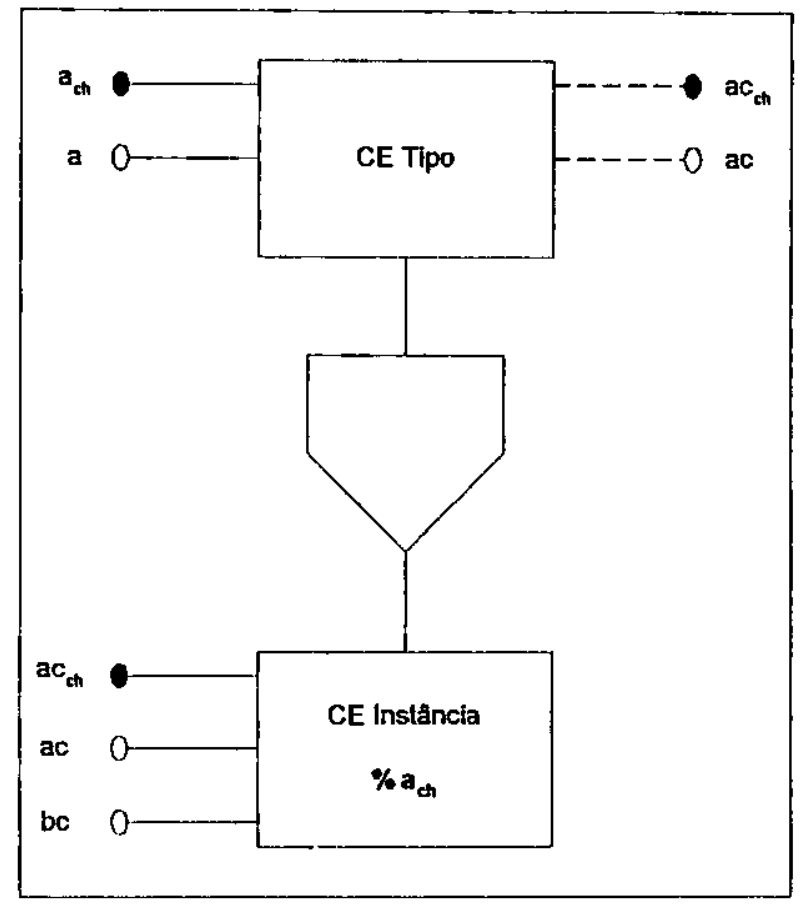

Figura 4.4 - Estrutura de Classificação de um CE em ME-R-C

Considera-se também um conjunto de entidades instanciadas de nome \% $a_{c h}$ (o símbolo \% representa o valor do atributo na entidade tipo origem), com atributos de instância ( $\mathrm{ac}_{\mathrm{ch}}, \mathrm{ac}, \mathrm{bc}$ ), onde $\mathrm{ac}_{\mathrm{d}_{1}}$ é a chave primária, $\mathrm{ac}=\left\{\mathrm{ac}_{1}, \mathrm{ac}_{2}, \ldots, \mathrm{ac}_{\mathrm{m}}\right\}-$ conjunto de atributos não chave "carimbados" a partir do conjunto de entidades tipo e bc $=\left\{b c_{1}, b c_{2}, \ldots, b c_{u}\right\}-$ conjunto de atributos especificos da instância.

Preliminarmente, faz-se o mapeamento do conjunto de entidades tipo envolvido, que é mapeado como qualquer $\mathrm{CE}$ regular do modelo. Assim cria-se a relação abaixo, contendo os seguintes atributos:

$$
\text { ConjTipo }=\left\{\underline{a}_{h}, a\right\}
$$

Já em relação a cada CE instância envolvido, existem duas opções para o mapeamento. A primeira segue diretamente a solução teórica e a segunda é mais facilmente implementável, permitindo maior portabilidade e independência de implementação, que também é freqüentemente mais eficiente. 


\subsubsection{Solução Teórica}

Pelo mapeamento que segue a solução teórica, cria-se uma relação para representar os atributos de classificação do conjunto de entidades tipo e os atributos específicos de cada CE instância. Para cada entidade instanciada do CE tipo cria-se um novo CE instância, ou seja uma nova relação. Essa solução permite que cada instância seja fielmente retratada, garantindo-se alto nível de representação semântica e total compatibilidade com os conceitos teóricos. Assim, para mapear-se os dados dos atributos de classificação do CE Conj Tipo cria-se a relação:

\section{AtrConjTipo $=\left\{\underline{a}_{d}, \underline{\text { nome atr }}\right.$, tipo, nulo, chave, valor $\}$}

onde $a_{c h}$ identifica cada instância (tupla) do conjunto de entidades tipo; nome_atr indica os nomes dos atributos de classificação (representado na figura por ac e $\mathrm{ac}_{\mathrm{d}_{\mathfrak{n}}}$ ) e os nomes dos atributos específicos de cada CE instância (representado na figura por bc); tipo indica o tipo desse atributo; nulo indica se ele pode ser ou não nulo; chave indica se o atributo é ou não chave e valor indica um valor "default" no caso de atributos não chave.

Note-se que estão representados nessa relação os atributos usuais suportados pelo modelo relacional para atributos de relações. Se outros atributos dos atributos tiverem que ser representados (e suportados diretamente pelo aplicativo, dado que o Modelo Relacional suporta apenas esses), então outros atributos devem ser incluídos nessa tabela.

Para cada conjunto de entidades instância, cria-se uma relação:

$$
\% \mathrm{a}_{\mathrm{dh}}=\{\{\text { nome_atr }\}\}
$$

Observa-se que a notação $\% \mathrm{a}_{\mathrm{c}}$ indica que o nome da relação é o valor atribuído ao atributo chave na entidade tipo que a originou.

É importante notar que o mapeamento apresentado ilustra como criar as relações no Modelo Relacional. No entanto, devem ser especificadas também as regras que governam a manipulação das relações mapeadas. No caso da abstração de classificação, as regras são bastante simples em todas as ocorrências mapeadas, sendo obtidas apenas garantindo-se as regras restrições de chave estrangeira normais do Modelo Relacional. Ilustrando no caso desta maneira de mapeamento, as 
regras que garantem a consistência da representação da classificação restringem-se a garantir que:

- A inclusão/remoção/modificação de uma tupla na tabela que representa o conjunto de entidades tipo corresponde sempre à inclusão/remoção/modificação das tuplas correspondentes na relação de dados do atributo, seguido da criação/eliminação/modificaçã்o da tabela correspondente à instância em questão;

- uma instância deve sempre ser criada/eliminada/modificada na relação correspondente a seu tipo, dado que podem existir muitas relações para o conjunto de entidades instância, de fato uma para cada tupla na relação que mapeia o conjunto de entidades tipo.

Essa solução pode apresentar, em certos casos, alguns problemas práticos, tais como número excessivo de relações, pois para cada entidade tipo cria-se um $\mathrm{CE}$ instância $\% \mathrm{a}_{\mathrm{ch}}$, conforme pode-se verificar nas regras de mapeamento descritas.

\subsubsection{Solução Prática}

Como uma tentativa de resolução desses problemas, criou-se a segunda maneira de realizar-se o mapeamento, chamada de maneira prática. Por essa regra mapeia-se qualquer número de conjuntos de entidades instâncias contando apenas com a utilização de duas relações: uma relação que mapeia $\mathrm{CE}$ tipo, que armazena os atributos próprios e os nomes atributos de classificação e dos atributos específicos de cada instância; e uma nova relação que armazena os valores dos atributos de todos os $\mathrm{CE}$ instância. A relação correspondente aos dados de cada atributo de classificação do $\mathrm{CE}$ tipo até poderia ser criada para auxiliar uma possível regra especial de unicidade entre vários sub-tipos nos atributos chave dos CE instância, o que não tem sentido prático, pois os dados dessa tabela (tipo de dado, nulo, etc.) tem que ser expressos já na geração da única tabela que armazena os valores de todos os CE instância.

Essa solução, entretanto, não é tão genérica como a anterior, pois permite que as variações particulares de cada CE instância sejam representadas apenas parcialmente, uma vez que os mesmos ficam restritos a um número máximo de atributos de classificação definidos em CE tipo.

Como a existência de atributos causa impacto não apenas na base de dados, mas também na interface com o usuário e na programação dos aplicativos, restringir a solução apenas aos 
atributos previstos no CE tipo não chega a ser uma restrição de fato, pelo menos até que as linguagens de programação e os sistemas de gerenciamento de interface com o usuário tenham recursos para suportar a abstração de classificação.

Assim, para o mapeamento da situação ilustrada na Figura 4.4, considerando-se, por exemplo, três o valor máximo de atributos do CE instância, as relações criadas são:

$$
\text { Conj'Tipo }=\left\{\underline{a}_{c h}, \text { a, nome } 1, \text { nome }_{2}, \text { nome }_{3}\right\}
$$

Embora haja um atributo que teoricamente integraria a chave do $\mathrm{CE}$ instância, ele será incluído na nova relação como atributo não chave, pois a tabela que armazenará os dados de todas as instâncias possui chave própria, conforme relação abaixo:

$$
\text { CE_Instância }=\left\{\underline{\text { dados }}_{\mathrm{ch}_{3}}, \text { valor }_{1}, \text { valor }_{2}, \text { valor }_{3}, \mathrm{a}_{\mathrm{ch}_{2}}\right\}
$$

$\mathrm{O}$ atributo dados $\mathrm{s}_{\mathrm{h}}$ é a chave da relação. Para preservar-se a origem dos dados insere-se na relação o atributo chave de ConjTipo (chave da entidade que criou a tupla), que atua como chave estrangeira, ligando os dados em si aos tipos de dados.

A Figura 4.5 ilustra a classificação de veículo em modelo de veículo, a exemplo do realizado em SIRIUS na seção 4.3 .

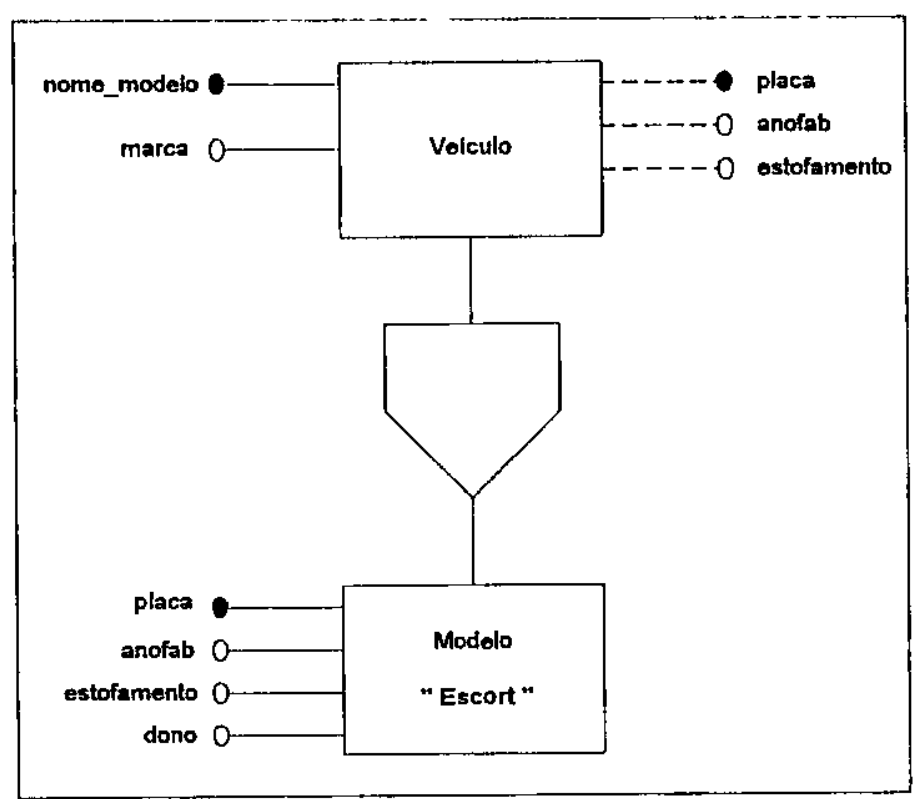

Figura 4.5 - Exemplo de Classificação em ME-R-C 
Seguindo esse esquema, são criadas as seguintes relações:

- Solução Teórica:

Veículo $=\{$ nome modelo, marca $\}$

AtrVeículo $=$ \{nome modelo, nome atr, tipo, nulo, chave, valor $\}$

$\%$ nome_modelo $=\{\{$ nome_atr $\}\}$

Ressalta-se que é criada uma relação para cada CE instância (cujo nome é o nome do modelo do veículo, atributo chave da relação do $\mathrm{CE}$ tipo). Assim, exemplos de tuplas das relações acima seriam:

\begin{tabular}{|c|c|c|}
\cline { 2 - 3 } Veículo & nome modelo & Marca \\
\hline \hline & escort & ford \\
\cline { 2 - 3 } & gol & volks \\
\hline
\end{tabular}

\begin{tabular}{|c|c|c|c|c|c|c|}
\hline AtrVeiculo nome modelo & nome atrclass & tipo & nulo & chave & valor \\
\hline & escort & placa & alfa-num & não & sim & \\
\hline escort & anofab & num & sim & não & \\
\hline escort & estofamento & alfa & sim & não & couro \\
\hline escort & dono & alfa & sim & não & \\
\hline gol & placa & alfa-num & não & sim & \\
\hline gol & anofab & num & sim & năo & \\
\hline gol & estofamento & alfa & sim & não & \\
\hline gol & combustível & alfa & sim & não & gasolina \\
\hline
\end{tabular}

\begin{tabular}{|c|c|c|c|c|}
\cline { 2 - 5 } escort & placa & anofab & estofamento & dono \\
\hline \multirow{4}{*}{ cfu1111 } & 1997 & couro & ana \\
\cline { 2 - 5 } & cvd1234 & 2000 & couro & carlos \\
\hline zyw5655 & 1983 & vinil & joaquim \\
\hline
\end{tabular}

\begin{tabular}{c|c|c|c|c|}
\cline { 2 - 5 } gol placa & anofab & estofamento & combustivel \\
\hline frc6432 & 1996 & vinil & gasolina \\
\hline cvd8600 & 2000 & couro & gasolina \\
\hline
\end{tabular}


Enfatiza-se que os atributos de classificação (placa, anofab, estofamento) devem ser criados para todas as instâncias, uma vez que foram definidos pelo CE tipo. Observa-se ainda, pela análise das tabelas, que todas as instâncias do veículo escort são criadas ("carimbadas") com estofamento de couro, pois esse é o valor "default" definido na tabela AtrVeículo. Entretanto, há uma tupla que possui estofamento de vinil, o que indica que o valor desse atributo pode ser localmente modificado, sem alteração dos valores do mesmo atributo nas outras instâncias (tuplas).

- Solução Prática (considerando-se o máximo de 4 atributos por instância):

Veículo $=\left\{\underline{\text { nome modelo }}\right.$, marca, nome 1, nome $_{2}$ nome nome $\left._{4}\right\}$

Instâncias $=\left\{\underline{\text { dados }}_{d_{1}}\right.$, valor $_{1}$, valor $_{2}$, valor $_{3}$, valor $_{4}$, nome _modelo $\}$

\begin{tabular}{c|c|c|c|c|c|c|} 
Veiculo & nome modelo & marca & nome & nome $_{2}$ & nome $_{3}$ & nome $_{4}$ \\
\hline \hline \multirow{4}{*}{ escort } & ford & placa & anofab & estofamento & dono \\
\hline gol & volks & placa & anofab & estofamento & combustível \\
\hline
\end{tabular}

\begin{tabular}{|c|c|c|c|c|c|c|} 
Instâncias & dados $_{c h}$ & valor1 & valor2 & valor3 & valor4 & nome modelo \\
\hline & 0001 & cfu1111 & 1997 & couro & ana & escort \\
\hline 0002 & cvd1234 & 2000 & couro & carlos & escort \\
\hline 0003 & zyw5655 & 1983 & vinil & joaquim & escort \\
\hline 0004 & frc6432 & 1996 & vinil & gasolina & gol \\
\hline 0005 & cvd8600 & 2000 & couro & gasolina & gol \\
\hline
\end{tabular}

Salienta-se que deve ser estabelecida uma correspondência unívoca entre a disposição dos atributos na tabela Veículos e a disposição dos valores na tabela Instâncias para efeito de criação/inserção/remoção de valores.

\subsubsection{Regras para o Mapeamento de CR Associados a CE Classificados}

Para melhor visualização das regras de mapeamento de CR associados a CE classificados, utiliza-se o esquema genérico apresentado nas regras de mapeamento anteriores, com CE tipo e $\mathrm{CE}$ instância $\% \mathrm{a}_{\text {ch }}$ contendo os mesmo atributos próprios e de classificação, com as mesmas 
restrições. Foram acrescentados dois relacionamentos e duas entidades, conforme ilustrado na Figura 4.6

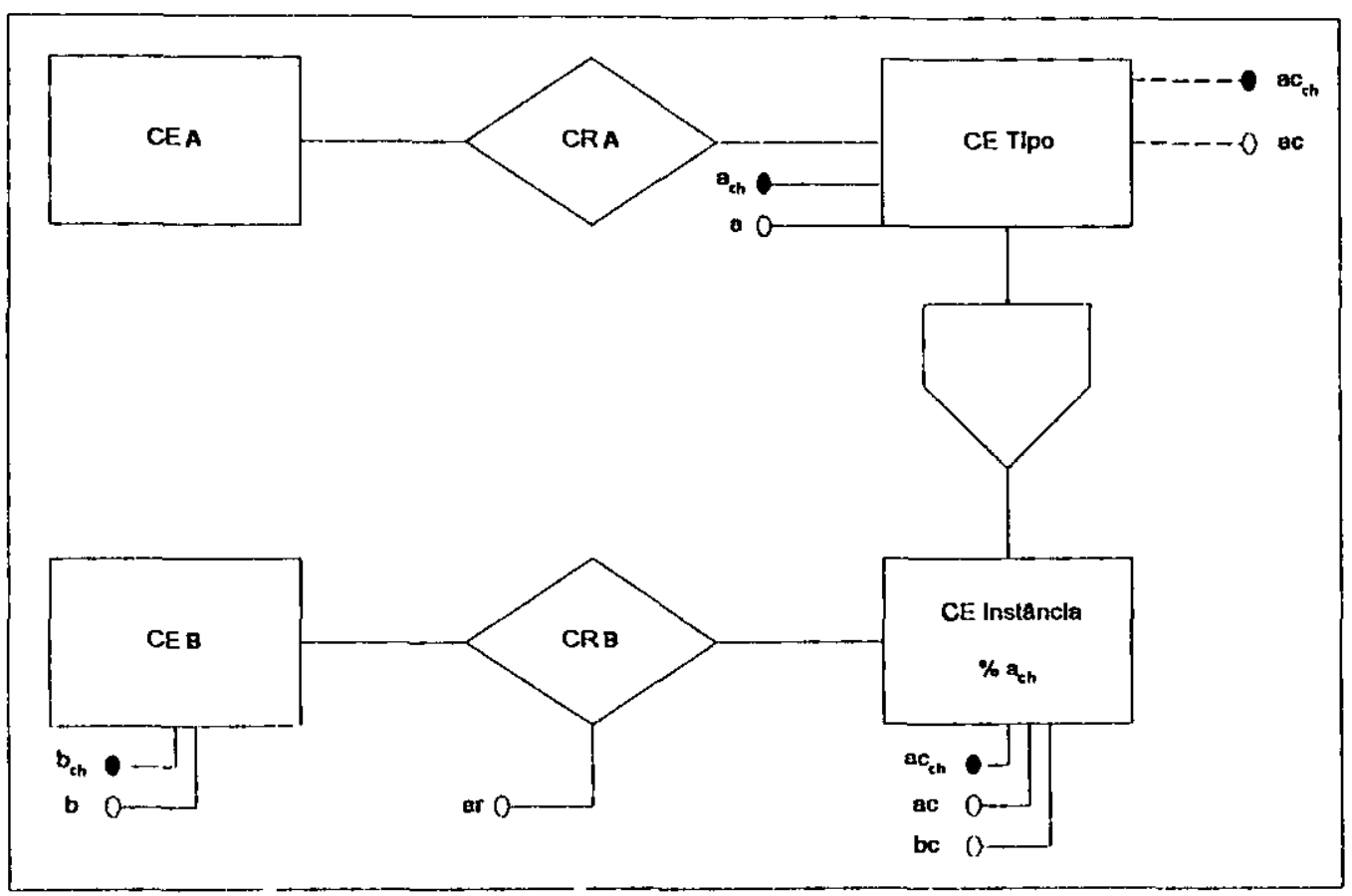

Figura 4.6 - Estrutura de Classificação Genérica de CR associado a CE instância em ME-R-C

Assim, foram introduzidos na figura anterior os conjuntos de entidades CE A e CE B, bem como os conjuntos de relacionamentos CR A e CR B. CE B possui atributos de instância (bch, b), sendo $b_{c h}$ a chave primária e $b=\left\{b_{t}, b_{2}, \ldots, b_{p}\right\}-o$ conjunto de atributos não chave; CR $B$ possui o atributo (ar), sendo $a r=\left\{a r_{1}, a r_{2}, a_{q}\right\}-o$ conjunto de atributos do relacionamento.

$O$ conjunto de entidades $\mathrm{CE} A$ e o conjunto de relacionamentos $\mathrm{CR} A$ (que não possuem atributos devido à sua irrelevância para o exemplo), bem como CE tipo, são mapeados normalmente, de acordo com as regras usuais. $O$ fato de um relacionamento associar um CE tipo não altera em nada seu mapeamento, sendo a ligação do $\mathrm{CR}$ ao $\mathrm{CE}$ realizada através، do atributo de instância que é chave do CE tipo, ou seja, no caso da Figura 4.6, o atributo $a_{\text {ch. }}$.

Já CR B requer tratamento especial, pois associa um CE instância. Para efetuar seu mapeamento deve-se, primeiramente, realizar-se o mapeamento do CE instância, de acordo com as regras definidas no tópico anterior. Somente após é que CR B pode ser mapeado, através de uma das soluções: 


\subsubsection{Solução Teórica}

O mapeamento de um relacionamento que ássocia CE instanciados é realizado de acordo com as regras básicas para o mapeamento de relacionamentos vistas no capítulo 03. Assim, a primeira consideração para o mapeamento de um CR é verificar-se sua ordem e cardinalidade. Qualquer que seja a escolha de modelagem do CR, existirá uma relação que o mapeia - pode ser criada uma relação específica para isso ou pode ser usada uma relação já existente, como por exemplo a relação que mapeia o $\mathrm{CE}$ que assume papel com multiplicidade $\mathrm{N}$ em um relacionamento binário de cardinalidade $1: N$. No entanto, considerou-se nesse trabalho que, para a solução teórica, se um CR associa um $\mathrm{CE}$ instância uma nova relação deve sempre ser criada. Isso porque, como um CE instância pode ser mapeado através de muitas relações, ocorre de fato uma replicação do CR, que passa também a ser instanciado em muitos "sub-CR" - um para cada instância do CE tipo.

O nome de cada relação criada deve concatenar o nome do CR com o nome do CE instância, para que os "sub.CR" sejam diferenciados. Os atributos que farão parte da chave da nova relação são os alributos pertencentes ì chnve dos Cl:'s associados pelo CR, incluindo os atributos que fazem parte da chave do CE instância. Já os atributos não chave de CR serão os atributos não integrantes da chave da relação.

Assim, de acordo com a estrutura de classificação genérica de CR associado a CE instância da Figura 4.6, cria-se uma relação para cada instância:

$$
\mathrm{CRb}+\% \mathrm{a}_{\mathrm{d}_{1}}=\left\{\underline{\mathrm{ac}}_{\mathrm{ch}}, \underline{\mathrm{b}}_{\mathrm{ch}}, \mathrm{ar}\right\}
$$

onde $\mathrm{CRb}+\% \mathrm{a}_{\mathrm{ch}}$ representa o nome formado a partir da concatenação do nome do relacionamento com o nome do $\mathrm{CE}$ instanciado.

Pode-se observar que essa maneira de mapeamento aumenta o número de relações geradas pelo sistema, aspecto que deve ser considerado na escolha do mapeamento mais adequado.

\subsubsection{Solução Prática}

A segunda maneira para a realização do mapeamento de $\mathrm{CR}$ associando $\mathrm{CE}$ instância cria uma única relação, que pode ser identificada pelo próprio nome do CR Como no caso do inapeaniento de CE instâncias, a solução prática apresentada não é genérica. Esta maneira parte 
do pressuposto que o CE instância foi mapeado pela maneira mais prática, onde cria-se uma relação para armazenar os nomes dos atributos de CE tipo e os nomes dos atributos dos CE's instância e outra relação para armazenar os valores dos atributos de todos os CE's instância.

Assim, de acordo com a estrutura de classificação genérica de CR associado a CE instância, nessa forma de mapeamento a relação criada possui como chave primária: o atributo chave do $\mathrm{CE}$ não instância associado pelo $\mathrm{CR}$, o atributo chave da relação ConjTipo (nomes dos atributos)

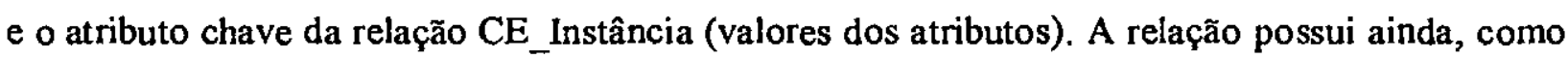
atributos não chave, os atributos de CRb.

$$
\begin{aligned}
& \text { ConjTipo }=\left\{\underline{a}_{\text {di, }}, a, \text { nome }_{1}, \text { nome }_{2}, \text { nome }_{3}\right\} \\
& \mathrm{CE}_{\rightarrow} \text { Instância }=\left\{\text { dados }_{\mathrm{ch}_{2}}, \text { valor }_{1}, \text { valor }_{2}, \text { valor }_{3}, \mathrm{a}_{\mathrm{cth}_{1}}\right\} \\
& \mathrm{CRb}=\left\{\underline{\mathrm{a}}_{\mathrm{ch}}, \underline{\operatorname{dadoS}}_{\mathrm{ch}}, \underline{\mathrm{b}}_{\mathrm{ch}}, \mathrm{ar}\right\}
\end{aligned}
$$

Portanto a escolha adotada para mapear o CE instância afeta como pode ser feito o mapeamento de cada CR que o envolve. Tem-se, como regra básica, que a mesma maneira adotada para mapear o CE instância pode ser utilizado para mapear cada CR que o associa.

Para que seja alterada a maneira de mapeamento do $C R$, considera-se a ordem do mesmo e a multiplicidade com que o $\mathrm{CE}$ instância participa do CR. Se a ordem é maior que dois, a mesma maneira de mapeamento deve ser empregada. De fato, as mesmas considerações feitas em [TEOREY_91] quanto às chaves de CE que participam de CR de ordem maior que dois aplicamse aqui, flexibilizando essa regra. Se a ordem for igual a dois (CR binário), a cardinalidade do CR determina a possibilidade de troca no método de mapeamento - CR de cardinalidade 1:1 ou $1: N$, onde o CE instância participa com cardinalidade 1 , permitem a troca do método de mapeamento; $\mathrm{CR}$ de cardinalidade $1: \mathrm{N}$ ou $\mathrm{N}: \mathrm{M}$, onde o $\mathrm{CE}$ instância participa com cardinalidade $\mathrm{N}$ não permitem a troca do método de mapeamento. 


\subsubsection{Regras para o Mapeámento de Agregaçố:}

$\mathrm{O}$ mapeamento de um $\mathrm{CE}$ resultante de uma agregação de dois ou mais $\mathrm{CE}$ 's componentes a partir de um CR pressupõe uma das seguintes situações:

a) no mínimo um dos $\mathrm{CE}$ componentes é classificável;

b) um dos CE's componentes define uma estrutura de dados que atua como indexador do CE agregação.

Assim, há dois casos, que serão tratados a seguir.

\subsubsection{No mínimo um CE componente é classificável}

Esta situação ocorre quando ao menos um dos $\mathrm{CE}$ associados pelo CR gerador da agregação é um CE tipo. Pode-se visualizar essa situação na Figura 4.7, que representa um esquema genérico feito nos mesmos moldes dos esquemas anteriores. Foi adicionada uma abstração de agregação

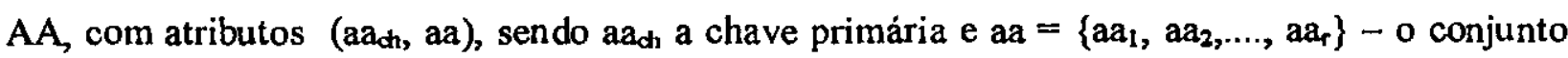
de atributos não chave. A agregação AA também possui os atributos de classificação ( $\mathrm{acc}_{\mathrm{ch}}$, aac), sendo aac $\mathfrak{c}_{\mathfrak{1}} \mathrm{o}$ atributo de classificação que será o atributo chave do conjunto de entidades instanciadas e aac $=\left\{\operatorname{aac}_{1}, \operatorname{aac}_{2}, \ldots ., \operatorname{aac}_{s}\right\}-o$ conjunto de atributos não chave do conjunto de entidades instanciadas.

Também adicionou-se aos esquemas anteriores um conjunto de entidades instanciadas de nome \%aаach (onde o símbolo \% representa o valor do atributo chave na entidade agregação, que é tipo). Esse novo $\mathrm{CE}$ possui atributos $\left(\mathrm{aac}_{\mathrm{ch}}\right.$, aac, $\left.\mathrm{bbc}\right)$, sendo aac $\mathrm{ch}_{\mathrm{c}}$ a chave primária, aac $=\left\{\mathrm{aac}_{\mathrm{c}}\right.$, $\left.\mathrm{aac}_{2}, \ldots, \mathrm{aac}_{\mathrm{s}}\right\}$ - o conjunto de atributos não chave "carimbados" a partir do conjunto de entidades tipo e $b b c=\left\{b b c_{1}, b b c_{2}, \ldots, b b c\right\}-o$ conjunto de atributos especificos da instância. Ressalta-se que esse novo conjunto de entidades instanciadas foi adicionado ao esquema por motivo semântico: a agregação ocorre com um CE tipo, ou seja, ocorre com todas as suas instâncias. Desse modo, existem, na verdade, várias agregações - uma para cada instância - fato que acarreta várias instâncias da agregação, que torna-se então tipo. Logo, a existência de um $\mathrm{CE}$ tipo em uma agregação acarreta a instanciação do CE AA como um todo. 


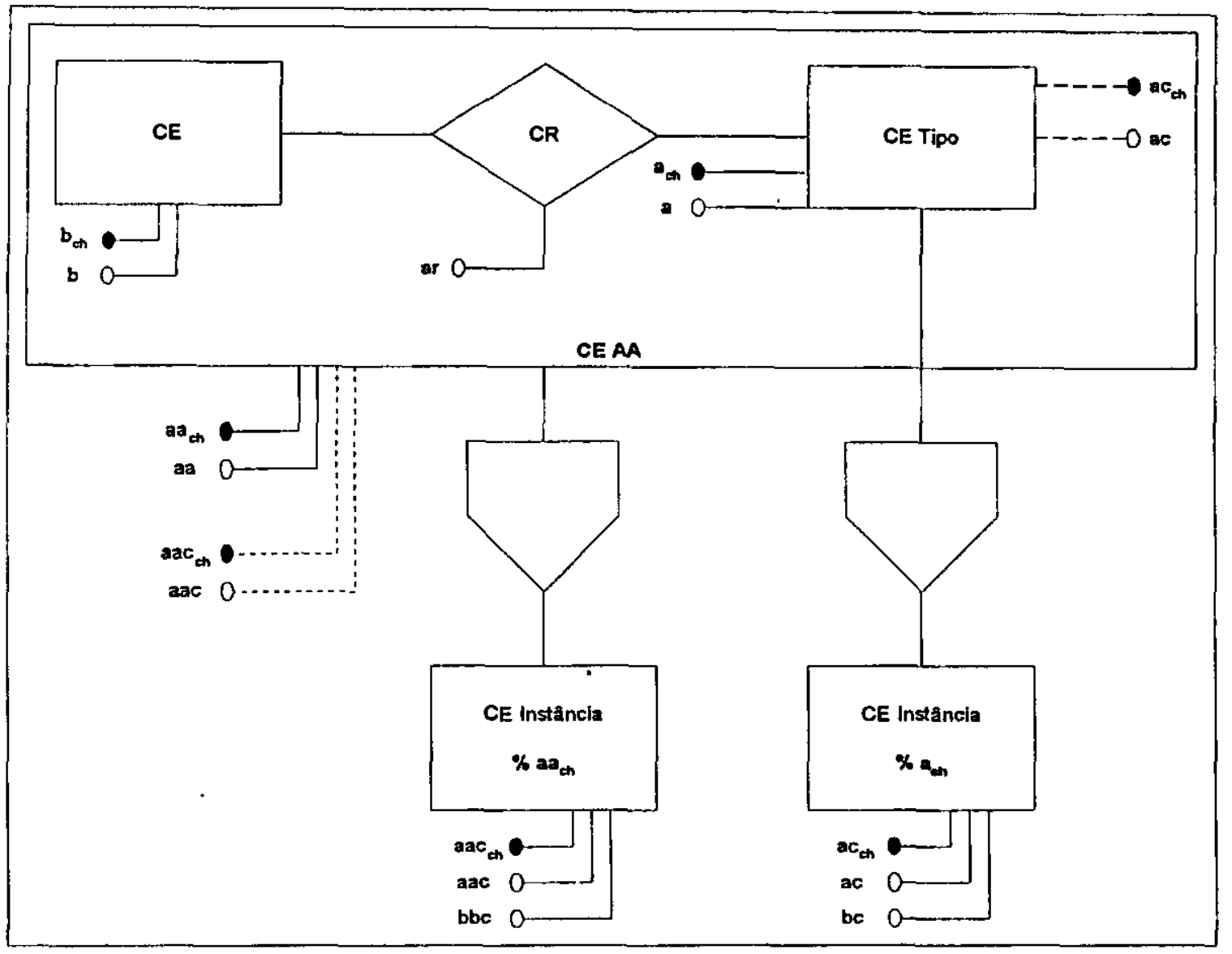

Figura 4.7 - Esquema Genérico de Classificação de Agregação no ME-R-C

De maneira semelhante aos casos anteriores há duas maneiras de realização do mapeamento. Em ambas, frisa-se que o mapeamento da classificação do $\mathrm{CE}$ componente deve ser feito antes do mapeamento do CE Agregação.

\subsection{Solução Teórica}

O mapeamento da classificação da agregação pela solução teórica é feito partindo-se do pressuposto que o mapeamento do $\mathrm{CE}$ instanciado tenha sido realizado em conformidade com a solução teórica apresentada anteriormente, ou seja:

AtrConjTipo $=\{\underline{a}$ th, nome atr, tipo, nulo, chave, valor $\}$

$$
\text { para cada instância : \%acth }=\{\{\text { nome_atr }\}\}
$$


Mapeia-se então a agregação, através das seguintes relações:

CE AA_AtrConjTipo $=$ \{aact, nome atr aa, tipo, nulo, chave, valor $\}$

$$
\% a a_{c h}=\left\{\underline{b}_{c h}, \underline{a}_{c h}, \underline{a c}_{c h},\{\text { nome_atr_aa }\}\right\}
$$

$$
\mathrm{CE} \mathrm{AA}=\left\{\underline{b}_{\mathrm{ch}}, \underline{\mathrm{a}} \mathrm{ch}, \underline{\mathrm{ac}} \mathrm{ch}, \underline{\mathrm{aa}} \mathrm{ch}, \mathrm{aa}, \mathrm{ar}\right\}
$$

Onde nome_atr_aa é o conjunto $=\left\{\underline{a a c}_{c h}, a a c, b b c\right\}$. Podem existir algumas variações nesse mapeamento, pois o mapeamento de uma agregação sem classificação, de acordo com o quarto passo do mapeamento do ME-RX para o M-Rel, visto no capítulo 3, possui duas opções. Se os atributos de $C R$ puderem ser repassados à agregação, $C R$ não é mapeado e o mapeamento da agregação é composto pelas relações acima. Caso os atributos de CR não possam ser repassados, CR precisa ser mapeado (de acordo com a forma teórica anteriormente vista), retirando-se da relação que mapeia o agregado - $\mathrm{CE} A \mathrm{~A}$ - os atributos de $\mathrm{CR}$.

\subsection{Soluçāo Prática}

O mapeamento da classificação da agregação pela solução prática é, analogamente, realizado partindo-se do pressuposto que o mapeamento do $\mathrm{CE}$ instanciado tenha sido realizado em conformidade com a solução prática anteriormente apresentada. Assim, considerando-se 30 valor máximo dos atributos dos CE's instâncias, criam-se as relações:

$$
\begin{aligned}
\text { ConjTipo } & =\left\{\underline{a}_{c_{h}}, a, \text { nome }_{1}, \text { nome }_{2}, \text { nome }_{3}\right\} \\
\text { CE_lnstância } & =\left\{\underline{\text { dados }}_{\text {h }}, \text { valor }_{1}, \text { valor }_{2}, \text { valor }_{3}, a_{\mathrm{c}_{1}}\right\}
\end{aligned}
$$

Mapeia-se então a agregação, através das seguintes relações:

$$
\text { ConjTipo } A A=\left\{\underline{b}_{c h}, \underline{a}_{c h}, \underline{a c}_{d h}, \underline{a a}_{d_{1}}, \text { aa, ar, nomel_aa, nome2_aa, nome3_aa }\right\}
$$

$C E \_$Instância $A A=\left\{\underline{\text { dados aa }}\right.$,h, valorl_aa, valor2_aa, valor3_aa, bch, $\left.a_{c h}, a c_{c h}, a_{c h}\right\}$ 
As mesmas observações da solução teórica em relação a $C R$ e seus atributos aplicam-se na solução prática. Assim, caso os atributos de CR não possam ser repassados, CR deve ser mapeado (de acordo com forma prática anteriormente vista), retirando-se da relação que mapeia o agregado - ConjTipo AA - os atributos de CR.

4.5.3.2. Um dos CE's componentes define uma estrutura de dados que atua como indexador do CE Agregação.

Quando um dos CE Componentes define uma estrutura de dados que atua como indexador do $\mathrm{CE}$ Agregação, o mapeamento correspondente deve considerar o mapeamento dessa estrutura de indexação, para que seja representada toda a carga semântica envolvida na representação. Assim, depara-se com uma situação onde os $\mathrm{CE}$ componentes que não são indice são instanciados com estruturas idênticas às originais, sendo que o $\mathrm{CE}$ componente indexador funciona como uma forma de referência às instâncias, mesmo não sendo chave.

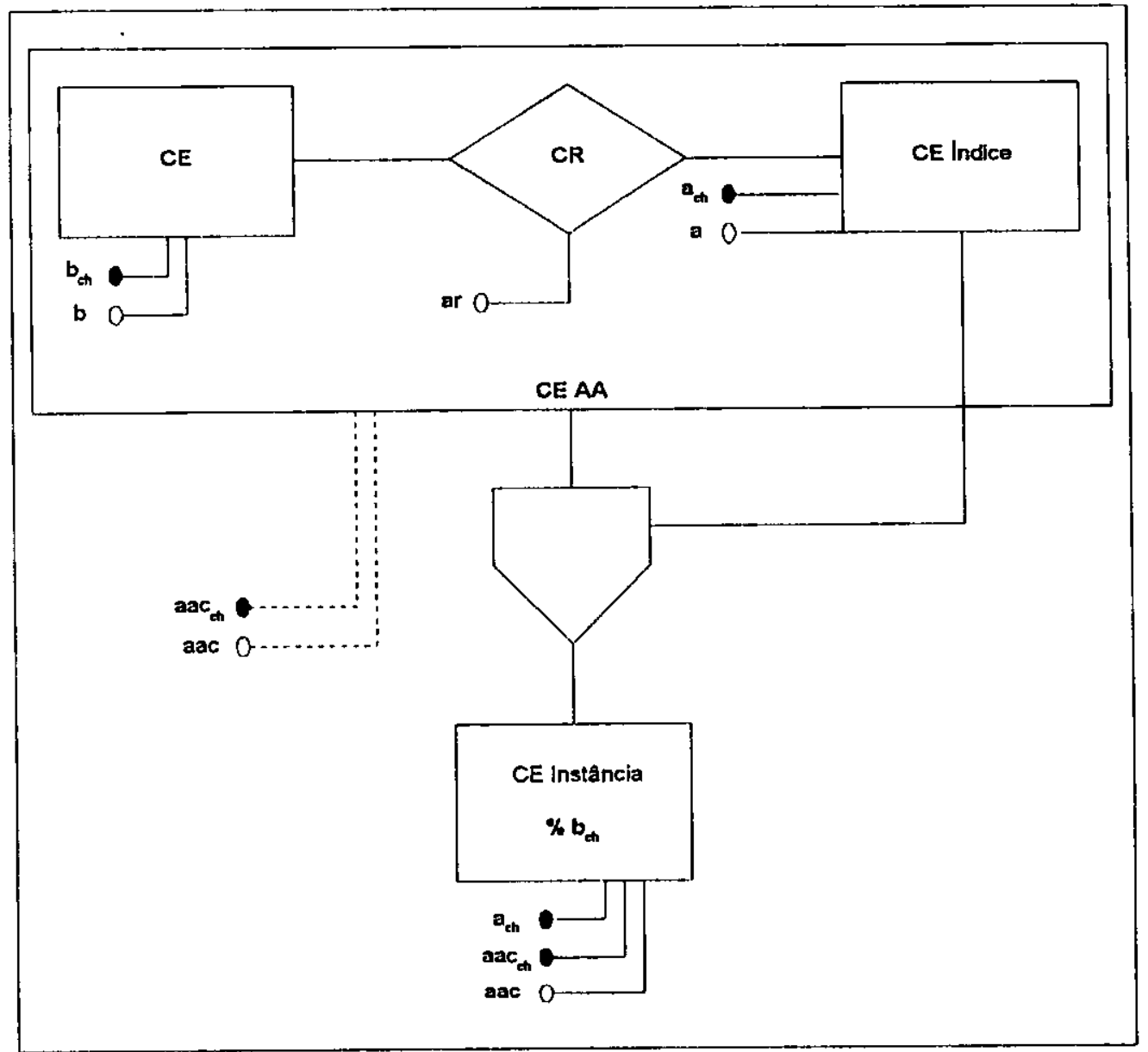

Figura 4.8 - Esquema Genérico de Classificação de Agregação com Índice em ME-R-C 
Conforme pode-se observar na Figura 4.8, há algumas mudanças no esquema representativo dessa situação, quando comparadô aò esquema anterior. Primeiramente, ressalta-se que o construtor de classificação é ligado ao $C E$ Indice. Também, para garantir que os CE's componentes que não são índice sejam instanciados com estruturas idênticas às originais, impõese, na forma de restrição, que

$$
\operatorname{Dom}\left(b_{c h}, b\right)=\operatorname{Dom}\left(a a_{c h}, a a c\right)
$$

Não há CE's participantes da agregação que são instanciáveis e que acarretam a instanciação do CE Agregação como um todo. Instancia-se, de fato, a agregação, onde um dos CE's funciona como índice e os demais são instanciados. Deste modo, os atributos de classificação do CE Instância são originados em todos os $\mathrm{CE}$ 's, com exceção do $\mathrm{CE}$ índice que fornece apenas uma das chaves dos CE's instâncias criados.

Neste trabalho considera-se apenas o caso de indexação através de uma seqüência ordenada. Essa estrutura é, sem dúvida, a mais utilizada na prática, sendo que os autores nunca se depararam com outro tipo de estrutura. É importante notar também que muitas situações teóricas podem ser solucionadas com a conversão para essa maneira de indexação.

Como as estruturas das tabelas de CE e CE_Instância são idênticas, optou-se pela criação de apenas uma tabela para a representação de todos os conjuntos de entidades instanciados. Para tal, utiliza-se uma nova tabela - pivô - que é responsável pela ligação entre as instâncias e as entidades que as criaram.

O mapeamento dessa situação, prática por excelência, consiste na criação de quatro tabelas: uma para $\mathrm{CE}$, uma para $\mathrm{CE}$ Índice, uma para $\mathrm{CE}$ Instância e uma para o pivô (que funciona como agregação) e outra para CE instância:

$$
\begin{gathered}
C E=\left\{b_{c h}, b\right\} \quad C E \_ \text {Índice }=\left\{\underline{a}_{c h}, a\right\} \\
C E \_ \text {Instância }=\left\{\underline{a a c}_{c h}, a_{c}\right\} \\
\text { Pivô }=\left\{\underline{a}_{c h}, \underline{b}_{c h}, a_{c c} c_{d 1}\right\}
\end{gathered}
$$




\subsection{Considerações Finais}

Com a criação do ME-R-C, insere-se um novo construtor semântico - abstração de classificação - no ME-RX, eliminando-se a prática comum de utilização de construtores semânticos (em especial a generalização) impróprios para a representação de situaçoes típicas de classificação, fato este que origina sobrecarga semântica indesejável e introduz pontos obscuros na modelagem.

Com a definição de regras práticas de mapeamento da abstração de classificação, acrescentamse novos passos aos já conhecidos, explanados no capítulo 3. Resumidamente, os passos modificados para o mapeamento do ME-R-C para o Modelo Relacional são:

- Primeiro Passo: mapeamento dos conjuntos de entidades regulares;

- Segundo Passo: mapeamento dos conjuntos de entidades fracas;

- Terceiro Passo: mapeamento das abstrações de generalização:

- alternativas 1, 2, 3 e 4;

- Quarto Passo: mapeamento das abstrações de agregação:

- alternativas 1 e 2 ;

- Quinto Passo: mapeamento das abstrações de classificação:

- classificação de CE's (soluções teórica e prática);

- classificação de CR's associados a CE's classificados (soluções teórica e prática);

- classificação de agregações;

* um dos componentes é classificável (soluções teórica e prática)

* um dos componentes é indice (solução prática)

- Sexto Passo: mapeamento de conjuntos de relacionamentos binários de cardinalidade 1:1

- Sétimo Passo: mapeamento de conjuntos de relacionamentos binários de cardinalidade $1: \mathrm{N}$

- Oitavo Passo: mapeamento de conjuntos de relacionamentos binários de cardinalidade N:M

- Nono Passo: mapeamento de conjuntos de relacionamentos de ordem maior ou igual a três

- Décimo Passo: mapeamento dos atributos multivalorados 
A Tabela 4.1 apresenta um resumo das relaçōes criadas em cada caso de mapeamento da abstração de classificação:

Tabela 4.1 - Casos da Abstração de Classificação e as Relações geradas no Mapeamento

\begin{tabular}{|c|c|c|}
\hline CASO & $\begin{array}{l}\text { TIPO DE } \\
\text { SOLUÇĀOO }\end{array}$ & RELAÇŌES \\
\hline \multirow[t]{2}{*}{ classificação de CE's } & teórica & $\begin{aligned} \text { AtrConjTipo }= & \left\{\text { ach, }_{\text {nome atr, tipo, nulo, chave, valor }\}}\right. \\
& \% a_{c h}=\{\{\text { nome_att }\}\}\end{aligned}$ \\
\hline & prática & $\begin{aligned} \text { ConJTipo } & =\left\{\underline{a}_{\mathrm{ch}}, \mathrm{a}, \text { nome }_{1}, \text { nome }_{2}, \text { nome }_{3}\right\} \\
\text { CE_Instância } & =\left\{\text { dadosch, }_{\text {dalor }}, \text { valor }_{2}, \text { valor }_{3}, a_{c h}\right\}\end{aligned}$ \\
\hline \multirow[t]{2}{*}{ classificação de CR's } & teórica & $\mathrm{CRb}+\% \mathrm{a}_{\mathrm{ct}}=\left\{\mathrm{ac}_{\mathrm{ch}}, \underline{\mathrm{b}}_{\mathrm{ch}}, \mathrm{ar}\right\}$ \\
\hline & prática & $\mathrm{CRb}=\left\{a_{c h}, \underline{\text { dados }}{ }_{c h}, \underline{b}_{c h}, a r\right\}$ \\
\hline \multirow[t]{2}{*}{$\begin{array}{l}\text { classificação de AA's } \\
\text { (1 componente } \\
\text { classiflcável) }\end{array}$} & teorica & 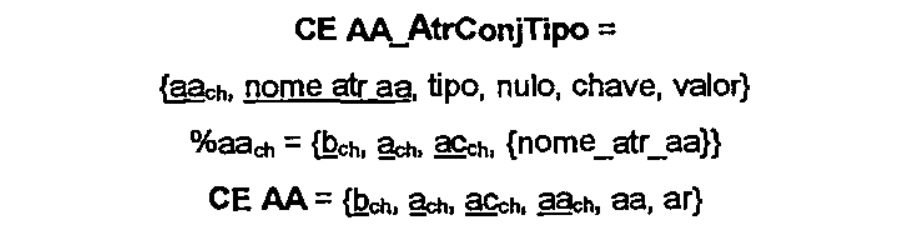 \\
\hline & prática & 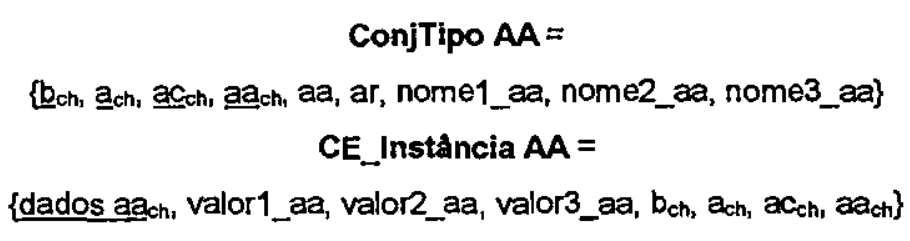 \\
\hline $\begin{array}{l}\text { classificação de AA's } \\
\text { (pivô) }\end{array}$ & prática & $\begin{array}{c}C E=\left\{b_{c h}, b\right\} \quad C E \_ \text {indice }=\left\{a_{c h}, a\right\} \\
C E \_ \text {Instáncia }=\left\{\underline{a a c}_{c h} a a_{c}\right\} \\
\text { Pivó }=\left\{\underline{a}_{c h}, \underline{b}_{c h}, a a c_{c h}\right\}\end{array}$ \\
\hline
\end{tabular}




\section{Capítulo 5: Estudo de Caso}

\subsection{Considerações Iniciais}

A idéia de se utilizar os conceitos da abstração de classificação na Modelo EntidadeRelacionamento Estendido surgiu no desenvolvimento de um novo sistema de suporte à administração de cooperativas médicas para a empresa UNIMED. A utilização desses conceitos trouxe beneficios e facilidades ao sistema desenvolvido que serão oportunamente abordados.

Para o desenvolvimento do sistema, foi necessária a compreensão da organização, do funcionamento e de algumas regras de negócio das cooperativas médicas, que serão sucintamente descritas na seção 5.2. Na seção 5.3 são demonstrados os principais aspectos do sistema MASTER, desenvolvido durante o estudo de caso. Já na seção 5.4 são abordadas as ocorrências da abstração de classificação durante o desenvolvimento do sistema. Finalmente, na seção 5.5, são feitas algumas considerações sobre o estudo de caso.

\subsection{Descrição do Estudo de Caso}

De acordo com uma lei federal, podem ser criadas cooperativas para a prestação de determinado serviço. Deste modo, em várias cidades do país, estabeleceram-se várias cooperativas de médicos, constituídas com o intuito primário de organizar e gerenciar a prestação de serviços médicos à sociedade, fornecidos através da contratação de planos de saúde.

Como a lei federal especifica que a área de atuação da cooperativa deve restringir-se à uma cidade ou região bem definida, as cooperativas não podem ter caráter nacional ou até mesmo estadual. Esse fato deixa a cooperativa de médicos em desvantagem em relação aos outros sistemas de planos de saúde, que são gerenciados por empresas. Não há, neste caso, restrições legais quanto a área de abrangência, sendo possível, então, dar aos segurados cobertura 
estaduais, nacionais e até mesmo internacionais. Deste modo, para poder se enquadrar na lei e fornecer aos seus beneficiários as" mesmas condições das empresas, as cooperativas médicas de várias cidades se uniram e criaram outras organizações, não caracterizadas como cooperativas, mas empresas de fato, atuando como elemento de ligação entre as cooperativas, e criando assim um sistema nacional denominado Complexo-UNIMED.

No Complexo UNIMED cada cooperativa de médicos é completamente independente, com organização e gerenciamento próprios, mas atendendo a alguns padrões definidos para poder integrá-lo. Essas cooperativas, chamadas de singulares, existem em grande número - uma em cada cidade ou região. Exemplos de singulares são: singular São Carlos, singular Rio Claro, singular Araraquara, etc.

Uma das empresas do complexo é a UNIMED-Brasil, que se caracteriza como um elemento de ligação entre as singulares. Uma das suas principais atividades é o desenvolvimento de sistemas de informação para a administração das atividades ligadas à medicina ou às singulares, possuindo para tal fím uma divisão de informática. Além do desenvolvimento dos sistemas, esta divisão também é responsável pelo suporte informatizado para as empresas centrais do complexo.

Como o complexo compõe-se de diversas empresas e cooperativas (singulares) com um alto grau de independência e liberdade de administração, os sistemas desenvolvidos pela divisão de

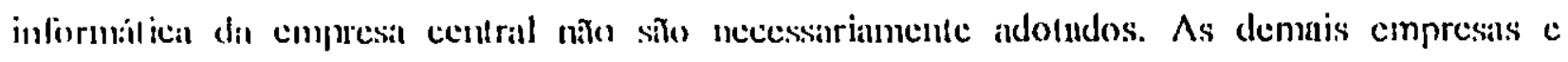
cooperativas podem adquirir os sistenıas se desejarem, mas também podem adquiri-los de oulras empresas e das grandes singulares, tais como São Paulo, Campinas, Blumenau e Porto Alegre, que possuem seus próprios centros de informática e desenvolvem sistemas. Assim, existe um mercado para a produção e venda de software, pelo qual competem as singulares e empresas do complexo que dispõem de sistemas desenvolvidos.

No estudo de caso, trabalhou-se, em conjunto com a UNIMED-Brasil, no desenvolvimento de um sistema de suporte à administração de cooperativas médicas. Esse sistema, denominado Sistema MASTER, deveria, portanto, ser capaz de gerenciar uma cooperativa de médicos ou uma empresa do complexo que trabalhe com a administração de planos de saúde. 
A UNIMED-Brasil já possuía um sistema, em uso há mais de cinco anos, denominado Sistema de Administração Médica - SLAMED, desenvolvido em Dataflex, executável em diversas plataformas operacionais em mais de 200 (duzentas) das mais de 300 (trezentas) cooperativas médicas do complexo. Entretanto, tomou-se a decisâo de se desenvolver o novo sistema - Master - para se tentar dominar essc mercado a longo prazo, eliminando-sc a compctição cntrc os sistemas desenvolvidos pela UNIMED-Brasil e os sistemas de funcionalidade similar desenvolvidos principalmente pelas singulares. A principal arma nessa manobra seria o melhor conhecimento, por parte da UNIMED-Brasil, das características gerais de diversas singulares, 0 que geraria um produto que atenderia mais amplamente as necessidades de cada usuário, podendo, ao mesmo tempo, se adequar melhor às necessidades de cada cooperativa. $\Lambda$ substituição deveria ser norteada pelo desenvolvimento de novas funcionalidades para o sistcma, suportada por uma reengenharia no sistema existente, atualizando sua tecnologia e usabilidade.

\subsection{Sistema de Administração de Cooperativas Médicas}

O novo sistema - Master - é, resumidamcnte, um sistema capaz de administrar requisiçõcs para a prestação de serviços médicos e as respectivas execuções dos serviços autorizados, partinclo dos beneficiários dos planos de saúde em vigor. Importante notar que a maioria dos planos de saúde é estabelecida com empresas em geral para a cobertura de serviços mćdicos aos funcionários, embora pessoas fisicas possam também firmar contratos para a cobertura pessoal e familiar.

O sistema é composto por quatro subsistemas principais (Figura 5.1). Cada subsistema é responsável por uma base de dados. O termo sublinhado significa que apenas esse subsistema atualiza os dados em sua base, embora os dados possam ser consultados pelos demais. Para tal fim, cada subsistenıa nào somente incorpora as suas operações de acesso as dados, mas tambem provê suporte para recepção e avaliação dos dados atualizáveis a partir dc outros subsistcmas. 


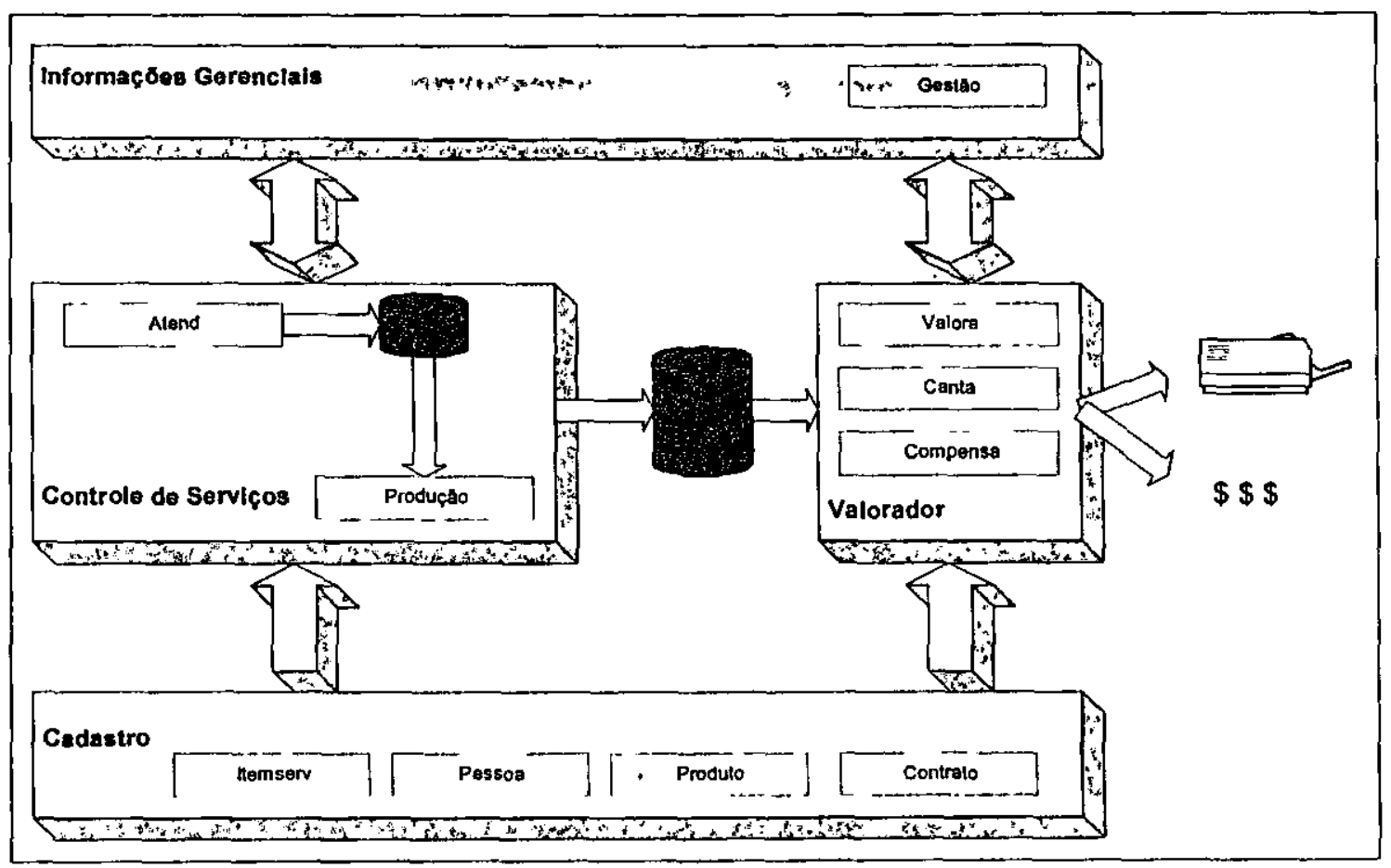

Figura 5.1 - Sistema Master

Os subsistemas são compostos por um ou mais módulos de funções específicas. Os subsistcmas são:

- Cadastro - subsistema que suporta a armazenagem de dados para a execução dos serviços de autorização de consultas, atribuição de valores e cobrança das mesmas, atuando como um repositório de informações para a unificação e integração de todo o sistema. Compõe-se por 4 módulos:

- Pessoa: armazena todos os beneficiários de planos de saúde, empresas contratantes, médicos cooperados, laboratórios e hospitais conveniados, outras singulares e qualquer outra pessoa física ou jurídica que tenha ligação com a singular detcntora do sistema;

- Produto: armazena os diferentes tipos de planos de saúde oferecidos pela singular, ou atendidos mediante convênio com outras singulares;

- Contrato: armazena todos os contratos de prestação de serviços realizados com empresas, famílias ou individuos; 
- Itemserv: armazena os diversos tipos de serviços que podem ser solicitados e cobertos, tais como procedimentos médicos, consultas, exames, diárias e taxas hospitalares.

- Controle de Scrviços - Composto por dois módulos, provê a interação do sistema Master com os usuários externos à organização:

- Atend: recebe todas as solicitações de atendimento médico para decidir quanto à autorização. Tambćm ć rcsponsávcl criação c manutcnção das solicitaçõcs cfetuadas.

- Produção: verifica os serviços executados, validando-os dc acordo com os rcgistros de solicitações de atendimento médico autorizadas. As autorizaçôes e registros de execução são mantidos consistentes com as informaçôes cadastradas e com o modo de atuação operacional diária específica da singular.

- Valorador de.Serviçıs - $\Lambda$ tribui valores uos serviços executados e validados, distribuindo os encargos e receitas aos respcctivos destinatários. l'ambém forncce informaçôcs para as diversas pessoas físicas e jurídicas envolvidas por intermédio de relatórios dos serviços prestados, bem com sua cobrança e pagamento. Pode ainda fornecer informações, associando a cada pessoa uma conta financeira e uma conla médica. A conta financeira permite operações de cobrança, pagamento e compensação, e a conta médica permite a futura integração do sistema com ferramentas de gerenciamento laboratorial e hospitalar. Também pode fornecer um prontuário eletrónico dos pacientes e informações pessoais para gerenciamento médico

\subsubsection{Inovação Tecnológica}

A organização do complcxo médico cria um conjunto de nccessidades particulares que sâo bastantes distintas das usualmente encontradas em empresas típicas. Na arquitetura tradiciona! matriz-filiais, a matriz pode desenvolver, ou pelo menos definir as estruturas da informação, as regras internas às filiais e as regras de operações entre filiais e das filiais com a matriz. Desta forma, embora haja a possibilidade de concessão de determinado grau de liberdade para as filiais, a matriz sempre detém o poder de definir ou somente caracterizar as operações fundamentais. Essa característica, cntretanlo, não pode ser considerada válida no Complexo 
Médico em questão, pois os relacionamentos entre singulares são de interesse exclusivo das partes, sem que, a princípio, nenhuma regra ou decisão envolvaquaisquer das empresas centrais.

Todos os sistemas em uso por diversas cooperativas, principalmente os desenvolvidos pela UNIMED-Brasil, devem ser altamente configuráveis e adaptávẹis às situações específicas das diversas singulares, para que seja interessante às mesmas sua aquisição. Tal flexibilidade diz respeito não somente à possibilidade de atender às singulares de tamanhos díspares, mas principalmente ao fato da não uniformização de regras de administração, tipos de contratos suportados, formas de distribuição de dados intra e inter-singulares e repasses de associados, entre outros tópicos.

Assim, os mecanismos tradicionais de desenvolvimento de sistemas, que utilizam tecnologias orientadas a objetos e hierarquias de generalização/especialização suportando herança de métodos e estruturas de informação, e a respectiva especialização de componentes, não são suficientes para atender às necessidades de adaptação e flexibilidade de configuração inerentes ao sistema proposto. Basicamente, existem três grandes desafios tecnológicos, apresentados pclo sistema Master, que a tecnologia atual não está apta a resolver. São eles:

- Extensa necessidade de particularizações de estruturas de informação e regras de gerenciamento. $\mathrm{O}$ uso de abstrações de generalização, representando a especialização de estruturas e regras e permitindo a herança das mesmas a partir de outras mais genéricas, constitui-se na tecnologia de ponta adotada hoje. Entretanto, essa tecnologia não se mostrou eliciente para a resolução dos problemas, pois conduz a um código com alto grau de parametrização local, causando dificuldades para a codificação e principalmente para a manutenção, pois regras em grande número, muitas mutuamente exclusivas ou conflitantes, devem ser incluídas e mantidas simultaneamente. Recursos conceituais para o projeto e implementação de código baseado em abstrações de classificação e substituição de valores "default" representaram uma resposta acadêmica possível e adequada;

- Modularização de funções, com configuração do sistema a partir de módulos em versões independentes. $\mathrm{O}$ sistema deve ser composto por diversos módulos configuráveis e parametrizáveis com grande liberdade, como indicado no tópico anterior, com a restrição adicional que um ou mais módulos podem não integrar o sistema de determinada singular. 
Um ou mais módulos podem, também, ser sistemas isolados de mesma funcionalidade, adyuiridess de fornecedores distintos ou desenvolvidos bealmente. Ainda assim esises módulos deveriam ser integráveis ao sistema, ao menos em nível de compartilhamento de dados (consulta e atualizaçâo).

Deste modo, nota-se que o sistema deveria prever ao mesmo tempo alto grau de interoperabilidade entre os módulos e acoplamento muito fraco. Para solucionar esse requisito, diversas tccnologias de versionamento de esquemas, programação bascada em eventos e geração de interfaces de programação de aplicativos baseadas em "drivers" e "plug-ins" tiveram que ser simultaneamente empregadas, alćm do suportc à classificaçâo, que possibilitou a integração das mesmas.

- Integração de informação sob demanda entre bases de dados distintas. Os dois tópicos anteriores referem-se a particularidades que ocorrem intra-singulares. No entanto, diferentes singulares podem estabelccer qualquer tipo de acordo entrc si, principalmente no que tange ao atendimento mútuo de beneficiários alheios. Essa situação pode ocorrer, principalmente, em dois níveis:

- repasse de beneliciários de mancira pcrmanente: um excmplo dessa situação ć uma empresa, com funcionários lotados eln diversas cidades, contratando uma singular para criar um convênio de atendimento a todos os scus funcionários. Nessc caso, os beneficiários lotados em cidades cobertas por outras singulares são repassados para elas, que passam a ter um contrato de atendimento com a singular original, sendo que somente essa última possui contrato com a empresa.

- atendimento de intercâmbio cventual: cssa situação ocorrc, por cxcmplo, quando um beneficiário em trânsito tem que ser atendido em outra singular, diferente da contratada, em uma situação de emergência.

Ambas situações requerem, ou indicam a nccessidade de existência de um banco de dados distribuido. No entanto, o banco não é distribuído de fato, pois uma singular não compartilha seus dados com as outras: a estrutura intcrna dos dados $\dot{e}$, na maioria das vezes, distinta das demais; a troca de informações é bi-direcional e eventual, com particularidades distintas em cad: conexão e, além disso, os dados de uma singular não são totalmente disponibilizados para as 
demais, com a justificativa de sigilo nas decisões gerenciais específicas. Pelos motivos acima expostos, técnicas de sistemas federados não se aplicam satisfatoriamente ao caso. Um exemplo de situação que revela a não aplicabilidade desse tipo de sistema é o não atendimento, por parte de alguma singular, a um contrato que foi feito entre um beneficiário e outra singular para cobertura com abrangência nacional. Esse fato, embora não desejável, é possível no Complexo Médico sob análise. Assim, técnicas inovadoras, tais como integração de esquemas sob demanda, compartilhamento de dados através de separação de objetos, evolução independente e reintegração pré-programada, tiveram que ser desenvolvidas.

Para que esse sistema pudesse ser realizado foram utilizados diversos recursos conceituais inéditos, que vêm sendo desenvolvidos pelo Grupo de Bases de Dados do ICMC, sendo que os principais são as técnicas para o compartilhamento de informações [PINHEIRO_98][FERREIRA_98][FERREIRA_96B] e o uso de hierarquias de classificação/instanciação, de que trata a presente monografia.

\subsection{Exemplos Práticos de Classificação}

\subsubsection{Classificação de CEs / CR Associados a CE Classificados}

Pessoas físicas e jurídicas devem ser identificadas pelas mais diferentes maneiras. Restringindose o exemplo para pessoas que se especializam em Beneficiários, considerou-se, como identificadores, aqueles tidos como "universais", ou seja C.P.F. e R.G. (para o Brasil, pois o sistema também previu a possibilidade de exportação). No entanto, quando uma empresa faz um contrato de prestação de serviço para seus funcionários (que serão os beneficiários do plano de saúde contratado), ela freqüentemente indica uma forma de identificação, a qual será utilizada na identificação do beneficiário na solicitação de um serviço, utilizando-se para tal da carteira da empresa contratante. Além disso, esta forma de identificą̧ão será igualmente utilizada quando a cooperativa reportar à empresa a relação de serviços executados para cada beneficiário.

Deste modo, de acordo com a Figura 5.2, criou-se o CE Tipo_de_Identificador, em que cada entidade é uın tipo, que possui um nome (identificador) que é a chave do CE. Cada 
Tipo_de_Identificador pode relacionar-se com uma ou mais empresas que o adotam e possui uma estrutura que foi definida com apenas dois atributos, ambos chaves do CE Instância. Cada entidade desse $\mathrm{CE}$ Tipo é instanciada em um novo $\mathrm{CE}$ Instância, que é relacionado com o $\mathrm{CE}$ Beneficiário, para que cada beneficiário possa ser identificado pelos vários Identificadores que ele, como funcionário segurado de una determinada empresa, deve ter.

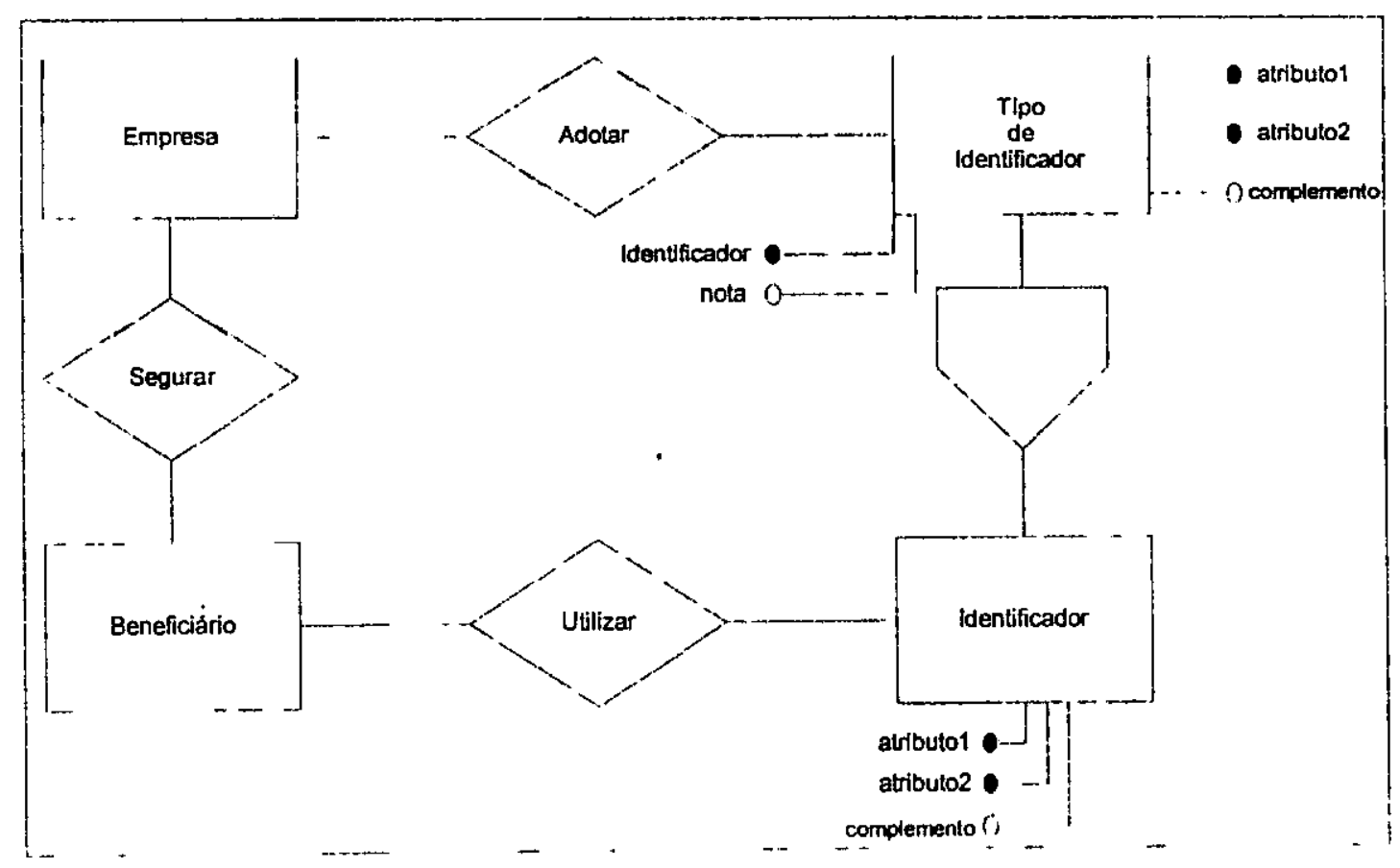

Figu ra 5.2 - Exemplo de Ocorrência da Classificąão no Estudo de Caso

No exemplo da Figura 5.2, Tipo_de_ldentificador é criada num gerenciador rclacional pclo comando:

CREATE TABLE Tipoldent

(Identificador CHAR (10),

Atributo_1 CHAR (15),

Atributo_2 CHAR (15),

Nota CHAR (60)

PRIMARY KEY (Identificador));

O CE Beneficiário também é mapeado normalmente. 
CREATE TABLE Beneficiário

(Unimed DECIMAL (4),

CodBenef DECIMAL (8),

Outros atributos não chave CHAR (...),

PRIMARY KEY (Unimed, Codbenef) );

\subsubsection{Mapeamento de CE's Classificados}

Existem duas opções para o mapeamento do construtor de classificação, conforme descrito no capitulo 4 - a primeira segue diretamente a solução teórica e a segunda é mais facilmente implementável, permitindo maior portabilidade e independência de implementação.

\section{Solução Teórica}

Por esta solução, cria-se uma tabela para cadá conjunto de entidades instanciado. $O$ mapeamento requer necessariamente o recurso de compilação dinâmica de comandos da linguagem SQL, preparados no aplicativo através da concatenação de cadeias de caracteres. Impõe-se que, sempre que uma tupla é inserida/removida/atualizada na relação que mapeia o CE Tipo, deve-se criar/apagar/modificar uma relação (CE instância) de acordo com os dados inseridos nessa tupla.

Nesse caso, o seguinte comando "simula" a criação das instâncias, apresentada assim para facilitar a compreensão; o comando real deveria ser "montado" adequadamente e utilizar sintaxe de compilação dinâmica e variáveis externas da linguagem hospedeira para habilitar o uso do comando CREATE TABLE com os parâmetros adequados, substituindo os nomes das tabelas e atributos como um editor de macros.

CREATE PROCEDURE Novo_Identificador

( IN id CHAR (10), IN at1 CHAR (15), IN at2 CHAR (15), IN nota CHAR (60)) BEGIN

INSERT INTO Tipoldent

(Identificador, Atributo_1, Atributo_2, Nota)

VALUES (id, at1, at2);

CREATE TABLE \%id

(Atrib1 CHAR (15), Atrib2 CHAR (15), complemento CHAR (60), PRIMARY KEY (Atrib1, Atrib2));

END 
Esta é a solução correta do ponto de vista teórico, pois permite que cada CE Instância seja adaptado adequadamente, de acordo com as particularidades de cada instância. Entretanto, do ponto de vista prático, essa solução apresenta alguns problcmas. Particularmentc, gera uma quantidade muito grande de tabelas na base, podendo comprometer, dependendo da quantidade de instâncias requeridas pela aplicação, a perfeita execução do sistcma. Além disso, devido às diferenças existentes entre as várias implementações da linguagem SQL e entre as linguagens hospedeiras, a solução não é completamente portável entre diferentes gerenciadores e ambientes de programação.

\section{Solução Prática}

A segunda maneira de realizar-se o mapeamento utiliza apenas duas tabelas: Identif, que possui identificador próprio e armazena os valores dos atributos de todos os tipos de identificadores, e TipoIdent, que armazena os nomes dos atributos de cada tipo de identificador. A seguir, exemplificam-se os procedimentos de criação de da tabela ldentif e de inserção de tipos de identilicadores:

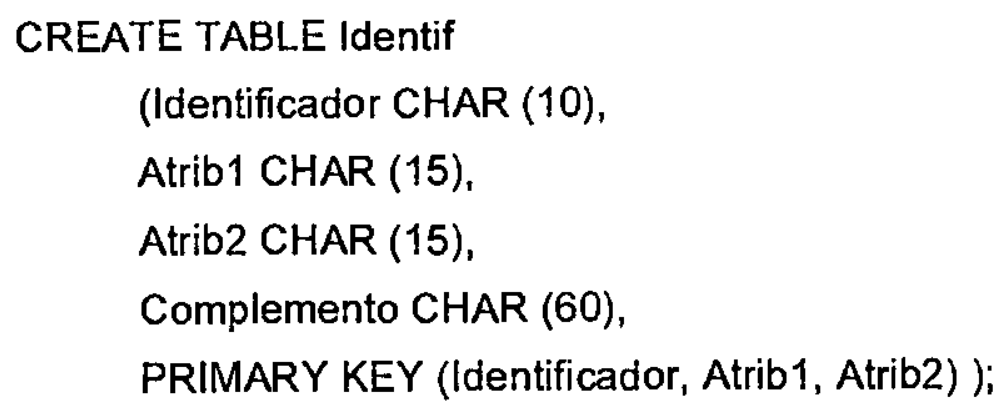

CREATE PROCEDURE Novo_Identificador

(IN id Char (10), IN at1 CHAR (15), IN at2 CHAR (15), IN Nota CHAR (60)) BEGIN

INSERT INTO Tipoldent

(Identificador, Atributo_1, Atributo_2, Nota)

Values (id, at1, at2);

END

Nesta solução deve-se observar que, sempre que o valor de um identificador for usado o valor do nome do identificador correspondente deve ser a ele concatenado, representando uma alternativa 
à colocação de uma chave estrangeira. Embora mais simples, esta solução não é completamente genérica como a anterior, pois não permite que variações particulares de cada identificador possam ser incorporadas ao sistema, uma vez que o número de atributos dos conjuntos de entidade instanciados é limitado.

A escolha entre as soluçóes deve ser feita baseando-se nas caracteristicas da aplicaçáo, sendo as principais o número de tuplas que ocorrerão no $\mathrm{CE}$ Tipo, o número de $\mathrm{CR}$ associados ao $\mathrm{CE}$ Instância, o número de particularizaçōes dos CE Instância e portabilidade do sistema. Quanto às variaçס̃es possíveis, deve-se considerar que as mesmas devem ser previstas não apenas na base de dados, mas também na programação correspondente.

A solução adotada para o exemplo apresentado utilizou a segunda solução com cinco atributos (Atribl a Atrib5), pois esse número de atributos foi considerado suficiente para representar todos os tipos de identificadores utilizáveis pelo sistema. A programação correspondente utilizou um módulo para interfaceamento com o usuário onde, uma vez escolhido o nome do identificador (TipoIdent.Identificador) este consulta a tabela Tipoldent para localizar os atributos Atribl a Atrib5 que têm nome. Para cada um deles, habilita-se um campo de entrada de dados textual, cujo nome é o nome recuperado no atributo correspondente; a seguir, os valores preenchidos pelo usuário são armazenados nos atributos Atrib1 a Atrib5 correspondentes da tabela Identif. A adoção dessa solução também permitiu que Cooperativas trocassem a definição de identificadores particulares quando efetuassem o repasse de beneficiários.

\subsubsection{Mapeamento do CR de um CE com um CE Instância}

Uma vez mapeado o CE Instância, faz-se o mapeamento do CR de maneira semelhante, ou seja, utilizando-se a mesma solução (teórica ou prática). Dessa forma, existem, igualmente, duas soluções para o mapeamento.

\section{Solução Teórica}

A maneira indicada pela solução teórica deve, a princípio, mapear o CR criando uma nova relação para cada tupla que ocorrer no $\mathrm{CE}$ Tipo. $\mathrm{O}$ nome de cada relação criada deve concatenar o nome do CR com o valor da chave da entidade correspondente desse CE Tipo. Os atributos não 
chave serão os atributos do CR, e os atributos chave serão os atributos dos CE associados ao CR, incluindo-se aí aqueles do CE Instância.

O procedimento Novo_Identificador foi modificado para incluir em seu final a criação da relação Utilizar da Figura 5.2 correspondente, o que pode ser realizado com o seguinte comando:

\section{CREATE PROCEDURE Novo_Identificador}

( IN id CHAR (10), IN at1 CHAR (15), IN at2 CHAR (15), IN nota CHAR (60)) BEGIN

INSERT INTO Tipoldent

(Identificador, Atributo_1, Atributo_2, Nota)

VALUES (id, at1, at2);

CREATE TABLE \%id

(Atrib1 CHAR (15), Atrib2 CHAR (15), complemento CHAR (60),

PRIMARY KEY (Atrib1, Atrib2));

CREATE TABLE Utilizar+\%id

(Unimed DECIMAL (4),

CodBenef DECIMAL (8),

Atrib1 CHAR (15),

Atrib2 CHAR (15),

PRIMARY KEY(Unimed, Codbenef, Atrib1, Atrib2)

FOREIGN KEY(Unimed, Codbenef)

Beneficiário REFERENCES (Unimed, Codbenef),

FOREIGN KEY (Atrib1, Atrib2)

\%id REFERENCES (Atrib1, Atrib2));

End

Pode-se observar que essa maneira de mapeamento aumenta o número de relações geradas pelo sistema, aspecto que deve ser considerado na escolha do mapeamento mais adequado. Por exemplo, quando existem dois $\mathrm{CR}$ associando um $\mathrm{CE}$ Instância, cada tupla no $\mathrm{CE}$ Tipo correspondente gera duas relaçôes que mapeiam os $C R$, além da relaçâo que mapeia o $C E$ Instância. 


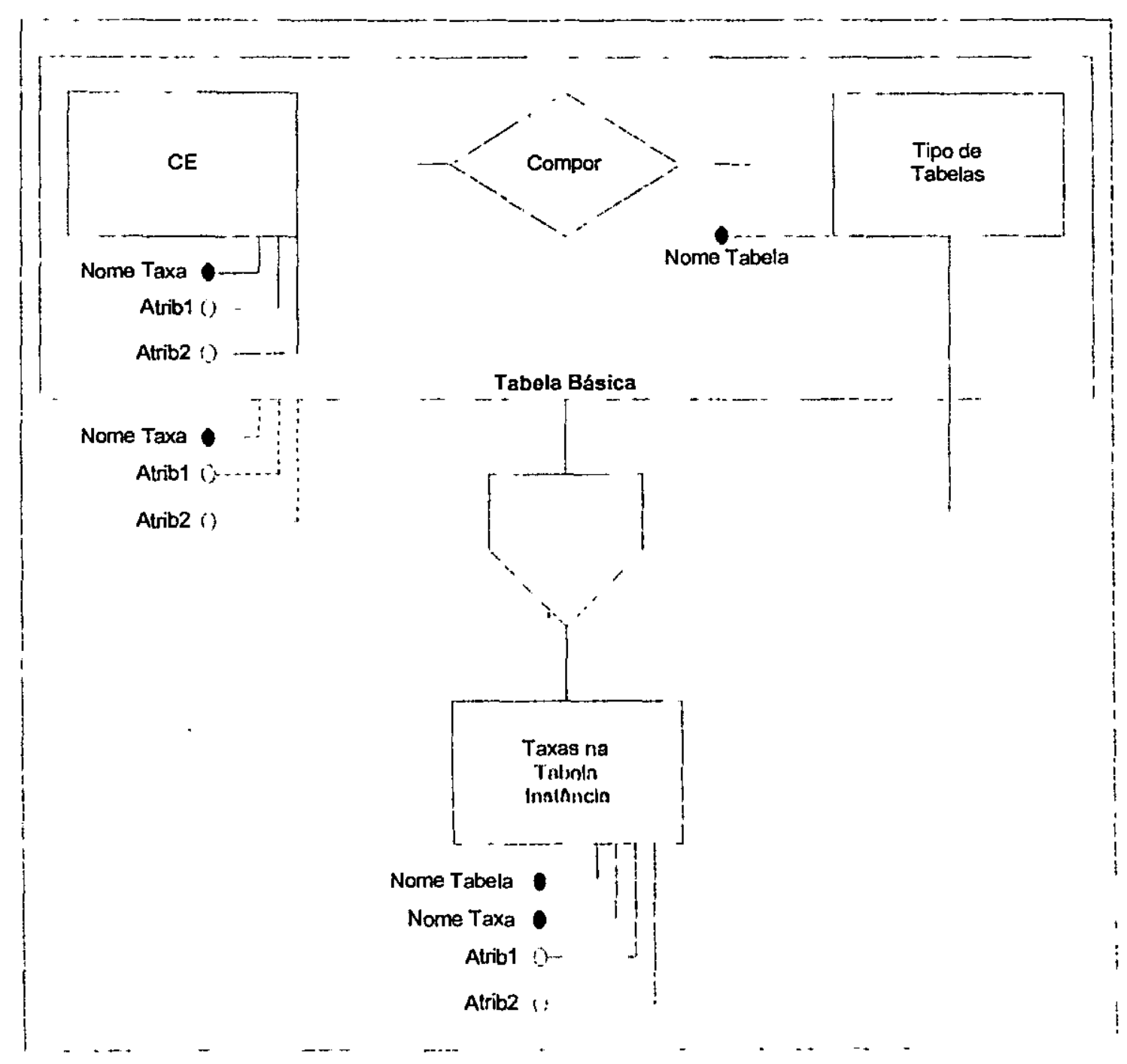

Figura 5.3 - Exemplo de Ocorrência da Classificação de um Agregação com Índice

Cada singular pode definir outras tabelas, podendo existir até mesmo mais de uma por plano contratàvel, utilizadas simultaneamente. Para tal lim, altera os valores a partir do valor "default" da tabcla básica e/ou seleciona cada taxa que pode intcgrar cada tabela. Essas tabclas "customizadas" são identificadas por um nome, sendo representadas pelo CE Típo de Tabela na Figura 5.3. Cada tabcla é, portanto, uma instanciação da tabela básica, em que o 'lipo de 'l'abela é, de fato, a forma de referência, embora não sendo chave. Devido a esse fato, cada Tipo de 'Tabcla foi denominado indice da tabela. Cada tabela instanciada é representada na pclo CE instância Taxas na Tabela Instância. 


\section{Solução Prática}

A segunda maneira de mapear o $\mathrm{CR}$ cria, a princípio, uma única relação, que pode ser identificada pelo próprio nome do $\mathrm{CR}$. De acordo com o capítulo 4, utilizando-se essa maneira de mapeamento, a relação que mapeia o $\mathrm{CR}$ utilizar da Figura 5.2 é definida com o seguinte comando:

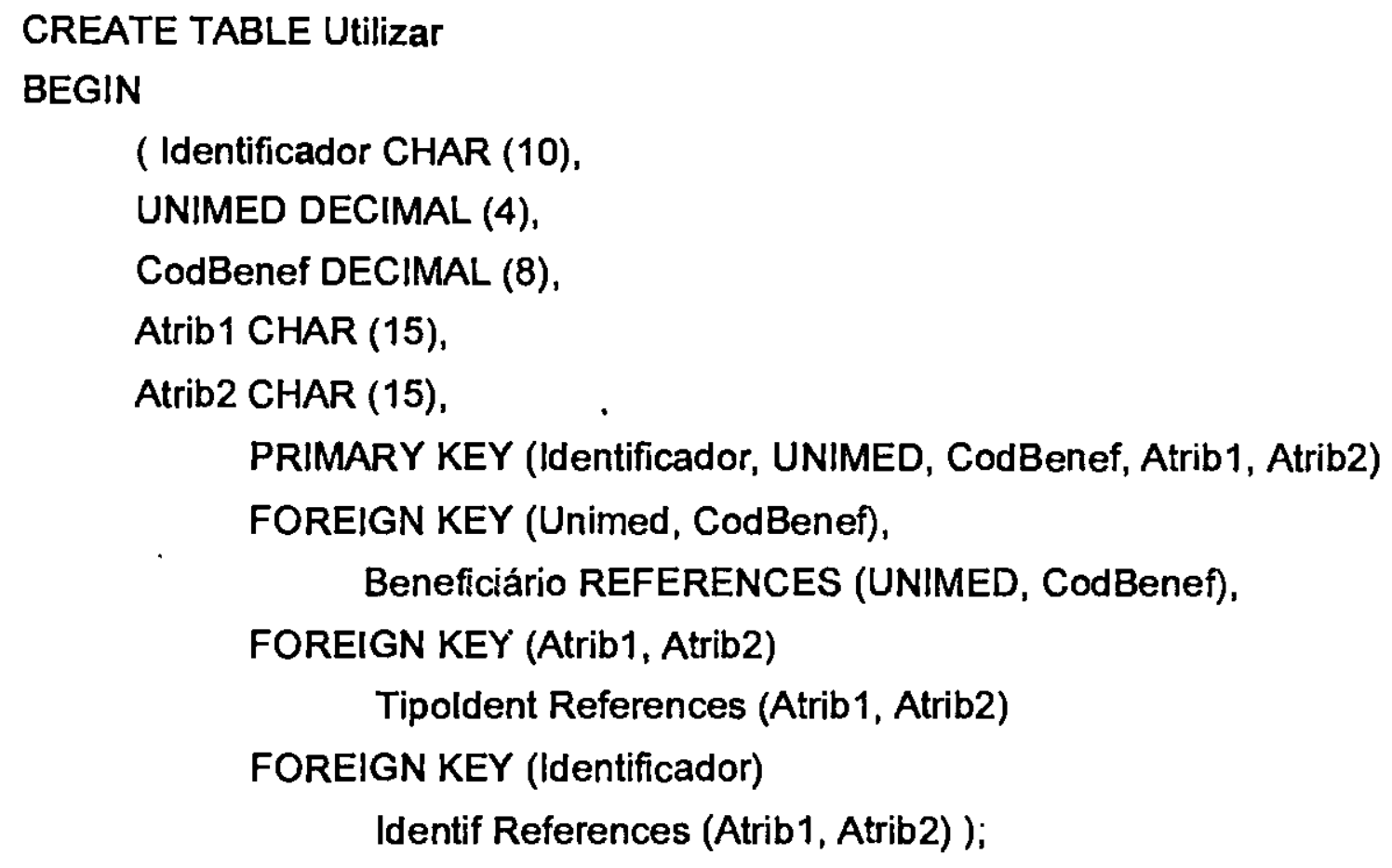

End

\subsubsection{Classificação de Agregação onde um dos CEs componentes atua como Índice}

Existe uma tabela básica, criada pela Associação Médica Brasileira - AMB, definindo os tipos básicos de taxas aplicáveis, tais como taxa de anestesia, taxa de uso de oxigênio, taxa de colocação/uso de equipamentos em quartos, etc. A coleção de todas as taxas básicas existentes é representada, na Figura 5.3, pelo conjunto de entidades Taxas, que possui como atributo chave o nome da taxa, além de outros atributos não chave, tais como valor da taxa, unidade de medida (tempo de uso, por evento, etc.) e outros. 
O construtor classificação mostrado na Figura 5.3 representa justamente o fato, relativamente . comum, de que tabelas inteiras podem ser instanciadas, o que teoricamente significa duplicar uma tabela tipo (básica, padrão, etc.). A duplicação nem sempre é uma solução adequada, pois o volume de dados da tabela pode ser bem maior que as alterações feitas em cada instância. Esse é, inclusive, o caso mais usual do estudo de caso apresentado. Assim, o mapeamento efetuado para o construtor de classificação, quando instanciando uma agregação indexada por um dos CE associados pelo CR gerador da agregação, procurou levar essa característica em consideração, sendo a única maneira estudada de mapeamento dessa situação.

O mapeamento dessa situação, de acordo com o explanado no capítulo 4, consiste na criação de quatro tabelas:

CREATE TABLE Tipo de Tabelas (

Codigo INTEGER,

Nome_taxa CHAR (15),

PRIMARY KEY (codigo) );

CREATE TABLE Taxas (
Codigo INTEGER,
Nome CHAR (15),
Atrib1 INTEGER
Atrib2 INTEGER,
PRIMARY KEY (codigo) $) ;$

CREATE TABLE Taxas Instância (

Codigo INTEGER,

Nome CHAR (15),

Atrib1 INTEGER, Atrib2 INTEGER,

PRIMARY KEY (codigo) );

\section{CREATE TABLE DefTabelas (}

Codigo_tabeia INTEGER,

Codigo_padrao INTEGER,

Codigo_instancia INTEGER,

PRIMARY KEY (codigo_tabela, codigo padrao)

FOREIGN KEY (codigo_tabela) REFERENCES Tipo de Taxas (codigo)

FOREIGN KEY (codigo_padrao) REFERENCES Taxas (codigo)

FOREIGN KEY (codigo_instancia) REFERENCES Taxas Instância (codigo)); 
A estrutura das tabelas Taxas e Taxas Instância é a mesma, o que corresponde ao conceito teórico que cada tabela instância deve ser uma cópia da tabela básica, com cada tupla alterada de acordo com a nccessidade da instância. No cntanto, $\mathrm{cm}$ vcz de se criar uma tabela para representar cada tabela médica instanciada, optou-se pela criação de apenas uma tabela adicional ('laxas Instância), que armazena todas as tuplas (taxas) modificadas a partir da tabela básica, independentemente da tabela instância a que pertençam. Através da criação da tabela DefTabelas faz-se a ligação entre as taxas modificadas e as tabelas instância que as geraram. Assim, uma tabela instância não precisa incluir as tuplas que não foram alteradas e que portanto coincidem com as tuplas da tabela básica a partir da qual foram criadas. Somente armazena-se, adicionalmente, as tuplas altcradas.

Assim, a tabela DefTabelas atua como un pivô, indicando para cada tabela as taxas incluídas e se cada laxa é a mesma da tabela básica ou foi alterada nessa tabela. Assim, sempre que uma nova tabela instanciando a tabela básica é criada, cria-se uma coleção de tuplas na tabela Defrabelas, uma para cada taxa da tabela básica, ligando o código da nova tabela aos códigos das taxas básicas. Nola-se quc, ncssc ponto, o atributo código instância recebe o mesmo valor do código padrão, indicando que a tupla não está instanciada, ou seja, que a taxa deve ser obtida a partir da tabela básica. Quando alguma tupla de determinada tabela instância é modificada, o atributo codigo instância é modificado para indicar a nova tupla (a original nunca é alterada) na tabela Taxas Instância

\subsection{Considerações Finais}

O presente estudo de caso mostra que determinadas necessidades práticas podem guiar o desenvolvimento teórico de recursos que se mostram necessários, validando conceitos que ainda estão em fase de estudo e consolidação. Além disso, os casos da abstração de classificação ilustrados são os mais comuns, significativos para a sua própria divulgação.

Da utilização da abstração de classificação no sistema alvo, pode-se dizer que conduziu a um projeto mais simples e mais próximo da realidade que modelou, de manutenção facilitada compensando o aumento de complexidade senântica do modelo de dados utilizado. 


\section{Capítulo 6: Conclusão}

\subsection{Contribuições deste Trabalho}

- Criação de um modelo prático, semelhante ao muito conhecido ME-RX, incluindo um construtor semântico que permite a representação da abstração de classificação.

- Criação de uma notação prática e intuitiva para o construtor de classificação.

- Criação de regras para o mapeamento da classificação para o Modelo Relacional nos casos mais freqüentes da ocorrência da classificação em modelo conceitual (ME-R-C). Esses mapeamentos cobrem não apenas o caso imediato da classificação ocorrendo isoladamente, classificando um $\mathrm{CE}$, mas também associada com as construtores semânticos de agregação e conjuntos de relacionamentos do modelo.

- Identificação do caso relativamente comum de classificação, em que as instâncias são identificadas por um índice.

- Suporte à manutenção de tabelas instanciáveis em implementação relacional.

Em muitas situações ocorre a necessidade de uma tabela indicar o conjunto de valores possíveis para um determinado atributo. Normalmente, quando esses valores são atômicos, ou pelo menos simples, essas situações são tratadas através de relacionamentos de integridade referencial. No entanto, se o tipo de dado envolvido é complexo, a manutenção da informação pode se tornar muito complexa. Esse é o caso de quando o tipo de dado é uma tabela. Um exemplo é a venda de produtos em uma ampla rede de concessionárias. A princípio, a tabela de preços deve ser única, mas para manter a competitividade, cada concessionária deve ter a liberdade de modificar os preços, por exemplo baixando o preços daqueles produtos produzidos em sua região. Nesse caso, existe uma tabela básica, da qual todas as demais são instâncias. De fato, os preços da tabela básica são valores "default", pois são copiados em cada instância feita a partir da tabela básica e não são valores herdados. Note-se que as tabelas de cada concessionária seguem as definições da tabela básica - que 
portanto atua como tabela tipo. Por outro lado, a tabela de uma concessionária não é a tabela básica, dado que a alteração de um valor na tabela da concessionária não muda o valor da tabela básica. Esse tipo de problema, quando ocorre em situações reais de projeto, tem levado a soluções locais, que com freqüência posteriormente não se mostram adequadas. A solução proposta neste trabalho leva em conta todas as componentes estruturais desse tipo de problema e apresenta a solução de implementação consistente com seu significado real. Além disso, essa solução permite simplificar o tratamento que deve ser dado a ela, minimizando também o volume de dados que precisa ser armazenado. Isso contribui tanto para facilitar a manutenção do sistema, quanto para minimizar problemas de inconsistência de dados.

- Demonstração da praticidade da solu ção apresentada, através da aplicação em um estudo de caso real.

A caracterização da abstração de classificação depende de um conjunto de conceitos que devem inicialmente ser tratados com um mínimo de rigor, para definir adequadamente o problema. Esse rigor está presente nos trabalhos que a envolvem, mas até agora isso tem levado ao não reconhecimento da necessidade da Abstração de Classificação por profissionais atuantes na área, que procuram soluções práticas para os problemas do dia a dia. Neste trabalho, utiliza-se um caso real de implementação de sistemas de administração, e mostra-se pelo menos três casos em que a classificação ocorre num mesmo sistema. Em todos os casos, as soluções teóricas indicadas pelo estudo efetuado se mostraram corretas e mais precisas do que as soluções locais inicialmente concebidas.

\subsection{Conclusões}

- A classificação ocorre com relativa freqüência em casos reais, mas não é bem suportada em nenhum modelo com ampla aceitação no meio profissional de produção de software.

- Isso obriga o projetista a usar outros construtores, originando sobrecarga semântica e problemas durante o desenvolvimento e a manutenção do sistema. 
- Em geral o projetista usa a abstração de generalização para substituir a falta de um construtor para a classificação. Isso tem se tornado prática tão comum que a própria formação dos projetistas tem sido comprometida, dificultando o tratamento adequado da classificação.

- Não existe ferramental, nem teórico nem prático para suportar a classificação, em particular em modelos de dados; ferramentas de projeto e desenvolvimento de software; linguagens de programação; sistema de interface com o usuário; sistemas de gerenciamento de base de dados.

- Este trabalho procurou desenvolver um suporte básico para a classificação em modelos de dados e em sistemas de GBD. Os resultados são os listados na seção contribuições.

\subsection{Sugestões para Futuras Pesquisas}

- Estender os métodos de mapeamento para incluir a generalização e suporte a atributos multivalorados.

Não foi efetuado o estudo de como deve ser realizado o mapeamento da classificação quando uma entidade é especializada, ou é uma especialização de outra. Conceitualmente, é admissível que um tipo de entidade genérico possa ser tanto classificável quanto instância de outro tipo. Igualmente, um tipo especializado pode também ser tanto classificável quanto instância de outro tipo. Assim, existem quatro possibilidades de interação da abstração de generalização com a de classificação, que devem ser estudadas para complementar aquelas apresentadas neste trabalho. Nenhuma delas ocorre no estudo de caso, portanto a freqüência com que tais situações ocorrem em casos reais não foi avaliada. No entanto, por uma questão de completeza teórica, esse estudo deveria ser eventualmente empreendido.

- Implementar uma ferramenta que automatize o processo de mapeamento da classificação.

- Desenvolver uma linguagem de especificação de classificação, para permitir estender o SQL para aceitar comandos que emulem a classificação (tal como existem extensóes ao SQL (vide SQL3) para suportar generalização. 
- Avaliar como sistemas de interface com o usuário podem suportar classificação, integrando os recursos apresentados neste trabalho para que SGBDs a suportem.

Para que um sistema seja implementado, as construções derivadas de ocorrências de classificação devem ser suportadas por todos os seus componentes. Um dos componentes vitais dos atuais sistemas de computação é o Sistema de Gerenciamento de Interfaces com o Usuário. Se múltiplos niveis de classificação ocorrem nos dados manipulados, e esses dados devem ser visualizados e informados pelo usuário, cntão devem haver recursos no SGIU para suportar a classificação também. Situações mais simples, como as abordadas neste traballio como soluçcões práticas, podem ser atendidas pelos atuais SGIUs sem grandes manobras por parte dos aplicativos. Porém nos casos em que essas soluções não forem possíveis para os dados, também não serão possíveis de serem atendidas pelos atuais gerenciadores. A identificação precisa da situação em que isso ocorre é quando existem atributos extras. Nesse caso, o sistema deve prover recursos para incluir cada atributo nas operaçôes de entrada e saída do sistema. Tal como todas as informações de definição de dados de cada atributo extra devem ser incluidas no mapeamento para o Modelo Relacional, todos os parâmetros que definem o comportamento nas operações de entrada e saída de cada atributo devem ser registrados para o SGIU.

- Avaliar como a classificação pode ser suportada em Linguagens de programação.

$\Lambda$ s mesmas considerações feitas no tópico anterior valem para as linguagens de programação. No entanto como estas são extremamente llexíveis, não existe uma razão pela qual a classificação não possa scr utilizada pclos compiladores atuais. $U$ ponto para o qual se chama a atenção aqui é que cmbora sẹja possivel implementar a classificação utilizando as ferramentas de programação atuais, isso não significa que o suporte para facilitar/orientar essa programação exista. Essa linha de pesquisa deve levar à unificação do suporte oferecido pelas outras linhas (SGBDs, SGIUs, etc.), e de outros conceitos. Por exemplo, essa pesquisa deve levar em conta que objetos tipo e objetos instância devem coexistir em tempo de compilação e em tempo de execução, servindo portanto de base para a integração conceitua' das atuais atividades em objetos persistentes em LP. 
- Avaliar a classificação em ambientes distribuídos.

A maior fonte de ocorrência da classificação verificada no estudo de caso, bem como em outros sistemas que se encontram na literatura, ocorre quando o sistema nitidamente apresenta "partes" que são por sua vez instanciadas, com gerenciamento descentralizado mas ainda existindo a necessidade de manter um grau razoável de integração entre elas. Essa situação é típica do estudo de caso, onde cada cooperativa médica é completamente independente das demais, mas ainda mantém o interesse de refletir um comportamento integrado. O mesmo ocorre no exemplo das concessionárias, que será usado aqui para efeito de ilustração. Dada essa característica, as soluções que têm sido dadas nos casos práticos avaliados podem ser classificadas em duas:

1) não se representa a classificação. Nesse caso, cada instância do sistema mantêm suas instâncias dos dados, e não existe uma representação "centralizada" para o tipo;

2) cada caso é tratado localmente, utilizando-se outras abstrações, em geral a generalização ou a composição para dar uma solução que é, na maioria das vezes, restritiva.

Com o crescente interesse em sistemas de apoio a tomada de decisão, ignorar o problema como no caso 1) não é mais possível. O segundo caso é caro demais para continuar sendo tratado isoladamente. Em ambos os casos, o meio de integração ocorre em sistemas distribuídos. Assim, o suporte da classificação em operações e atividades próprias de ambientes distribuídos passam a ser importantes. Essas necessidades correspondem à troca de informações entre os centros de tomada de decisões $\mathrm{e}$ as unidades operacionais dos empreendimentos. Dessas considerações fica claro que uma das principais frentes de trabalho visando a introdução do suporte da abstração de classificação corresponde ao desenvolvimento de sistemas distribuídos. 


\section{Referências Bibliográficas}

\section{Referências Citadas}

[BIAJIZ_92] Biajiz, M. - MRO* - Uma atualização do Modelo de Representação de Objetos c uma Abordagen lormal. Dissertação de mestrado aprescntada ao IC'MC-USP, julho de 1992.

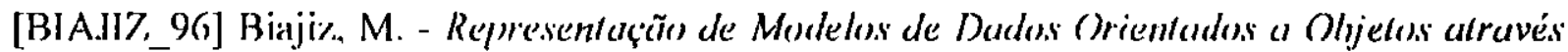

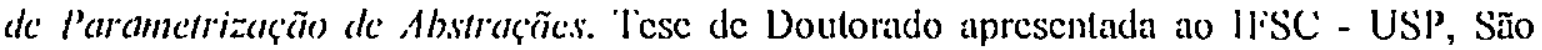
Carlos.

[CERI_92] Batini, C.; Ccri, S.; Navathe, S. B. - Conceptual Database Design: An EntilyRelationship Aproach, The Benjamin/Cummings Publishing Company, Inc. 1992.

[CHEN_76] Chen, Peter P. S. - The Entity-Relationship Model - Toward a Unified View of Data. ACM Transaclions on Dalahase Systems, vol 1, nº 1, p. 9-36, March 1976.

[DAHCHOUR_98] Dahchour, M. - Formalizing Materialization Using a Melaclass Approach. 10 th Int. Conf. on Advanced Information Systems Engincering, CAiSE'98, LNCS 1413, p. 401-421, Pisa, Italy, June 1998.

[ELMASRI_94] Elmasri, R. c Navathc, S.B. - I'undamentals of Database Systems. AddisonWesley Puhlishing Company, 1994.

[GOMES_99] Gomes, larissa P. S. - Método para Projeto de Aplicativos centrados em BDOO utilizando Abstração de Generalização. Dissertação de mestrado apresentada ao ICMC-USP, agosto de 1999.

[HULL_87] Hull R. e King R. - Semantic Database Modeling: Survey, Applications and Research Issues. ACM Compuling Surveys, Vol.19, No3, pg. 201-259, September 1987.

[LOUCOPOULOS_94] Loucopoulos, P. (Ed.) Entity-Relationship Approach - ER'94, Springer-Verlay I eclure Noles in Compuler Sciences, 1994.

[PIROTTE_94] Pirollc, Alain; Zimányi, Esleban; Massart, D. and Yakusheva, T. Materialization: a powcrfiul and ubiquitous abstraction pattcrn. In 20th Int. Cont. on Very Large Data Bases, VLDB'94, p. 630-641, Santiago, Chile, 1994. 
[PIROTTE_97] Pirotte, Alain; Zimányi, Esteban - Generic Relationship in Information Modeling. In EDBT Summer School, Capri, Italia, Setembro 1997.

[TAIVALSAARI_96] Taivalsaari, Antero - On the Notion of Inheritance. ACM Computing Surveys, vol 28, n 3, p. 439-479, September 1996.

[TRAINA_88] Traina Jr., C. e Slaets, J.F.W. - Um Modelo de Representação de Objetos. In Anais do 3o. Simpósio Brasileiro de Banco de Dados, Recife, pg. 227-242, Março de 1988.

[TRAINA_91] Traina Jr., C. - GEO - Um Sistema de Gerenciamento de Dados Orientado a Objetos - Estado Atual de Desenvolvimento e Implementação. Anais do 6o. Simpósio Brasileiro de Banco de Dados, Manaus, 1991.

[TRAINA_92] Traina Jr., C. - Notas de Aula. ICMC-USP, 1992.

[TRAINA_94] Traina Jr. C.; Traina, A. J. M.; Biajiz, M. - O Papel da Abstração Instanciação em um Meta-Modelo de Abstrações para BDOO, In Anais do IX Simpósio Brasileiro de Banco de Dados, São Carlos - S.P.,pg. 173-187, Setembro de 1994.

[TRAINA 98] Traina Jr., C.; Ferreira, J. E. - Notas de Aula. ICMC-USP, 1998.

\section{Bibliografia Adicional}

Camolesi Jr., L.; Traina Jr., C. - Tratamento de Múltiplos Aspectos de Projetos através de um Gerenciador de Esquemas de Dados para Modelos Orientados a Objetos. Anais do VIII Simpósio de Banco de Dados, Campina Grande - PB, maio de 1993.

Cattell, R.G.G. - Object Databases and Standards. Lectures Notes in Computer Science, $\mathrm{n}^{\circ}$ 940, pg. 1-11, 1995.

Dimitris N. Chorafas - Manufacturing Databases and Computer Integrated Systems. pp.320, Crc Press, Inc./Lew is Publishers, 1993.

Ferreira, J. E., Traina Jr., C. - Distribution Aspects in Databases for Project Support Enviroments. In Anais of the XII International Conference of the Chilean Computer Science Society, Santiago do Chile, October 1992.

Gamma, Erich; Helm, Richard; Johnson; Ralph; Vlissides, John - Design Patterns - Elements of Reusable Object Oriented Software, Addison-Wesley Professional Computer Series. 
Kog,I.W.; Uoi,B.C.; Ho, Y.S. - A Model Using Classes as a Basic Organization Tool*. tectures Notes Compuler Science, $11^{\circ} 760$, pg. 429 a $443,1994$.

Liddle , S. W. ; Embley, D. W.; Woodfield, S N. - A Seamless Model for Oljject-Oriented Systems Development. Leclures Notes in Computer Science, $\mathrm{n}^{\circ} 858$, pg. 123 a 141...September 1994.

Mcleod D. e Hammer M. - Dalabase Descriplion with SDM: A Semantic Database Model. ACM Transaclion on Dalabase Syslems, Vol.6, N³, Seplember 1981, Pg. 351-386.

Navathe, S.B. - Evolution of Data Modeling for Databases. Communications of The ACM, vol.35, 1"9, pg. 112-123, Selembro 1992.

Rieu, D.; Nguyen, G.; Culet. A ;Escamilla, C. - Instanciation multiple el classification d'objers. In Sepliènue journées Bases de données Avancées, I,yon, France, 1991.

Ruiz, D.D.A. - Generalização e Agregação de Atividades: Conceilos Clássicos aplicudos à. Representação Dinâmica de Aplicações de Escritório. In $10^{\circ}$ Simpósio Brasileiro de Banco dc Dados, pg.229- 224, Outubro de 1995.

Sciore, E. - Object Specializarion. ACM Transactions on Information Systems, vol.7, n², pg. 103-122, Abril 1989.

Sheck, H. e Shcoll M. H. - Evolution of Data Models. In Leclure Notes In Computer Science, Vol.466, py. 135-153, 1990.

Su, S.Y.W. - Modelling Integrated Manufacturing Data with SAM*. IEEE Computer, Vol.19, $\mathrm{N}^{\circ} 1$, Janeiro 1986, pg.34-39.

Takai, O. K. - Estudo Solre a Representação de Atributos com Características Gráficas em uma Base de Dados Oricntada a Objelos. Dissertação de mestrado apresentada ao ICMCUSP, março de 1993.

l'raina Jr., C. - Máquina e Modelo de Dados Dedicados para Aplicações em Lingenharia. Tese de Doulorado, IFQSC-USP, dezembro de 1986.

Zand, M.; Collins, V.; Caviness, D. - A Survey of Current Object-Oriented Databases. Database Advances, Vol.26, $\mathrm{n}^{\circ} 34$, py. 14-29, Fevereiro de 1995.

Zhao, L. and Robcrts, S.A - An Object-Oriented Data Model for Database Modelling, Implementation and Access. The Conputer Journal, vol. 31, $1^{\circ} 2,1988$. 